University of Louisville

ThinkIR: The University of Louisville's Institutional Repository

\title{
Evaluating the impact of statewide policy implementation on interorganizational collaboration at the regional level : an application of network analysis.
}

\author{
Nida Moez Ali \\ University of Louisville
}

Follow this and additional works at: https://ir.library.louisville.edu/etd

Part of the Community Health and Preventive Medicine Commons, Health Services Research Commons, and the Public Health Education and Promotion Commons

\section{Recommended Citation}

Ali, Nida Moez, "Evaluating the impact of statewide policy implementation on interorganizational collaboration at the regional level : an application of network analysis." (2017). Electronic Theses and Dissertations. Paper 2656.

https://doi.org/10.18297/etd/2656

This Doctoral Dissertation is brought to you for free and open access by ThinkIR: The University of Louisville's Institutional Repository. It has been accepted for inclusion in Electronic Theses and Dissertations by an authorized administrator of ThinkIR: The University of Louisville's Institutional Repository. This title appears here courtesy of the author, who has retained all other copyrights. For more information, please contact thinkir@louisville.edu. 


\title{
EVALUATING THE IMPACT OF STATEWIDE POLICY IMPLEMENTATION ON INTERORGANIZATIONAL COLLABORATION AT THE REGIONAL LEVEL: AN APPLICATION OF NETWORK ANALYSIS
}

\author{
By \\ Nida Moez Ali \\ B.S., University of Michigan, 2012 \\ M.P.H., Texas A\&M University, 2014 \\ A Dissertation \\ Submitted to the Faculty of the \\ School of Public Health and Information Sciences \\ of the University of Louisville \\ in Partial Fulfillment of the Requirements \\ for the Degree of \\ Doctor of Philosophy in Public Health Sciences \\ Department of Health Promotion \& Behavioral Sciences \\ University of Louisville \\ Louisville, KY
}

May 2017 
(C) 2017 by Nida Moez Ali

All rights reserved 

EVALUATING THE IMPACT OF STATEWIDE POLICY IMPLEMENTATION ON INTERORGANIZATIONAL COLLABORATION AT THE REGIONAL LEVEL: AN APPLICATION OF NETWORK ANALYSIS

\author{
By \\ Nida Moez Ali \\ B.S., University of Michigan, 2012 \\ M.P.H., Texas A\&M University, 2014 \\ A Dissertation Approved on
}

April 24, 2017

by the following Dissertation Committee:

Monica L. Wendel, Dr.P.H., M.A.

Dissertation Chair

Liza M. Creel, Ph.D., M.P.H.

Jelani C. Kerr, Ph.D., M.S.P.H.

Brandy N. Kelly Pryor, Ph.D., M.A. 


\section{DEDICATION}

To my family, the pillars of my strength. 


\section{ACKNOWLEDGMENTS}

When my family and I immigrated to the United States about 20 years ago, perhaps the most valuable asset we had at the time was a vision. I am here today because of that vision. Growing up, my parents always reminded me that when life-long learning is a commitment, the commitment can sustain the learner in you. Mom and dad, thank you for dreaming, for allowing me to dream, and for helping to make this dream a reality. I am most grateful for your unconditional love, support, and encouragement. You both have nurtured and supported me in countless ways, always finding a way to be a part of my life from across the world. Thank you for always allowing me to explore the world through my own eyes, encouraging me to capture a glimpse of realities different from my own, and being there for me if I somehow got lost in the complexities of it all. You both radiate an inner light, one that emits generosity of spirit and depth of character, qualities I strive to emulate.

Perhaps the most rewarding part of my doctoral journey was being surrounded by ordinary people that are doing extraordinary things. First and foremost, I would like to thank Monica for taking a leap of faith and allowing me to join her team in Louisville. I am not sure you realize how many opportunities I have been afforded under your mentorship. Thank you for helping bring this undertaking to fruition. You continue to inspire me with your work ethic, dedication, intellect, experience, kindness, and humility. Your guidance, honesty, mentorship, and contagious laughter have been a gift. 
I would like to extend my sincerest thanks to Liza for her methodological expertise in social network analysis. Thank you for being so willing to meet with me to discuss ideas and brainstorm ways to present data. Your guidance and mentorship is much appreciated.

Special thanks to Ryan for his mentorship throughout my journey as a doctoral fellow and for his assistance with qualitative analysis. I would also like to thank the rest of my committee, Drs. Kerr and Kelly-Pryor, for your time and feedback.

To my sister, Kanwal, my partner in crime, my best friend, many thanks, for reminding me why I chose to pursue a PhD... I promise it's not because I think I'm better than you... I don't need a $\mathrm{PhD}$ to prove that. Thank you for continuing to set the standard so much higher for the rest of us. I am especially grateful to you for your continuous and boundless support - unparalleled in its loyalty and depth. I could always count on you to remind me that first and foremost I am your api. May you one day see yourself through my eyes.

The greatest gifts in life are ones that can't be bought. Many thanks to my dearest childhood friends, Anar, Shaina, and Shehfina for giving me the gift of friendship. Thank you for the thought provoking conversations, the countless memories, and the timely laughs. It was on the toughest days that I was reminded zindagi wakame gulzar hai. With you all, I am always \#2blessed2Bstressed.

Friends and colleagues at the school and elsewhere, thank you for your support. 


\begin{abstract}
EVALUATING THE IMPACT OF STATEWIDE POLICY IMPLEMENTATION ON INTERORGANIZATIONAL COLLABORATION AT THE REGIONAL LEVEL: AN APPLICATION OF NETWORK ANALYSIS
\end{abstract}

Nida Ali

April 24, 2017

One challenge to improving population health in the United States is that the systems tasked with the responsibility of providing services across the continuum of care often operate in silos, missing opportunities to provide quality, coordinated care. In 2011, Texas received approval from the Centers for Medicare and Medicaid Services (CMS) for a five-year 1115(a) Medicaid Waiver Demonstration Project. This dissertation focuses on one element of the Waiver, the Delivery System Reform Incentive Payment (DSRIP) Program, which was designed to incentivize activities that support organizations' collaborative efforts with other organizations in addressing the Triple Aim strategies. DSRIP was implemented through the formation of 20 Regional Healthcare Partnerships (RHPs) across Texas. These RHPs represent networks comprised of organizations within sectors and across sectors, including hospitals, community mental health centers (CMHCs), and public health departments among others. Three overarching research questions were posed:

1. To what extent did participation in DSRIP affect the role CMHCs had within their RHPs? 
2. To what extent did the formation of RHPs impact intersectoral collaboration under DSRIP?

3. Which community-based partners did DSRIP providers perceive as critical to delivery system reform, and what types of connections were formed with such partners?

A non-randomized, pre-post interorganizational network study design was used to assess collaboration within each RHP, where data were collected for three time periods. The findings suggest:

1. The Waiver prioritized mental health, promoted collaboration, and allowed CMHCs to provide intergovernmental transfer funds, all of which elevated the role and power of CMHCs in their RHPs.

2. The Waiver promoted meaningful opportunities for intersectoral collaboration, particularly around resource and data sharing for service integration efforts. This allowed otherwise unintegrated organizations, such as public health agencies and CMHCs to assume more central roles in delivery system reform.

3. DSRIP-participating organizations worked extensively and uniquely with community-based partners to integrate more forcefully the social determinants of health with health care in order to address the needs of low-income populations. Future waivers should consider expanding the pool of providers to include social service and non-traditional partners who are critical to population health improvement and health service delivery transformation. 
TABLE OF CONTENTS

PAGE

ACKNOWLEDGMENTS .......................................................

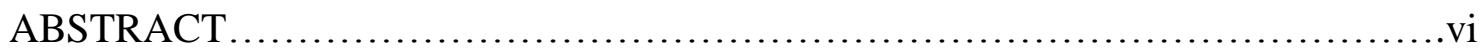

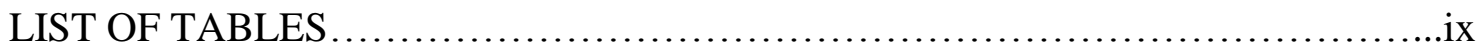

LIST OF FIGURES .......................................................

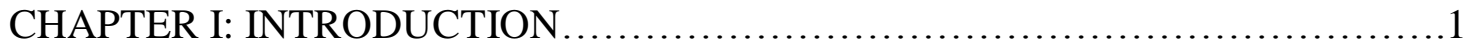

CHAPTER II: REVIEW OF THE LITERATURE................................ 14

CHAPTER III: METHODOLOGY ......................................... 36

CHAPTER IV: ASSESSING THE IMPACT OF THE TEXAS MEDICAID 1115

TRANSFORMATION WAIVER ON COMMUNITY MENTAL HEALTH CENTERS:

AN APPLICATION OF NETWORK ANALYSIS .................................62

CHAPTER V: EXAMINING OPPORTUNITIES FOR SUSTAINED

INTERSECTORAL PARTNERSHIPS THROUGH THE TEXAS MEDICAID 1115

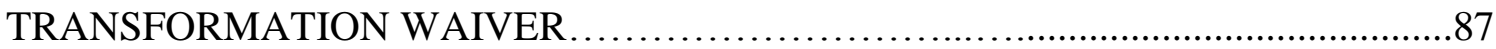

CHAPTER VI: IDENTIFYING AND EXPLICATING PARTNERSHIPS WITH KEY COLLABORATORS BEYOND ESTABLISHED NETWORKS THROUGH THE TEXAS MEDICAID 1115 TRANSFORMATION WAIVER ......................113

CHAPTER VII: DISCUSSION AND CONCLUSIONS ..........................139

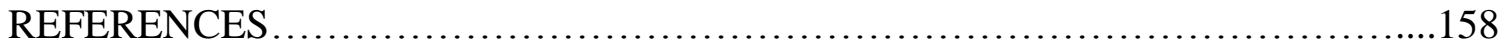

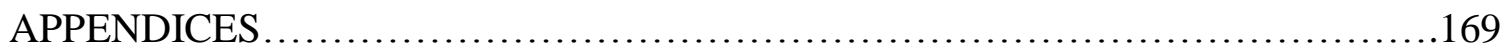

Appendix A: Interorganizational Network Survey, $\mathrm{T}_{0} / \mathrm{T}_{1}$ Instrument................169

Appendix B: Interorganizational Network Survey, $T_{2}$ Instrument................172

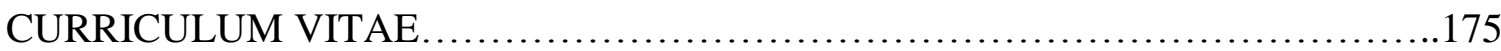




\section{LIST OF TABLES}

TABLE PAGE

1. Network Measures Categorized by Levels of Analysis...........................28

2. Network Measures............................................................. 41

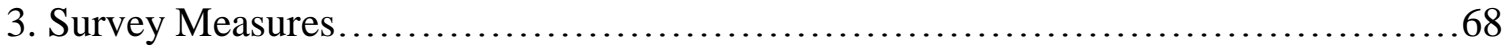

4. Changes in Degree and Betweenness Centrality of CMHCs.........................75

5. Changes in Percent Homophily of CMHCs..........................................78

6. Changes in Average Strength of Ties of CMHCs.................................... 80

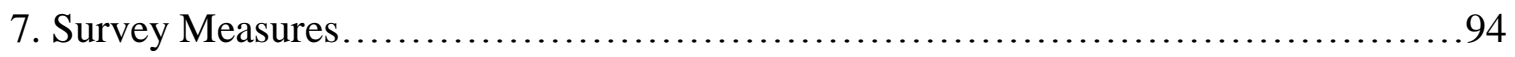

8. Within-sector and Intersectoral Ties, All Collaboration............................98

9. Within-sector and Intersectoral Ties, Joint Program/Service Delivery ................99

10. Within-sector and Intersectoral Ties, Tangible Resource Sharing..................100

11. Within-sector and Intersectoral Ties, Formal Data Sharing......................101

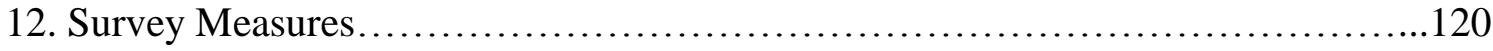

13. Other Organizational Partners Reported by DSRIP Participants....................124

14. Characteristics of Collaboration with Other Organizational Partners................125

15. Distribution of Collaboration with Other Organizational Partners, Joint

Program/Service Delivery ...................................................... 131

16. Distribution of Collaboration with Other Organizational Partners, Tangible Resource

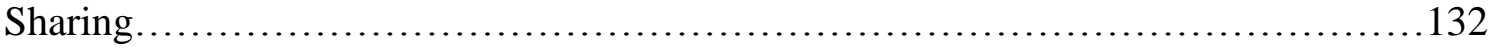

17. Distribution of Collaboration with Other Organizational Partners, Formal Data

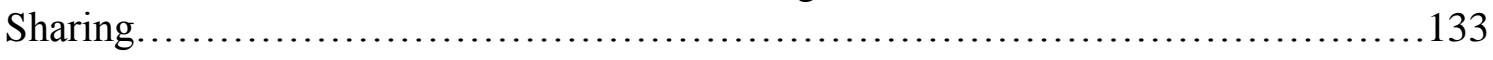




\section{FIGURE}

\section{LIST OF FIGURES}

PAGE

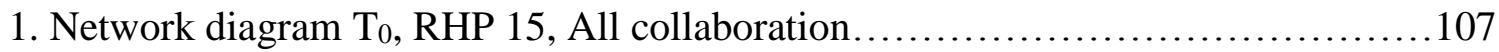

2. Network diagram $T_{2}$, RHP 15, All collaboration............................. 107

3. Network diagram $T_{0}$, RHP 15, Tangible resource sharing......................107

4. Network diagram $T_{2}$, RHP 15, Tangible resource sharing.......................107

5. Network diagram $T_{0}$, RHP 15, Formal data sharing........................... 107

6. Network diagram $T_{2}$, RHP 15, Formal data sharing............................107 


\section{CHAPTER I \\ INTRODUCTION}

\section{Background}

Health is primarily shaped by four key forces: heredity, medical services, environment, and lifestyle (Olden, 2011). Over the course of an individual's life span, there is a range of health services he or she may seek, which are categorized across a continuum of care (Olden, 2011). One challenge to achieving optimal health is that the systems tasked with the responsibility of providing care across this continuum often

operate in silos, missing opportunities to provide quality, coordinated care. As the United States (US) population is becoming increasingly diverse, health needs are evolving. As a result of an inefficient health care delivery system, many of these needs are overlooked (Robert Wood Johnson Foundation, 2011). Inaccessibility to quality health care, the absence of coordinated care, a lack of understanding about health insurance use and health system navigation, and the presence of health disparities contribute heavily to a fragmented health care system.

In 2015, US health care spending amounted to \$3.2 trillion (Centers for Medicare and Medicaid Services [CMS], 2015). Some of the primary drivers of health care costs include an aging population, an increase in chronic illness prevalence, and consumer demand (Mack, 2016). Despite high health care spending, efforts to improve health are 
lacking as evidenced by deficiencies in access to care, health system quality, and equity, among other issue (Davis, Stremikis, Squires, \& Schoen, 2014). Life expectancy is one of the most universally accepted indicators of health status. The National Research Council, Committee on Population (2013) found that the US has one of the lowest life expectancies compared to other industrialized countries despite spending the most per capita, which begs the question: What is going on?

One of the pivotal features that differentiates the US from most other industrialized countries is the absence of universal health insurance coverage (Davis et al., 2014). Some of the most prominent features of a universal coverage system include elements such as acknowledgment of the idea that health care is a fundamental right of individuals (inclusion of everyone), public financing, public accountability, and public stewardship (World Health Organization, 2012). Such systems are shown to promote the Triple Aim strategies, an approach to increase access to care, enhance quality of care, reduce costs, and improve population health (Institute for Healthcare Improvement, 2009; World Health Organization, 2012).

\section{Affordable Care Act and Beyond}

The Patient Protection and Affordable Care Act (ACA), a comprehensive health reform law, was intended to expand coverage, reduce health care costs, and improve health care delivery systems within the US (Obama, 2016). Under the ACA, millions of Americans were able to obtain health insurance coverage; however, concerns related to access and cost of care (e.g. increased premiums) persist (Davis et al., 2014; Obama, 2016). These issues have serious economic consequences, which are often passed on to consumers and taxpayers. In fact, a study aimed at examining how the US health care 
system compares to other industrialized countries suggests that the US ranks last among 11 other industrialized countries on indicators of efficiency, equity, healthy lives, and cost-related problems as it relates to access (Davis et al., 2014).

Under the new presidency, it is evident that a wave of uncertainty about the future of health care is underway. Many question what a "repeal [ACA] and replace" would look like. Others question whether "replace" is even on the agenda (Obama, 2017). Some are fearful as they consider the potential implications of these changes on their ability to prevent and manage existing health conditions (Obama, 2017). These issues, among others, warrant a key question about the future of health care: To what extent will the existing fragmented health care system be impacted under the new administration and Congress? Bearing in mind the potential implications of a new health care system, it is crucial to consider the ways in which the systems that deliver health services can work with each other to fill existing gaps in the continuum of care.

While improving access to care is critical, the systems that deliver health services must be willing to work collaboratively to pursue opportunities that improve health. As the shift from an episodic, volume-based payment (fee-for-service) to an integrated, value-based (fee-for-value) model is becoming more prominent in health service delivery, there is a unique window of opportunity for health care providers to work in collaboration with other entities to meet the demands of a new model of service delivery. As such, there is a need to adopt innovative approaches to service delivery that improve quality of care, increase access to care, and reduce costs of care. Before considering the ways in which organizations can work collaboratively, it is essential to discuss the importance of collaboration as it relates to health care service delivery. 


\section{Importance of Collaboration}

Continuing cost inflation and changing disease patterns paired with workforce shortages and increasing demand are some of the major reasons why health service delivery organizations must consider strategic and efficient use of scarce resources. The problems faced by health service delivery systems are complex and multifaceted (Shi \& Singh, 2014). Collaborative partnerships provide an opportunity to conserve capital and make effective use of limited resources (Mitchell, 2008). Before discussing the benefits of collaboration, it is important to define collaboration. In general terms, to collaborate with others is to work with them in achieving some type of shared goal or objective (Mitchell, 2008). Collaboration is also often mutually beneficial and well-defined by those engaged (Mitchell, 2008). What makes collaboration important is that it plays a key role in meeting community-wide goals, particularly as it relates to meeting complex health needs. The National Association of County and City Health Officials (NACCHO) (2017) suggests several benefits of collaboration:

1. cost and effort are not duplicated;

2. fragmentation among services, programs, and initiatives is reduced;

3. high-quality, more integrated outcomes for end users;

4. integration of diverse perspectives among agencies;

5. improved communication among agencies;

6. increased trust and understanding among individuals and organizations;

7. potential for organizational and individual learning;

8. better ability to achieve key outcomes (para. 5).

Equipped with preliminary knowledge about the benefits of collaboration, it is worthwhile to explore the contexts in which there is potential for collaboration to occur, particularly as it relates to health service delivery. The 1115 Medicaid Transformation Waiver provides such an opportunity. 


\section{Section 1115 Medicaid Demonstration Waiver: Potential for Collaboration Overview of 1115 Medicaid Transformation Waivers}

Medicaid is a joint federal and state program that assists low-income populations (e.g. adults, children, pregnant women) with the costs of medical services. Medicaid is administered by states, but eligibility for Medicaid varies from state to state (Centers for Medicare and Medicaid Services [CMS], n.d.). Although the scope of services varies from state to state, mandatory benefits include services like inpatient and outpatient hospital services, physician services, and laboratory and x-ray services among others (CMS, n.d.). "Section 1115 of the Social Security Act gives the Secretary of Health and Human Services authority to approve experimental, pilot, or demonstration projects that promote the objectives of the Medicaid and Children's Health Insurance Program (CHIP) programs" (CMS, 2013).

Section 1115 waivers have traditionally been used to test and implement coverage approaches outside the scope of existing federal program rules (CMS, 2013). These waivers are usually granted for an initial five-year period of time with an option to request an extension for three additional years. Many states have received Waivers dating back to 1982 (Artiga, 2011). Waivers are used to achieve a broad range of goals, such as expanding coverage to those not otherwise eligible for Medicaid, altering benefits and cost-sharing, modifying provider payments, extending coverage during emergencies, and transforming delivery systems (Artiga, 2011). Perhaps most importantly, these waivers can inform policy development and provide federal and state governments with opportunities to use these demonstrations to test changes that could potentially be 
implemented in federal Medicaid policy (Rosenbaum, Schmucker, Rothenberg, \& Gunsalus, 2016).

\section{Overview of the Texas 1115 Medicaid Transformation Waiver}

In 2011, Texas received approval from the Centers for Medicare and Medicaid Services (CMS) for a five-year 1115 Medicaid Waiver Demonstration Project (Waiver). The overarching goal of the Waiver was to achieve the Triple Aim strategies by increasing access to care, improving quality of care, and decreasing costs of care (Texas Health and Human Services [HHS], n.d.). Implementation of the Waiver consisted of three elements, including expansion of Medicaid managed care, redesign of the uncompensated care payment structure for hospitals, and transformation of health care delivery through the Delivery System Reform Incentive Payment (DSRIP) Program. This study focused on the organizations that participated in DSRIP, which provides financial incentives to eligible providers implementing one or more evidence-based projects, as approved by HHSC and CMS. These projects focus on infrastructure development and program innovation and redesign, while requiring measurement of quality improvements and outcomes (HHS, n.d.). Unlike a traditional grant, funds for DSRIP were directly tied to meeting performance metrics (Gates, Rudowitz, \& Guyer, 2014).

The state of Texas is geographically vast, and the populations are diverse; therefore, different regions in the state have differing health needs. As such, the Texas Health and Human Services Commission chose to implement DSRIP in Texas by creating 20 Regional Healthcare Partnerships (RHPs). RHPs served as a mechanism to plan, implement, and monitor DSRIP activities (Texas Health and Human Services [HHS], n.d.). While the composition of each RHP varied, each included at minimum an 
intergovernmental transfer entity (responsible for generating funds eligible for state match under the waiver), an anchor institution (RHP management entity), and a performing provider (e.g. hospital, community mental health center, health department, medical district, academic health science center, and physician practice) (HHS, n.d.). A key element that distinguishes Texas from other states that implemented DSRIP was that Texas chose to expand eligibility for organizations who can participate in the program. For example, in the California DSRIP program, only public hospitals were eligible as performing providers. Since Texas chose to expand eligibility, there were increased opportunities to engage in collaboration both within and across sectors (HHS, n.d). Thus, the waiver presents a unique opportunity to assess collaboration through partnerships for public funding and delivery of services to Medicaid and uninsured patients in Texas.

\section{Evaluating Collaboration}

The literature suggests various approaches for assessing collaboration among organizations, which will be covered in more depth in Chapter 2. Social network analysis (SNA) is one way to map and measure relationships and flows between individuals, organizations, groups, and other entities (actors). This powerful tool has been applied across disciplines to study patterns of connection among various actors who are embedded within a network of interrelationships with other actors (Borgatti, Everett, \& Johnson, 2013). Unlike standard statistical techniques, however, SNA applies relational methods for understanding and analyzing connections between actors. Therefore, it is important to examine closely the ways in which SNA can be applied in health services delivery to capture, understand, and identify relationships between various organizations. 


\section{Networks}

\section{Social Networks}

The world in which we live is interconnected, presenting opportunities to assess patterns of connection. Borgatti and colleagues (2013) suggest that "networks are a way of thinking about social systems that focus our attention on the relationships among the entities that make up a system, which we call actors or nodes" (p. 1). Network analysis has been applied across various disciplines, such as public health, health service delivery, and political science, among others. As such, there are a number of different types of networks, including information networks, social networks, stream networks, interorganizational networks, or transportation networks. For example, network analysis has been used in public health to study disease transmission, particularly HIV/AIDS, which helped to identify various risk factors for contracting the disease (Luke \& Harris, 2007).

SNA allows us to understand, visualize, and analyze relationships between actors. As mentioned, actors can represent individuals or organizations. Both actors and the relationships between actors can have specific characteristics. One of the main reasons relationships are an essential aspect of network analysis is because they provide the foundation for a given network. Relationships between actors are characterized by ties, such as marriage or information sharing. Characteristics of actors are often referred to as “attributes." Borgatti and colleagues (2013) provide some basic assumptions that guide network analysis:

1. Relationships are key to network analysis.

2. Network analysis is about the structure and position of actors within a particular network.

3. Networks provide opportunities and constraints. 
4. Actors cannot be treated as isolated entities. Actors influence each other, either directly or indirectly.

5. The structure of a network is important.

6. The unit of analysis is the network (made up of actors and the relations between them) and not always the individual.

7. Ideas, objects, or materials can flow through relationships.

Network analysis distinguishes between three levels of analysis: the node, the

dyad, and the network (Borgatti et al., 2013). These levels drive the questions asked and influence the types of methods used. Among other applications, what makes network analysis particularly useful is that it facilitates the process of describing the structure of a network or characterizing aspects of actors' positions within the network (Borgatti et al., 2013). Equipped with this knowledge, it is important to explore network analysis in the context of interorganizational collaboration.

\section{Interorganizational Networks}

Interorganizational network analysis is a specific type of network analysis that focuses on examining patterns of relationships among organizations (Morrissey, 1992; Provan \& Milward, 1995). The actors in interorganizational networks are organizations, and the ties are the relationships that exist between organizations. SNA is commonly used to examine the structure and quality of relationships between organizations within interorganizational networks (Borgatti et al., 2013; Popp, MacKean, Casebeer, Milward, \& Lindstrom, 2014). Ties between organizations can include information sharing, patient referrals, formal data sharing, joint program or service delivery, or resource sharing (Provan, Fish, \& Sydow, 2007). Interorganizational network analysis has been applied extensively across disciplines in the literature (Luke \& Harris, 2007; Popp et al., 2014; Provan, Fish, \& Sydow, 2007)), which will be explored in detail in Chapter 2. 
Networks can further be distinguished by type and function (Popp et al., 2014). Several types of networks seem to emerge from the literature, including service delivery, information diffusion, knowledge exchange, community capacity building, and innovation (Borgatti \& Foster, 2003; Huerta, Caebeer, VanderPlatt, 2006; Isett et al., 2011; Milward and Provan; 2006). All of these networks have different functions, so it is likely that relationship evolution will manifest differently based on the type of network.

Given the different types of networks and their respective functions within interorganizational networks, Hill (2002) provides various levels of analysis that can be used to assess network effectiveness. These levels form the basis of interorganizational network analysis. Hill (2002) proposes four levels of analysis: individual, organizational, network, and community. The individual level is concerned with measuring the impact the network has on individuals who interact in the network on behalf of an organization s/he represents, as well as the impact the network has on individual clients (Popp et al., 2014). The organization level focuses on evaluating the impact that a particular network has on member organizations. The network level of analysis may focus on network maturity and the strength of relationships across the whole networks. Lastly, the community level strives to measure the impact networks can have on the communities they serve (Popp et al., 2014).

As mentioned above, SNA is a powerful tool that allows researchers to capture relationships that exist between organizations to illustrate network structure and the types of relationships that exist between actors. Given that the RHPs under the Waiver served as distinct interorganizational networks, an application of network analysis can inform an understanding of how collaboration among organizations within the RHPs evolved over 
time and what that may imply about the structure of each RHP and the role of particular organizations participating in the RHPs.

\section{Relevance to Public Health}

Public health is central within the continuum of care. The Waiver provided a unique opportunity to integrate non-traditional service delivery organizations, such as public health agencies and community mental health centers to a system typically limited to traditional health care providers. This is important because public health agencies are acknowledged as important organizations that provide access to population-based services in ways that can contribute to the Triple Aim strategies for an improved health care system. Assessment is a core function of public health, and public health agencies in conjunction with other organizations had an opportunity to identify activities that were locally relevant to addressing the needs of each region. Since public health is collaborative by nature and relies on partnerships to improve health and well-being within and across communities, this program provided a window of opportunity for public health organizations to form relationships across sectors (e.g. community mental health centers, hospitals) while addressing regional health needs.

Public health services have been historically and systematically underfunded and under-resourced (American Public Health Association, 2012). Since the Waiver incentivized collaboration, public health agencies had an opportunity to leverage funding through multiple partners and potentially expand and integrate the services provided across other organizations. Application of network analysis to the RHPs may highlight the role of public health agencies as fundamental in the larger health service delivery system for improving and maintaining population health. Furthermore, the Waiver 
presented an opportunity to reconcile perspectives of public health and health care to focus on prevention, equity, and population health, key aspects that the US health care system is currently struggling to address.

\section{Importance}

Addressing existing inefficiencies in the US health care system can best be characterized as complex and multifaceted. Piecemeal efforts have proven to be unsustainable and ineffective. Instead, such problems require comprehensive efforts that bring together a wide range of stakeholders with diverse knowledge, skills, resources, and expertise in addressing the Triple Aim strategies. Texas' Waiver provides a unique opportunity to assess how organizations work together for service delivery transformation. What makes this study particularly interesting is that it involves an examination of organizations across sectors embedded within networks. Findings can inform policies at the state and federal levels to promote collaboration across sectors for the integration of health services.

Organizations responsible for delivering health services have generally operated in silos; however, this program provided a mechanism to engage organizations from different sectors in collaborative partnerships. While traditional forms of measuring collaboration have helped to characterize factors that promote or hinder relationships, more sophisticated collaboration tools, such as social network analysis can help to visualize patterns of relationships among organizations and highlight implications about the structure of the network and the roles of the organizations embedded within the network. This information helps understand opportunities and constraints each organization may experience within the context of the network. Moreover, since Texas 
was the first state to implement DSRIP through the formation of RHPs, this collaborative provider network approach can be adapted in other states to address health service delivery concerns responsive to local needs. This study will aim to evaluate the impact of the implementation of DSRIP on interorganizational collaboration at the regional level. 


\section{CHAPTER II}

\section{REVIEW OF THE LITERATURE}

\section{Current State of Health Care}

Health care reform continues to be a matter of national debate as a direct result of rising health care costs and poor health outcomes. While the Affordable Care Act has expanded and improved insurance coverage, concerns related to quality and efficiency persist (Davis et al., 2014; Obama, 2016). These concerns are exacerbated by the uncertainty of health care under the new administration. Adler and Hoagland (2012) suggest that health care costs are driven by several key factors, some of which include:

1. Fee-for-service reimbursement;

2. Fragmentation in care delivery;

3. Administrative burden on providers, payers, and patients;

4. Population aging, rising rates of chronic disease and co-morbidities, as well as lifestyle factors and personal health choices; and

5. Advances in medical technology (p. 6-7).

Prior to the Affordable Care Act, a fee-for-service reimbursement model was commonly used in the health care system (Obama, 2016). The FFS model incentivizes providers to focus on quantity of services (e.g. additional tests, procedures) delivered as opposed to the quality of services, which has the potential to increase both the volume and cost of care with little to no impact on health improvement (Miller, 2009). This is concerning because it contributes further to a fragmented health care 
system that fails to deliver quality services across the continuum of care (Miller, 2009).

Additionally, the health care system has operated in silos treating physical and behavioral health separately, which creates an interruption in the continuum of care (Institute of Medicine, 2001). Fortunately, the health care landscape is undergoing a paradigm shift from volume- to value-based care, which encourages population health management and incentivizes quality, safety, and efficiency (Leavitt et al., 2016; Obama, 2016). This shift provides a window of opportunity to improve coordination of care across a range of providers, both traditional and non-traditional (e.g. behavioral health, public health), which aligns well with the Triple Aim strategies. The Institute for Healthcare Improvement (2009) characterizes the Triple Aim as an approach to:

1. Improve the health of the defined population;

2. Enhance the patient care experience (including quality, access, and reliability); and

3. Reduce, or at least control, the per capita cost of care (p. 64).

As we consider collaboration among a diverse mix of providers, it is essential to consider the mechanisms through which providers may collaborate. That is, providers may choose to form strategic alliances informally or they may be called upon to participate in more formal collaborative partnerships. As defined above, interorganizational networks are comprised of relationships between organizations. As such, it is important to understand the differences between formal and informal networks as it relates to collaboration in health services delivery.

\section{Formal versus Informal Networks}

A network is "a set of nodes and the set of ties representing some relationships, or lack of relationship, between the nodes" (Brass, Galaskiewicz, Greve, \& Tsai, 2004, p. 795). Isett and colleagues (2011) distinguish formal networks from informal networks by 
suggesting that formal networks are created by a larger convening body where membership may be mandatory or have some sort of incentive attached to participation. Informal networks tend to more socially structured and provide more flexibility with respect to the nature of relationship building (Isett et al., 2011). In a mandated collaboration between the education, health, and social service sectors, researchers found that the effect of being mandated was highly influenced by pre-existing relationships among participating organizations (Luke \& Harris, 2007; Heffren, McDonald, Casebeer, \& Wallsten, 2003). When pre-existing relationships were effective and built on trust, the mandated structure provided more resources and permission; however, when these relationships were not as effective, resources that were tied to being mandated incentivized organizations to work more effectively in conjunction with one another, or the mandated collaboration reinforced a lack of interest to collaborate (Heffren et al., 2003). For informal networks, Provan and Lernaire (2012) suggest that similarity on a particular attribute (e.g. size, type of organization), proximity, and having prior relationship experience with a particular organization contributes to the development of strong connections among organizations. Moreover, adopting an appropriate network culture that accommodates the needs of participating organizations, in part, shapes the potential for the development and growth of relationships among organizations within a particular network (Popp et al., 2014).

With an understanding of the siloed attempts traditionally used to address complex health needs in health care, we are more aware of the resulting consequences associated with such approaches. Equipped with this information and knowledge about 
formal and informal collaboration, it is important to consider potential challenges associated with intersectoral collaboration.

\section{Challenges to Collaboration in Interorganizational Networks}

Networks are often evolving and can best be characterized as complex (Huerta et al., 2006; Provan \& Lemaire, 2012). As such, the literature points to a number of challenges that may emerge for organizations embedded within an interorganizational network (Popp et al., 2014). Organizations often have differing priorities and perspectives, so achieving consensus about the purpose and goals of the network can be

difficult (Provan \& Lemaire, 2012). Developing relationships built on trust can be a time consuming process (Gulati, Lavie, \& Madhavan, 2011). Organizations have different approaches to decision making and subscribe to different models of transparency, which can make it difficult to agree on specific processes and outcomes (Huerta et al., 2006). Provan and Lemaire (2012) also suggest the potential loss of autonomy as a barrier to participating in networks. Additionally, conflicts can arise as a result of power imbalances within the network (Provan \& Lemaire, 2012). Despite challenges, however, complex approaches at the systems level, such as delivery system reform, require organizations across sectors to collaborate in meaningful ways. In fact, the literature suggests that organizations have worked effectively in conjunction with other organizations to fulfill specific goals.

\section{Collaboration Networks in Health Service Delivery}

There are a number of exchanges documented among health care organizations and other service delivery organizations within the network literature. Health and human services networks are often developed to strengthen service delivery systems and to 
manage population health across the continuum of care (Foster-Fishman, Salem, Allen, \& Fahrbach, 2001; Greenhalgh, Robert, Macfarlane, Bate, \& Kyriakidou, 2004; Provan \& Milward, 1995). Luke and Harris (2007) consolidate findings in a literature review and suggest that health care systems that serve HIV/AIDS clients, behavioral health clients, and the elderly tend to work with each other in sending and receiving funding, receiving client referrals, and utilizing joint programs or engaging in service delivery. In a study comparing the integrated and coordinated nature of four different networks of community mental health centers, the following ties were reported among organizations: patient referrals sent and received, case coordination, joint programs, and service contracts (Provan \& Milward, 1995). Another study focused on promoting service delivery integration by examining interorganizational interactions related to the exchange of client information, sharing of resources, and participation in joint ventures (Foster-Fishman et al., 2001). Certain relationships between organizations, such as service delivery, are more common and more likely to be sustained because they require less negotiation when compared to system-level planning activities (Bryson, Crosby, \& Stone, 2006). Thus, a preliminary examination of these exchanges suggests that organizations that deliver health care services are attempting to integrate services and programming with each other, which highlights the importance of shifting to more integrated delivery systems. This is particularly important because integrated delivery models have the potential to address the Triple Aim strategies in working towards a more efficient health care system. 


\section{Integrated Delivery Systems}

The World Health Organization's (2008) working definition of integrated delivery systems is "the management and delivery of health services so that the clients receive a continuum of preventive and curative services, according to their needs over time and across different levels of the health system (p.1)." There are two major types of integration that fall under IDS: horizontal and vertical integration. Horizontal integration can be characterized by the integration of organizations providing similar types of services under a larger management structure. Vertical integration focuses on integrating organizations that provide different services under a larger management structure (Essential Hospitals Institute, 2013).

Horizontal integration tends to focus on consolidating organizational resources by forming local networks of multihospital systems, mergers, or strategic alliances with neighboring hospitals (Burns \& Pauly, 2002). Vertical integrations tend to focus on meeting goals directly related to the Triple Aim strategies (e.g. efficiency, access, quality, cost). What differentiates IDS models from other models is that they focus on key aspects associated with efficient health care systems, such as coordination of care, population health management, culture, values, and leadership, and continuous innovation and learning to improve value (Enthoven, 2009). Moreover, IDS models can provide a framework upon which to base potential collaborations, specifically as it relates to delivery system reform.

\section{Value of Intersectoral Collaboration}

An intersectoral collaboration is "a recognized relationship between part or parts of the health sector with part or parts of another sector which has been formed to take 
action on an issue to achieve health outcomes...in a way that is more effective, efficient or sustainable than could be achieved by the health sector acting alone (WHO International Conference on Inter-sectoral Action for Health, 1997, p.3.). Before discussing the context in which there is potential for collaboration to occur, it is important to highlight key benefits of intersectoral collaboration:

1. Intersectoral partnerships provide organizations with the opportunities to strengthen limited resources and make more efficient use of resources (Bryson et al., 2006; Provan \& Lemaire, 2012).

2. In the delivery system reform context, such partnerships provide opportunities to provide coordinated care and improve the quality of services provided across the continuum of care (Provan \& Lemaire, 2012).

3. Such collaborations have an increased potential for creating opportunities for innovation (Provan \& Lemaire, 2012).

While such relationships can be difficult to create and sustain over time, they provide meaningful opportunities for organizations to fulfill their directional strategies in meeting the needs of the communities they serve (Bryson et al, 2006).

\section{Opportunities for Delivery System Reform}

\section{Texas 1115 Medicaid Transformation Waiver}

The 1115 Medicaid Transformation Waiver (Waiver) provides an opportunity to assess intersectoral collaboration within formal networks. Section 1115 Medicaid demonstration waivers are intended to allow states to test changes in coverage, benefits, provider payments, and cost sharing. In doing so, these waivers provide a mechanism to assess delivery system reform (Artiga, 2011). Each state has the flexibility to shape their waiver program based on the needs of its population. In 2011, Texas was approved for a 5-year demonstration project. The goals of the Waiver were to increase access to care, improve quality of care, and decrease costs of care (Triple Aim strategies). One element

of the Waiver was the Delivery System Reform Incentive Payment (DSRIP) program, 
which was designed to incentivize activities that support hospitals' collaborative efforts with other organizations to address the Triple Aim strategies. Projects funded through DSRIP were required to focus on four main areas: infrastructure development, program innovation, quality improvements, or population-focused improvements (Gates, Rudowitz, \& Guyer, 2014). Under DSRIP, providers had to meet performance metrics to qualify for funds (Gates et al., 2014).

The state chose to implement DSRIP through the formation of 20 Regional Healthcare Partnerships (RHPs), a decision based on the geographic vastness of the state and the diversity of the populations in the different regions of the state. RHPs were collaborations of interested entities that worked collectively to submit a regional plan of action for health care delivery system reform, supported coordinated delivery of quality care, and invested in system transformation driven by the local needs of communities, populations, and hospitals. As mentioned previously, each RHP was comprised of an anchor institution and other participating member organizations, such as intergovernmental transfer (IGT) organizations, and those providing services (e.g. hospitals, community mental health centers, public health departments). The anchor organization served as the coordinating body for each RHP, working with providers to identify DSRIP projects based on regional health needs and facilitating shared learning among DSRIP providers throughout the demonstration period. IGT entities were those organizations (e.g. cities, counties, hospital districts, hospital authorities, and academic health science centers) that have public funds eligible for state match under the waiver (HHSC, n.d.). Since states are responsible for paying their share of the cost of DSRIP activities under Medicaid financing requirements, a source of state funding had to be 
identified to match federal funding; IGT entities provided these local matches (Gates et al., 2014).

Within the RHPs, many organizations already had existing relationships with other organizations. Moreover, with a focus on delivery system reform, it would be interesting to assess whether local implementation of these activities through RHPs strengthened intersectoral collaboration among organizations in each region and what that implies about the role of organizations within each RHP. In order to do so, we must consider tools that have been used in the past to evaluate collaboration among organizations.

\section{Assessment Tools for Collaboration}

The literature points to a number of tools for measuring collaboration, a few of which are briefly highlighted below (Centers for Disease Control and Prevention [CDC], 2007). A widely used measure is the Levels of Collaboration survey (Frey, Lohmeier, Lee, \& Tollefson, 2006). The Levels of Collaboration Scale was developed for the purpose of assessing collaboration among grant partners. It provides five levels of collaboration (networking, cooperation, coordination, coalition, and collaboration) and relationship characteristics for each level. On a scale of 0 to 5 , with 0 being no interaction at all and 5 being the collaboration level using Hogue's taxonomy, respondents are asked to indicate the extent to which they collaborate with each of the other grant partners.

These responses can be aggregated to provide a mean level of perceived collaboration for each of the different partners (Frey et al., 2006). This scale provides a meaningful way to identify additional opportunities where there is potential for collaboration to occur and suggest opportunities to sustain existing relationships. 
The Wilder Collaboration Factors Inventory is another frequently used tool that presents an opportunity to assess factors that contribute to successful collaborative activities. It includes 40 items with six subscales (Mattessich, Murray-Close, and Monsey, 2004), covering environment, member characteristics, communication, purpose, process, and resources. The survey uses a 5-point Likert scale measuring the level of agreement with each item and provides a useful way of measuring group-level perceptions of collaboration in identifying strengths and challenges across multiple domains (Mattessich et al., 2004). Additionally, there are also a number of tools for assessing relationships, communication, and trust—all critical elements of interorganizational collaboration (Currall \& Judge, 1995; Simatupang \& Sridharan, 2005).

A more powerful tool for assessing collaboration is social network analysis (SNA). SNA is a way to describe, map, and analyze connections between actors (e.g. individuals, organizations, groups). The utility of the tool requires a closer examination.

\section{Social Network Analysis}

\section{History}

Social network analysis dates back to the 1930s when Jacob Moreno, a psychiatrist presented the first sociogram at a meeting of the Medical Society of the state of New York. He had mapped a social network focused on an epidemic of runaways at the Hudson School for Girls in upstate New York using sociometry. He argued that the flow of ideas and social influence impacted whether and when girls ran away. In the 1940s and 1950s, matrix algebra and graph theory began to emerge in the context of social network analysis and was beginning to gain more traction. In fact, psychologists, 
political scientists, economists, and sociologists began to take great interest in social network analysis (Borgatti, Mehra, Brass, \& Labianca, 2009). Over the years, the approach has been adopted across a number of disciplines, such as anthropology and public health.

\section{Social Network Theory and Perspectives}

Networks vary across a number of essential dimensions, such as a broad typology of ties studied in network analysis (e.g. information sharing, affective ties). They also vary based on network structure, which can influence the role of particular actors embedded within networks. Borgatti and colleagues (2013) highlight some basic concepts of network structure:

1. Node: The entities that make up the network (e.g. individuals, organizations, cities).

2. Tie: The relationships that constitute the network (e.g. information sharing). Ties can be directed or undirected. Ties can also be valued.

3. Node Attribute: Characteristics of a node (e.g. age, gender).

4. Network Boundaries: Boundaries that identify the nodes that are included and excluded from the network (Foster-Fishman, Salem, Allen, \& Fahrbach, 2001).

SNA is predicated on the idea that an individual's behavior is influenced by the web of interrelationships in which they are embedded. What makes SNA particularly useful is that it provides information about the opportunities presented to and constraints imposed upon actors within the network (Borgatti et al., 2013; Katz, Lazer, Arrow, \& Contractor, 2004). The focus of the analysis is on the relationships between actors, which assumes interdependence among actors. Additionally, this information can be visualized graphically and provides meaningful information about the structure of the whole network and the roles of specific actors within the network (Borgatti et al., 2013; Katz et 
al., 2004; Wasserman \& Faust, 1994). Equipped with this understanding, it is important to consider networks in which organizations operate.

\section{Interorganizational Network Analysis}

Interorganizational network analysis is an extension of social network analysis. In interorganizational networks, actors are organizations and social network methods are used to assess patterns of connections among organizations. Provan and Kenis (2008) suggest that there are multiple reasons that drive organizations to join or form networks, such as the desire to gain legitimacy, serve clients more effectively, obtain more resources, and address complex problems that could not have been possible to do alone.

Popp and colleagues (2014) suggest that there are multiple benefits of interorganizational networks some of which include access to resources and efficient use of resources; an increased ability to share risk in pursing innovative endeavors; ability to provide coordinated; high quality services across the continuum of care; an opportunity to engage in knowledge and information exchange; or to share responsibility (Popp et al., 2014).

While there are clear advantages of participating in interorganizational networks, there are also disadvantages of participation, which can include challenges with consensus building, loss of autonomy, and the time consuming nature of relationship building (Popp et al., 2014). As such, Popp and colleagues (2014) recommend that organizations exercise caution when entering networks and the decision to do so should rely heavily on the potential for achieving collaborative advantage, the idea that "a welldeveloped ability to create and sustain fruitful collaborations gives companies a significant competitive leg up" (Kanter, 1994, p.1). This decision is often influenced by 
the extent to which the network is voluntary (informal) or mandated (formal), where most networks can generally be characterized as falling somewhere in between this continuum. "Formal networks are consciously created with some sort of binding agreement for participation, whereas informal networks are more organically derived - an outgrowth of organizational contingencies that multiple actors come together to address" (Isett, Mergel, LeRoux, Mischen, \& Rethemeyer, 2011, p. i162).

Borgatti and colleagues (2013) and Popp and colleagues (2014) describe key characteristics of interorganizational networks that can be captured through SNA:

1. Dyadic relationships: The building blocks of networks defined as the relationships that exist between two organizations.

2. Density: Overall level of connectedness among organizations embedded within the network. Density is the number of ties reported by organizations within a network as a proportion of the total number of ties that could exist (Wasserman \& Faust, 1994).

3. Centrality: The extent to which an organization is central within the network. This is often shaped by the number of links (both direct and indirect) an organization has as well as its position within the network relative to other organizations.

4. Multiplexity: A measure of strength of ties between organizations based on the different types of ties (resource sharing, data sharing, service delivery) that exist between organizations.

5. Matrix representation: one way of representing network data where rows and columns refer to actors and cell entries contain the value of the relationship linking the actors. Ties can be binary (no tie $=0$, tie $=1$ ) or they can be valued (O’Malley \& Marsden, 2008).

a. One-mode matrix: The rows and columns in an adjacency matrix refer to the same set of entities (person-by-person).

b. Two-mode matrix: The rows and columns refer to different sets of entities (rows correspond to people and columns correspond to events) (O’Malley \& Marsden, 2008).

6. Relational data: Information about relationships can be combined with attribute data (characteristics of an actor) to assess compositional measures, such as homophily (the extent to which an organization connects with similar others).

7. Network graphs: A visual representation of networks, with organizations being represented by shapes and relationships being represented as lines (Borgatti, Everett, \& Freeman, 2002). 
Given the complex nature of networks, it is important to analyze network effectiveness at multiple levels. Wasserman \& Faust (1994) suggest three levels of analysis for network data: actor-level, dyad-level, and network-level. The smallest unit of analysis in a network is an actor within a particular social setting. The dyadic level focuses on the structures of relationships between two actors, and the network level focuses on the strength of relationships across the whole network. Table 1 presents some common measures that have been reported in the literature across each level of analysis. It is also worthwhile to understand the implications of these measures as it relates to service delivery. 
Table 1. Network Measures Categorized by Levels of Analysis

\begin{tabular}{|c|c|c|c|}
\hline Level of Analysis & Measure & Definition & Sources \\
\hline \multirow{5}{*}{ Actor-Level } & Centrality & $\begin{array}{l}\text { Measure of an organization' s power and influence within the } \\
\text { network. }\end{array}$ & Freeman, 1979 \\
\hline & Degree & Number of ties an organization has at a given point in time. & Freeman, 1979 \\
\hline & Betweenness & $\begin{array}{l}\text { Extent to which an organization falls on the shortest path } \\
\text { (geodesic path) between any other two other organizations. }\end{array}$ & Freeman, 1979 \\
\hline & Closeness & $\begin{array}{l}\text { Number of ties it takes to reach every other organization in the } \\
\text { network. }\end{array}$ & Freeman, 1979 \\
\hline & Eigenvector & $\begin{array}{l}\text { Extent to which an organization is connected to other } \\
\text { organizations that are well connected. }\end{array}$ & Bonacich, 1987 \\
\hline \multirow[t]{2}{*}{ Dyad-Level } & Multiplexity & $\begin{array}{l}\text { A measure of strength of ties between organizations based on } \\
\text { the different types of ties (resource sharing, data sharing, service } \\
\text { delivery) that exist between organizations. }\end{array}$ & $\begin{array}{l}\text { Tichy, Tushman, \& } \\
\text { Fombrun, 1979; Provan et } \\
\text { al., } 2007\end{array}$ \\
\hline & Reciprocity & Extent to which ties are mutual among two organizations. & Wasserman \& Faust, 1994 \\
\hline \multirow{3}{*}{ Network-Level } & Density & $\begin{array}{l}\text { Overall level of connectedness among organizations embedded } \\
\text { within the network. Density is the number of ties reported by } \\
\text { organizations within a network as a proportion of the total } \\
\text { number of ties that could exist. }\end{array}$ & Wasserman \& Faust; 1994 \\
\hline & Centralization & $\begin{array}{l}\text { Extent to which network ties revolves around one or a few } \\
\text { organizations. }\end{array}$ & Freeman, 1979 \\
\hline & $\begin{array}{l}\text { Intersectoral } \\
\text { Ties (Density } \\
\text { by Groups) }\end{array}$ & $\begin{array}{l}\text { Number of ties between (and within) organizations in different } \\
\text { sectors of the health care delivery system. }\end{array}$ & $\begin{array}{l}\text { Foster-Fishman et al., } \\
2001\end{array}$ \\
\hline
\end{tabular}


Degree, closeness, betweenness, and eigenvector are all measures of actor centrality (Bonacich, 1987; Freeman 1979). Researchers tend to report degree centrality most frequently based on the intuitiveness of the measure. Centrality allows one to identify those actors that occupy important positions within the network (Cook \& Emerson, 1978). For example, actors who have high betweenness tend to have greater potential in influencing others near them within the network (Friedkin, 1991). Since closeness measures are based on ideas of efficiency and independence, actors high on closeness measures have the potential to efficiently transmit information without necessarily having to seek information from other peripheral actors (Friedkin, 1991). Since both degree and closeness centrality measures provide information on the transmission of information and influence to others through direct or short paths, researchers have hypothesized that the pathway of influence for the two measures might be similar (Valente, Coronges, Lakon, \& Costenbader, 2008).

A greater number of ties makes it easier for central actors to access and control resources and engage in enhanced knowledge transfer (Fattore, Frosini, Salvatore, \& Tozzi, 2009; Oliver and Montgomery, 1996; Van Wijk, Jansen, \& Lyles, 2008). Compared to non-central organizations within a network, central organizations are more embedded within the flow of information and resources (Cook \& Emerson, 1978). Central organizations have the potential to assume gatekeeping roles within the network, as they control access to valued resources (Provan, Huang, \& Milward, 2009). Gibbons suggests that the most effective communication and information sharing occurs in networks with a central actor and direct ties between actors (Gibbons, 2007). Valente and colleagues (2007), however, caution against a network that is too centralized as this could 
potentially jeopardize the functioning of that network. This may, in part, be explained by Carboni and Milward's (2012) findings, which suggest "the more centralized a network is, the less resilient the network will be to systemic shocks" (p. 540).

Robust networks tend to have several paths between any two nodes. The central idea behind multiplexity is that if some actors or links are removed or damaged, other pathways for uninterrupted information flow exists. In fact, changes in the frequency, reciprocity, and nature of network ties and interactions over time may suggest increased network capacity as a result of increased collaboration. Additionally, the complexity of relationships is likely to increase as interorganizational relationships mature, which results in strengthened relationships and sustained collaboration (Provan \& Milward, 2001). Provan and Lemaire (2012) indicate that strong and weak ties are both valuable within a network. When organizations are connected to one another, there is high closure, which is useful for building and maintaining trust and for sharing information that is generally well known. Weak ties can result in structural holes, which are gaps in connectedness within a network that have the potential to generate novel ideas and approaches (Burt, 2005).

For service delivery, network density generally tends to increase over time (Venkatraman \& Lee, 2004). Network density tends to be highest for information exchange ties (Fried, Johnsen, Starrett, Calloway, \& Morrissey, 1998; Kwait, Valente, \& Celentano, 2001; Johnsen, Morrissey, \& Calloway, 1996; Provan, Nakama, Veazie, Teufel-Shone, \& Huddleston, 2003; Morrissey, Tausig, \& Lindsey, 1985). The lowest densities appeared in more formal types of ties, including resource exchanges (Fried, Johnsen, Starrett, Calloway, \& Morrissey, 1998; Johnsen, Morrissey, \& Calloway, 1996), 
formal linkage agreements (Kwait, Valente, \& Celentano, 2001; Valente, Coronges, Stevens, \& Cousineau, 2008) and joint programs (Kwait, Valente, \& Celentano, 2001). Compared to less dense networks, networks with high density possess more pathways for information and resource exchange to flow (Valente et al., 2007). Increased connectedness paired with reciprocity of ties can also promote resource exchange and collaboration within the network (Ramanadhan et al., 2012). In terms of centralization, compared to less centralized networks, networks that are more centralized with one (or a few) key organization can use those organizations to disseminate information and innovative ideas more quickly. In their investigation of the management and governance of service delivery networks, Provan and Milward (1995) found that "networks integrated and coordinated centrally through a single core agency, are likely to be more effective [in contributing to network maturity, sustainability, and resilience, which are strongly linked to network learning and growth] than dense, cohesive networks integrated in a decentralized way among the organizational providers that make up the system" (p. 24).

Interorganizational networks can be viewed as a way to address complex issues in health service delivery by leveraging a broad set of resources and increased capacity. These networks can often be intersectoral requiring collaboration between and across sectors (Bryson et al., 2006). Interestingly, a study on addressing cancer disparities through intersectoral partnerships suggests that the number of diverse connections and the strength of connections are important drivers of collaborative efforts (Ramanadhan et al., 2012).

Homophily is the extent to which organizations connect with similar organizations (McPherson, SmithLovin, \& Cook, 2001). In the service delivery context, 
homophily can help to characterize the extent to which an organization is engaging in intersectoral action with other organizations. Network effectiveness can, in part, be attributed to the ways in which organizations are developing ties. In non-mandated, emergent networks, homophily contributes to the development of strong network ties among organizations (Provan \& Lemaire, 2012). McPherson and colleagues (2001) suggest that nodes link together because of common attributes (e.g. gender, age, race, service orientation). However, diversity of connections is required to maximize innovation within the network. In informal interorganizational networks, Greengalgh and colleagues (2004) have suggested that the decision to adopt an innovation and sustain efforts is based on homophily. A few studies have used measures of homophily, specifically percentage homophily and the E-I index to measure cross-organizational type diversity for an organization's network ties or to assess new ways of improving health care delivery among networks of health care providers (Bevc, Retrum, \& Varda, 2015; Heijmans, Jan van Lieshout, \& Wensing; 2017; Moore, Smith, Simpson, \& Minke, 2006). Findings suggest that homophily can both improve opportunities available or it can impose certain constraints on actors.

Taken as a whole, this information provides a broad overview of how interorganizational network analysis can be used to understand the structural and contextual characteristics of networks at both the organizational and whole network levels. Equipped with this understanding, interorganizational network analysis can prove to be a powerful tool in analyzing relationships between organizations in each RHP network under the Waiver. 
Based on the literature, previous studies have utilized interorganizational network analysis to map and measure collaboration within networks and to show changes in collaboration over time to demonstrate the effectiveness of network structure or development. A large number of network studies in health service delivery focus on whole network analysis. While measures about the whole network increase our understanding about the structure of the network, its evolution, and the impact this has on participating organizations, fewer studies focus on the role of organizations within service delivery networks and the potential impact this may have on collaboration. This information is particularly relevant as the shift to more integrated models of care are becoming apparent, providing opportunities to consider how best to integrate otherwise unintegrated or less central organizations. Additionally, it is unclear to what extent intersectoral partnerships are sustained in health services delivery. Lastly, the literature points to a number of common types of ties that can exist between organizations that deliver health services (e.g. joint service delivery, resource sharing).

There is relatively little discussion about the specific nature of relationships (based on structure and content exchanged) and how those relationships can be used to drive delivery system reform, specifically when networks are created in response to a policy change. Delivery system reform is predicated on the idea that innovative service delivery models will be used to address quality of care, access to care, and costs of care. The Waiver provides an opportunity to assess how collaboration among organizations between and across sectors evolved over time. Capturing the nature of relationships both within and beyond mandated networks can provide insight about the unique ways in which organizations are collaborating to improve health. 


\section{Research Questions}

It is worthwhile to extend network analysis to the Waiver. More specifically, interorganizational network analysis can be used as a tool to answer some of the following research questions:

1. To what extent did participation in Delivery System Reform Incentive Payment Program affect the role community mental health centers had within their Regional Healthcare Partnerships?

2. To what extent did the formation of Regional Healthcare Partnerships impact intersectoral collaboration under the Delivery System Reform Incentive Payment Program?

3. How and with whom did Delivery System Reform Incentive Payment Program participating organizations collaborate with outside of the established Regional Healthcare Partnership network?

Research question 1 focuses on examining measures of centrality at the organization-level for community mental health centers. Under DSRIP, community mental health centers were afforded unique opportunities to work with other organizations that provide key services on the continuum of care, an opportunity that is not otherwise readily available. Interorganizational network analysis will be used to map and characterize changes in the position and role of community mental health centers in each RHP over time.

Research question 2 focuses on understanding the extent to which the Regional Healthcare Partnerships were successful in promoting intersectoral collaboration among network members. Delivery system reform focuses on improving access to care and managing population health, which requires organizations across sectors to form strategic alliances. Interorganizational network analysis will be used to map and characterize changes in intersectoral collaboration within each RHP over time. A closer examination of how intersectoral partnerships evolved over time may suggest factors that contribute to 
sustained partnerships across sectors and the implications this may have on network development.

Research question 3 focuses on identifying key community-based partners that are critical for delivery system reform relationships who were not formal participants within the RHPs and the nature of the relationships that RHP member organizations pursued with these organizations. Qualitative analysis will be used to identify organizations with whom RHP member organizations collaborated with outside of the RHP and to characterize the nature of those relationships. Chapter 3 provides a detailed methodology for the research study. 


\section{CHAPTER III METHODOLOGY}

\section{Background}

Despite variations in the way networks are perceived based on discipline and lines of research, common themes, such as relationships, social interactions of organization, members, connectedness, collective action, cooperation, and trust continue to ground network perspectives. Brass and colleagues define networks as "a set of nodes and the set of ties representing some relationships, or lack of relationship, between the nodes" (Brass, Galaskiewicz, Greve, \& Tsai, 2004, p. 795). More specifically, interorganizational network analysis focuses on relationships between organizations where a node is an organization, and a tie is some sort of relationship between two nodes, such as information sharing, joint service delivery, or resource sharing. Traditional methods for assessing partnerships tend to focus on gathering data on characteristics of partners to draw comparisons and conclusions about social connections. However, network analysis focuses primarily on collecting relational data between actors where information on actor characteristics is often collected as secondary data. These data can then be captured graphically to present relationships between actors.

In other states' 1115 Medicaid Waivers, the Delivery System Reform Incentive Payment (DSRIP) Program activities focused on providing funds to public hospitals for delivery system reform. The Texas 1115 Transformation Waiver expanded the eligibility 
pool of DSRIP-initiatives to include a broad array of providers, both hospital and nonhospital. Eligible entities acting as performing providers for DSRIP activities included local public and private health care organizations, community mental health centers, local health departments, hospital districts, academic health science centers, and other entities. Thus, the implementation of DSRIP in the state provides a unique opportunity to assess the nature and impact of collaborative provider networks as it relates to delivery system reform.

With respect to the methodology more broadly, the data were collected as part of an evaluation of Texas' Waiver that was conducted by Texas A\&M University, the University of Texas, and the University of Louisville under contract by the Texas Health and Human Services Commission (HHSC) and is therefore being presented here as secondary data.

\section{Study Design}

Each RHP represents a distinct implementation structure through which transformation was assumed to be taking place; therefore, it is important to examine each network as a whole (e.g. network characteristics and network outcomes of each RHP) (Creel, Wendel, \& Ali, 2016). The most effective way to assess the RHP-level networks is through interorganizational network analysis where each participating organization reports on links with each of the other participating organizations within the defined network (Provan, Fish, and Sydow 2007). As such, a non-randomized, pre-post interorganizational network study design was used to assess collaboration for the RHPlevel networks. Open-ended, qualitative questions were added as a follow up to each 
quantitative question to contextualize the nature of relationships. Data collection focused on gathering information about interorganizational ties during three time periods:

1. Twelve (12) months prior to the creation of the RHPs, Calendar year $2011\left(\mathrm{~T}_{0}\right)$

2. Demonstration Year 2, Calendar year $2013\left(\mathrm{~T}_{1}\right)$; and

3. Demonstration Year 4, Calendar year $2015\left(\mathrm{~T}_{2}\right)$.

\section{Data Collection}

Interorganizational network data for $\mathrm{T}_{0}$ and $\mathrm{T}_{1}$ were collected between January and May of 2014 (Creel et al., 2016). There was no possibility of collecting $\mathrm{T}_{0}$ data as the RHPs were forming, but information prior to the creation of RHPs is important in understanding changes in relational data among network members. As such, $\mathrm{T}_{0}$ data were collected in the same interview immediately after $T_{1}$ data was gathered. In order to remove any response-shift bias, Howard and Dailey (1979) suggest a method of asking respondents to report twice on each self-report measure, asking first to report on the current time period and asking immediately after to report on the pre-intervention time period. This minimizes response-shift bias because both answers are contextualized by the respondent from the same perspective (i.e., their post-intervention response does not simply reflect a more sophisticated understanding of the purpose of the intervention than when they were pre-tested). Although this method is not ideal, other studies with similar limitations have used this approach to reduce response shift bias in obtaining accurate data (Bray, Maxwell, and Howard 1984, Schwartz and Sprangers 1999, Nakonezny and Rodgers 2005, Schwartz 2010). Data for $\mathrm{T}_{2}$ were collected between January and mid-July of 2016.

For two of the three research questions, the sampling frame was all organizations participating in DSRIP across the 20 RHPs. One of the analysis only included 
organizations participating in DSRIP across 19 RHPs (described in detail below). The RHPs represent networks comprised of relationships within sectors (i.e., hospitals, community mental health centers, public health departments), as well as relationships across sectors (i.e. relationships between hospitals and governmental entities, community mental health centers and public health departments, or other public-private partnerships) (Creel et al., 2016). Those organizations participating in uncompensated care only $(n=92)$ were excluded from the study due to their limited role in their RHP. The composition of these RHPs varied, but at minimum included the anchor institution (administratively responsible for coordination), participating intergovernmental transfer (IGT) entities, and DSRIP performing providers. Data were collected at the organizational level (sampling frame: $n=388$ participating organizations for all 20 RHPs at $T_{0} / T_{1}$, and $n=406$ participating organizations for all 20 RHPs at $T_{2}$ ). The unit of analysis is at the RHP level $(n=20)$.

The anchor institution in each RHP worked directly with member organizations to disseminate information about the nature of the survey questions and content and identify an appropriate respondent at each organization who would be knowledgeable of the DSRIP-related ties with other organizations asked about in the survey. The anchor institutions compiled and submitted the contact information for each organization's respondent for every round of data collection. The respondent could be at any level within the organization, but participating respondents generally held management positions (e.g. CEO, CFO, medical staff, or DSRIP project managers). According to the evaluation report, this single key informant approach is often used in network studies assuming a single respondent from each organization was knowledgeable about the range 
of interorganizational exchanges (Foster-Fishman et al. 2001). For this reason, the specific survey questions posed were limited to administrative level interactions as opposed to front-line service delivery.

Data were collected via computer-assisted telephone surveys with representatives of each participating organization. The identified respondent for each organization was contacted by email to schedule a time for the phone-administered survey asking them to report on their organization's relationship with each of the other organizations in the RHP. In some cases, the respondent chose to invite other organizational representatives to join them for the phone survey using a conference call or speaker phone. An information sheet summarizing respondent participation was emailed to participants prior to and reviewed with participants at the beginning of each telephone call. This sheet was approved by the University of Louisville Institutional Review Board (IRB) and the Texas A\&M University IRB. The survey was loaded into Qualtrics® to manage question flow and allow for electronic documentation of responses.

\section{Measures}

The network survey was structued such that respondents answered a series of yes/no questions about their organization's relationship with other organizations in their RHP (Creel et al., 2016; Provan and Milward 1995, 2001). Specific measures are outlined in Table 2. Open-ended questions were added to probe for qualitative information about each relationship, kinds of collaborative services, or nature of data sharing to assist in interpretation of the results. Qualitative responses were not audio-recorded and thus not transcribed verbatim; however, interviewers documented these responses within the survey. An additional measure was added for $\mathrm{T}_{2}$ to accommodate participant feedback 
and address existing concerns among participants about capturing DSRIP-related ties with organizational partners outside established networks. See Appendix A and B for data collection instruments for $\mathrm{T}_{0} / \mathrm{T}_{1}$ and $\mathrm{T}_{2}$, respectively (Creel et al., 2016).

\section{Table 2. Network Measures}

\begin{tabular}{|c|c|c|c|}
\hline Construct & To (Pre-Waiver) Measures & $\mathrm{T}_{1}(2013) \& \mathrm{~T}_{2}(2015)$ Measures & Source \\
\hline $\begin{array}{c}\text { Any } \\
\text { Collaboration } \\
*\end{array}$ & $\begin{array}{l}\text { "In the year prior to the } \\
\text { establishment of RHP [\#], did } \\
\text { your organization work with [x } \\
\text { organization] at all?" }\end{array}$ & $\begin{array}{l}\text { "Does your organization currently } \\
\text { work with [x organization]?" }\end{array}$ & $\begin{array}{l}\text { Provan \& } \\
\text { Milward, } \\
1995\end{array}$ \\
\hline $\begin{array}{c}\text { Joint Service } \\
\text { Delivery }\end{array}$ & $\begin{array}{l}\text { "In the year prior to the } \\
\text { establishment of RHP [\#], did } \\
\text { your organization collaborate } \\
\text { with [x organization] to deliver } \\
\text { services?" }\end{array}$ & $\begin{array}{c}\text { "Does your organization currently } \\
\text { collaborate with [x organization] to } \\
\text { deliver services?" }\end{array}$ & $\begin{array}{l}\text { Foster- } \\
\text { Fishman et } \\
\text { al., 2001; } \\
\text { Provan \& } \\
\text { Milward, } \\
1995\end{array}$ \\
\hline $\begin{array}{l}\text { Resource } \\
\text { Sharing }\end{array}$ & $\begin{array}{l}\text { "In the year prior to the } \\
\text { establishment of RHP [\#], did } \\
\text { your organization share } \\
\text { tangible resources with [x } \\
\text { organization] for the purpose of } \\
\text { increasing access to services?" }\end{array}$ & $\begin{array}{l}\text { "Does your organization currently } \\
\text { share tangible resources with [x } \\
\text { organization] for the purpose of } \\
\text { increasing access to services?" }\end{array}$ & $\begin{array}{c}\text { Provan, } \\
\text { Nakama, } \\
\text { Veazie, } \\
\text { Teufel- } \\
\text { Shone \& } \\
\text { Huddleston, } \\
2003\end{array}$ \\
\hline Data Sharing & $\begin{array}{l}\text { "In the year prior to the } \\
\text { establishment of RHP [\#], did } \\
\text { your organization have an } \\
\text { agreement in place to share } \\
\text { patient data with [x } \\
\text { organization]?" }\end{array}$ & $\begin{array}{c}\text { "Does your organization currently } \\
\text { have a data sharing agreement with } \\
\text { [x organization]?" }\end{array}$ & $\begin{array}{l}\text { Johnsen, } \\
\text { Morrissey, \& } \\
\text { Calloway, } \\
1996\end{array}$ \\
\hline $\begin{array}{l}\text { Organization } \\
\text { al Partners } \\
\text { outside } \\
\text { network }\end{array}$ & & $\begin{array}{l}\text { ONLY FOR T } \text { : "Other than the } \\
\text { organizations I' ve asked you about, } \\
\text { can you tell me the names of up to } 3 \\
\text { other organizations with which you } \\
\text { work the most on activities that } \\
\text { target improved access or services } \\
\text { for the underserved?" [Open-ended } \\
\text { with three boxes - these will pre- } \\
\text { populate follow-up questions so we } \\
\text { are asking the same questions about } \\
\text { these new orgs as we are those orgs } \\
\text { already in our list]. }\end{array}$ & $\begin{array}{l}\text { New } \\
\text { measure } \\
\text { based on } \\
\text { participant } \\
\text { feedback }\end{array}$ \\
\hline
\end{tabular}




\section{Analysis}

For interorganizational network analysis, survey responses for each organization from $T_{0}, T_{1}$, and $T_{2}$ must be arranged into a square adjacency matrix format using network software Ucinet 6 (Borgatti, Everett, \& Freeman, 2002). Each matrix includes all organizations participating in DSRIP for a respective RHP in both the rows and columns, thus creating an $\mathrm{N}$ by $\mathrm{N}$ matrix such as:

\begin{tabular}{|l|c|c|c|}
\hline & Organization 1 & Organization 2 & Organization 3 \\
\hline Organization 1 & - & 1 & 0 \\
\hline Organization 2 & 1 & - & 1 \\
\hline Organization 3 & 0 & 1 & - \\
\hline
\end{tabular}

Any given box in the matrix represents the tie(s) between two organizations and the diagonal of the matrix is meaningless since ties from an organization to itself are not of interest. This is referred to as an $\mathrm{N}$ by $\mathrm{N}$ matrix format, with $\mathrm{N}$ representing the number of organizations in a network. Each RHP had four separate matrices for each tie type (any collaboration, joint program/service delivery, resource sharing, and data sharing) in each of the time periods $\left(\mathrm{T}_{0}, \mathrm{~T}_{1}\right.$, and $\left.\mathrm{T}_{2}\right)$, where 0 indicated no tie and 1 indicated the presence of a tie. When data about a tie is missing, the cell is left empty. Analytically, missing values are treated as no present tie. Additionally, network diagrams can be created using companion software NetDraw 2 (Ucinet 6, NetDraw 2) to capture the structural changes in networks visually over time.

Whole network data are particularly sensitive to missing data, and response rates were not 100 percent in all RHPs. As such, the data were symmetrized to reflect 
relationships between organizations if one responding organization indicated collaboration. In network analysis, symmetrization refers to the process of making the data match between organizations. For example, if Organization A indicates a tie with Organization B, and Organization B either did not participate in the study or did not note the same tie, it is assumed that the tie exists because one of the organizations indicated that it did. The final data show a tie between them as if it were indicated by both organizations (making the matrix symmetrical). While assuming reciprocity of a tie is not the most conservative approach, depending on confirmed relationships or relationships that are indicated by both organizations may actually fail to show relationships that exist (Bolland \& Wilson, 1994; Foster-Fishman et al., 2001). As such, this approach allows for the impact of missing data to be minimized.

The network literature and the context of Texas' formation of RHPs suggest specific questions for how the collaborative relationships of organizations participating in DSRIP might change over time and what that may imply about the role of specific organizations within the network. The next several sections present an overview of the methodology for each of the three proposed papers. Each section provides a brief overview for contextual purposes, proposes an overarching research question with hypotheses where applicable, and details an analytic strategy used to answer the research question posed.

\section{Paper I. Assessing the impact of the Texas Medicaid 1115 Transformation Waiver on Community Mental Health Centers: An application of network analysis}

An overall national ranking for the prevalence of mental illness by state indicates that Texas ranks 36 (out of 51 states), yet it has one of the lowest rates of access to 
mental health care services (Mental Health America, 2015). DSRIP provided a timely opportunity to integrate behavioral health services in addressing gaps within the US health care system. Under DSRIP, Texas chose to expand the pool of providers eligible for DSRIP funds, which had previously only been available to public hospitals. Participation in a regional healthcare partnership (RHP) expanded access to the pool of providers that could collectively work with community mental health centers (CMHCs) to implement innovative and effective solutions for addressing behavioral health care needs in each region. This provided CMHCs with opportunities to maximize development of and improve access to quality behavioral health care services in transforming the health care delivery system in Texas. In fact, CMHCs were allotted at least 10 percent of the total available funds in each RHP under DSRIP. As such, it seems worthwhile to explore the ways in which the role of CMHCs has evolved as a result of DSRIP.

Research Question: To what extent did participation in DSRIP affect the role community mental health centers had within their Regional Healthcare

\section{Partnerships?}

\section{Hypothesis 1: Community Mental Health Centers become more central over the} implementation period.

\section{Analytic Strategy}

Power is a fundamental element of social structures (Hanneman \& Riddle, 2005). In network analysis, structural position can impact the amount of power an organization possesses, an organization's ability to control and influence others, the extent to which an organization can serve in a broker role for other organizations in the network, and the 
potential to serve as a hub for information or resource exchange. Examining the extent to which organizations are central to the network provides useful information about the constraints and opportunities available to an organization within the network.

In network analysis, centrality is a measure of how network structure and position contribute to an organization's importance and power. The most frequently used centrality measures include degree, closeness, betweenness, and eigenvector. Each measure of centrality represents a unique way organizations might influence the way information flows through the network (Hanneman \& Riddle, 2005). While it is useful to look at various measures of centrality, the focus of this study is to use two specific measures of centrality — degree centrality and betweenness centrality — to assess how central CMHCs are within the networks and in what types of relationships they play a more central role. Degree centrality is the number of links an organization has with other organizations at a certain point in time, which implies that organizations with the most number of connections with other organizations within a network are the most central. Betweenness centrality measures the extent to which an organization falls along the shortest path (geodesic path) between two other organizations. Betweenness centrality can indicate opportunities for gatekeeping, brokering, and controlling flows of network content. Focusing on these two measures of centrality keeps the analysis manageable across all RHP networks. Another justification for using these two measures is that degree and closeness centrality measures are both based on direct ties, so it may be more useful to explore another measure of centrality with degree centrality (Borgatti et al., 2013). In examining correlations between degree, closeness, betweenness, and flow, Bolland (1988) found that centrality measures of degree, continuing flow, and closeness 
were highly intercorrelated while betweenness was not correlated with the other measures.

Interorganizational network analysis was used to describe and map how central CMHCs are within each of the 19 RHPs. The Ucinet 6 software package was used to calculate degree and betweenness centrality measures for CMHCs within each RHP. Additionally, these measures are reported for each type of tie (e.g. joint program/service delivery, tangible resource sharing, formal data sharing). While the Ucinet 6 output generates degree and betweenness scores for every organization in the network, centrality scores for only CMHCs are reported and compared over time for each type of tie across 19 RHPs (network). RHP 15 only included one CMHC and thus was excluded. Since there were multiple CMHCs within a network, the average of the point centrality measures are reported. This information provides unique insight about the ways in which the role of CMHCs evolved over time, the types of ties in which CMHCs played a more central role, how a central role can be leveraged by CMHCs to impact health service delivery in Texas, and the implications all of this may have in expanding the role of CMHCs within the State to improve behavioral health outcomes.

The point and percent changes were calculated to determine changes in the centrality measures (degree centrality and betweenness centrality) of CMHCs between $\mathrm{T}_{0}, \mathrm{~T}_{1}$, and $\mathrm{T}_{2}$ for each type of tie. Results are reported at the state-level. Point change refers to the point change in the centrality measure across time periods, which can be calculated by subtracting the value of the measure from the furthest time period from the value of the measure from the most recent time period. The percent change refers to the change in the centrality measure in the context of the starting point, which can be 
calculated by dividing the point change over the time period by the value of the measure at the starting time period (e.g. $\left.\left(\mathrm{T}_{1}-\mathrm{T}_{0}\right) / \mathrm{T}_{0}\right)$.

\section{Hypothesis 2: Over time, community mental health centers have more intersectoral partnerships. \\ Analytic Strategy}

In a network, each organization has a unique set of characteristics (attributes). These characteristics can play an important role in determining whether or not a tie forms between two organizations. The presence or absence of a tie can impact opportunities (e.g. access to novel information or resources) to which an organization may be exposed (Borgatti et al., 2013). In network analysis, homophily is a measure of whether two actors are likely to be connected. In simple terms, homophily is the extent to which organizations form ties with other organizations based on similarity. In order to understand how homophily is measured in network analysis, it is important to clarify a few key concepts about ego networks. Ego networks are comprised of an ego (focal node) and the nodes to whom the ego is directly connected (alters) as well as the ties among the alters (Borgatti et al., 2013). Hanneman and Riddle (2005) clarify that "a network has as many egos as it has nodes."

Two organizations who share some characteristic (e.g. two hospitals) are more likely to form ties than two organizations who do not share the same characteristic (e.g. a hospital and a public health department) (Hanneman \& Riddle, 2005). As such, homophily provides a meaningful way to assess a network's surrounding context and composition in ways that influence the formation of ties. Selection and social influence are two mechanisms by which homophily can emerge. Selection refers to the tendency of 
organizations to form ties with other organizations that have similar characteristics. Social influence refers to the idea of an organization modifying its behaviors (or characteristics) to align more closely with the organizations that surround it. While selection focuses on organizational characteristics that can drive the formation of ties, social influence focuses on how existing ties in the network can impact characteristics of organizations (Borgatti et al., 2013). As such, the purpose of this study is to use a measure of homophily to assess change in intersectoral partnerships at the node level (CMHCs) over time. In other words, to what extent are CMHCs forming ties with organizations different from themselves.

Interorganizational network analysis was used to describe and map the extent to which CMHCs tended to have ties with organizations different from themselves (e.g. hospitals) across the 19 RHPs over time. RHP 15 only included one CMHC and thus was excluded. The Ucinet 6 software package was used to calculate homophily for CMHCs within each RHP using the ego networks function. The measure of homophily generated by the ego networks function is reported at the organizational-level (each organization within the RHP has a score for the homophily measure). Ego networks are comprised of an ego (focal node), its alters (actors to whom the ego is directly connected), and the ties, if any, among the alters (Borgatti et al., 2013). Percent homophily is a measure of the proportion of an ego's (i.e. CMHCs) alters that have the same characteristic as the ego. Essentially, this measure reports the percentage of ego's ties that have same attribute (in this case the attribute is organization type). Additionally, percent homophily is reported for each type of tie (e.g. joint program/service delivery, tangible resource sharing, formal data sharing). While the Ucinet 6 output generates percent homophily scores for every 
organization in the network, this study is specifically interested in scores for CMHCs over time for each type of tie across the 19 networks. Since each CMHC has a different service area and provides services to a different number of counties, the percent homophily scores for each CMHC across the three time periods are multiplied by the number of counties it serves. Since there are multiple CMHCs within an RHP, the sum of all their scores was calculated and divided by the total number of counties all CMHCs' serve within a particular RHP. This number is reported for the results. This information provides information about why homophily is present in the network as it relates to CMHCs, how selection or social influence might affect evolution of the network, and the implications this has for CMHCs as it relates to future tie formation for health service delivery in Texas.

The point (percentage point change) and percent changes were calculated to determine changes in percent homophily of CMHCs between $T_{0}, T_{1}$, and $T_{2}$ for each type of tie. Since each CMHC has a different service area and provides services to a different number of counties, the percent homophily scores for each CMHC across the three time periods are multiplied by the number of counties it serves. Since there are multiple CMHCs within an RHP, the sum of all their scores will be calculated and divided by the total number of counties all CMHCs' serve within a particular RHP. This number will be reported for the results. Results are reported at the state-level. 


\section{Hypothesis 3: Over time, ties are stronger among community mental health centers}

compared to the other types of organizations in the Regional Healthcare

\section{Partnership.}

\section{Analytic Strategy}

Relationships among organizations are generally complex; organizations within a network are connected in many ways simultaneously (Hanneman \& Riddle, 2005).

Network multiplexity is a measure of the strength of relationships between organizations. An organization connected to other organizations in multiple ways may suggest a more complex, collaborative partnership, an indicator of relationship strength. Provan and colleagues (2007) suggest that multiplex ties between two organizations suggest stronger relationships because if one of those ties were to erode, there are other ties that would still keep the two organizations connected. Multiplexity is a measure that had already been calculated by adding together the three types of ties (joint program/service delivery, tangible resource sharing, and formal data sharing). Network multiplexity is expressed as the mean number of ties between two organizations and the strength of ties score can range between one and three (Isett \& Provan, 2005). Strength of tie is directly associated with multiplexity, where a higher multiplexity score indicates a stronger tie.

Interorganizational network analysis was used to assess and map the strength of ties between CMHCs and other organizations within each of the 19 RHPs. RHP 15 only included one CMHC and thus was excluded. The Ucinet 6 software package and its companion software Netdraw were used to create network maps for some RHPs to illustrate visually changes in strength of ties between CMHCs and other organizations. In the network diagrams, strength of ties is indicated by the width of the tie that exists 
between any two organizations. The heavier the line (tie) between two organizations, the stronger the relationship between the two organizations. Although multiplexity is a dyadic-level measure in its purest form, it can be captured at the node-level in the form of descriptive statistics.

Multiplexity/strength of ties data is available in an $\mathrm{N} \mathrm{x} \mathrm{N} \mathrm{matrix} \mathrm{format} \mathrm{for} \mathrm{each}$ RHP. Each of the 19 network matrices was pasted into SPSS to generate univariate statistics for each organization's strength of tie in the network. An average strength of tie was calculated for each organization, and a corresponding standard deviation (SD) was used to assess variation. Since there were multiple CMHCs within each RHP, a single average strength of tie score is reported across all CMHCs within an RHP (an average of the averages of CMHCs will be calculated). In order to compare the average strength of tie for $\mathrm{CMHC}(\mathrm{s})$ within a network to another group within the network, an average strength of tie score was calculated for all of the other types of organizations (e.g. an average of the averages of all non-CMHC organizations will be calculated). This information provides unique insight about the changes in average tie strength observed over the different time periods, particularly as it relates to CMHCs (in comparison to all other types of organizations). This can also highlight the extent to which CMHCs maintained their average tie strength over time. Ranges are reported across organizations for both the CMHC group and the non-CMHC group.

The point (percentage point change) and percent changes were calculated to determine changes in the average strength of ties for CMHCs compared to non-CMHCs between $\mathrm{T}_{0}, \mathrm{~T}_{1}$, and $\mathrm{T}_{2}$. Results are reported at the state-level. 
DSRIP presented a unique window of opportunity for CMHCs to work in conjunction with other providers (e.g. hospitals, public health departments) to achieve the Triple Aim strategies. As such, this study focuses on characterizing the role of CMHCs within each RHP over time based on their structural position, intersectoral connections, and strength of ties. This information provides valuable insight on the opportunities presented and the constraints imposed on CMHCs as they sought to integrate their services with other types of organizations in improving health.

\section{Paper II. Examining opportunities for sustained intersectoral partnerships through the Texas Medicaid 1115 Transformation Waiver}

Since the state expanded eligibility of providers for the DSRIP funding pool, it was possible for a broad range of providers beyond public hospitals to participate in delivery system reform. This provided a unique opportunity to identify ties that existed between organizations in different sectors of the health care delivery system. This study focuses on the extent to which DSRIP facilitated increased collaboration among organizations that belong to different sectors within the RHPs. Within the context of this study, intersectoral ties are those ties that exist between organizations in different sectors of the health care delivery system (e.g. a hospital has a tie with a community mental health center or a public health department has a tie with a hospital district). Assessing such relationships can provide insight about the ways in which human, social, intellectual, and financial capital can be pooled to improve efficiency and increase capability to address the complex health needs of individuals. In fact, Foster-Fishman and colleagues (2001) suggest that intersectoral ties may indicate a higher likelihood of service integration, which can combat issues of fragmentation in health care delivery. 


\section{Research Question: To what extent did the formation of Regional Healthcare Partnerships impact intersectoral collaboration under the Delivery System Reform Incentive Program?}

\section{Hypothesis 1: The formation of RHPs leads to increased intersectoral ties over time.}

Analytic strategy

The RHPs represent networks comprised of relationships within sectors (e.g. relationships among public health departments) and relationships across sectors (e.g. relationships between hospitals and community mental health centers). The purpose of this analysis is to evaluate intersectoral connections within all 20 RHP networks over time. As such, the study uses interorganizational network analysis to numerically and graphically capture relationships both within and across sectors in each of the 20 RHP networks.

As mentioned above, the Ucinet 6 for Windows software package was used for the analysis of network data (Borgatti, Everett, \& Freeman, 2002). Ucinet 6 is capable of analyzing both relational data and nodal (organization) attribute data, which are both essential to address this research question. The examination of intersectoral connection within network analysis requires a firm understanding of a key characteristic of networks: network density. As stated earlier, network density is the number of existing connections among network organizations as a proportion of the total possible connections (Wasserman \& Faust, 1994). Network density provides critical information about the connectedness of a network, which can influence the flow of information, the exchange of resources, and accessibility to novel information. While denser networks provide more opportunities to share information and exchange resources, networks that are sparsely 
connected may provide improved access to different types of actors and novel resources (Borgatti et al., 2013). However, the impact of density on a network is contingent on both the characteristics of organizations that make up the network and the type of relation being studied (Borgatti et al., 2013).

In Ucinet 6, the density-by-groups function was used to assess intersectoral connections for each type of tie (e.g. joint program/service delivery, tangible resource sharing, formal data sharing). The resulting output generated densities by sector that vary from zero to one. These densities were multiplied by 100 to express the percentage of ties found within sectors (e.g. among hospitals) and also between sectors (e.g. hospitals' ties with community mental health centers) within a network for each type of tie. In order to assess sector-level patterns for within-sector and intersectoral connections, the density of connections among members of the same sector and between different members of various sectors was examined for $\mathrm{T}_{0}$ to $\mathrm{T}_{2}$. This information can offer a critical perspective on the nature of intersectoral ties across RHPs, the types of ties in which intersectoral connections are more likely to form, the ways in which intersectoral ties evolve over time, and the implications all of this may have on health service delivery in Texas.

Additionally, network maps were created for RHP 15 to characterize visually the patterns of relationships that exist between network members within and across sectors among the different types of ties. Results will present changes in collaboration by tie type, where an "increase" represents an increase in collaboration and "no increase" represents a decrease or no change in collaboration. Both point and percent changes for the density of connections from $\mathrm{T}_{0}$ to $\mathrm{T}_{2}$ are reported within and between sectors by tie 
type. A gray shaded area represents either the absence of collaboration or a zero as the starting density for $\mathrm{T}_{0}$, which yields an undefined value for percent change. Each sector has an $\mathrm{n}$, which represents the number of RHPs that include organizations that fall within that particular type of sector.

\section{Paper III. Identifying and explicating partnerships with key collaborators beyond established networks in the Texas Medicaid 1115 Transformation Waiver}

During the $\mathrm{T}_{0} / \mathrm{T}_{1}$ data collection phase, participants expressed concern about not being asked to report on relationships with community-based partners they work with who are not formal participants in the RHP (e.g. those organizations excluded from the sampling frame). This was identified as a gap during data collection since several participants reported working closely with other non-member organizations on DSRIPrelated activities. Including these non-member organizations in the sampling frame for each RHP was impossible given the vast number of other organizations that could exist. In an attempt to address and accommodate participant feedback from the $\mathrm{T}_{0} / \mathrm{T}_{1}$ data collection phase, the $\mathrm{T}_{2}$ survey included a new question about other organizational partners. Respondents were asked to list up to three other organizations with which they worked the most on activities to target the underserved population in their community. For each new organization listed, the survey included the same questions about types of ties that were asked about RHP member organizations (e.g. joint program/service delivery, tangible resource sharing, formal data sharing). As such, this study focuses exclusively on data obtained from this $\mathrm{T}_{2}$ cross-sectional measure. 


\section{Research Question: Which community-based partners did DSRIP providers perceive as critical for delivery system reform and how did they collaborate? \\ Analytic Strategy}

This study used a primarily qualitative research design to explore and analyze the relationships DSRIP providers perceived as critical with community-based partners who are not eligible to participate in DSRIP. As responses were examined within this study, an inductive approach was used to identify conceptual categories that capture the relevance and nature of critical relationships as they emerge from the data. Additionally, descriptive statistics were calculated at the RHP- and state-wide level to describe the composition of the sample and characterize the frequency with which the three major types of relationships between RHP-member organizations and other community-based organizations occurred. This information also helps contextualize themes that emerged through qualitative data analysis. Content analysis was conducted using an iterative thematic approach to coding in order to identify key themes that help to provide contextual information about the nature of relationships pursued by RHP member organizations. Themes were compared within and across cases, paying particular attention to deviant cases and possible reasons for differences.

With respect to the nature of the data, responses were not audio-recorded and thus not transcribed verbatim; however, interviewers documented interview responses within the survey. Qualitative responses were then extracted from the survey, color-coded by the type of DSRIP organization, and sorted by the type of community-based partner.

Responses were generally brief and focused on a specific type of tie. Each response was treated as a segment of text and included the type of relationship (e.g. joint 
program/service delivery, tangible resource sharing, and formal data sharing), the nature of that relationship (the content of the response), and the RHP number of the organization reporting the relationship. Since part of the research question strives to understand which community-based partners are critical for DSRIP collaboration, three tables were created to map out the type of community-based partners with whom DSRIP providers are working with to deliver joint programs/services, share tangible resources, and share formal data. Based on those tables, certain relationships between particular DSRIP providers and community-based partners were selected for closer examination.

Data about each relationship were coded in two phases: initial and focused coding. Initial/line-by-line coding was used to characterize the nature of each relationship by tie type, specifically focused on capturing the various types of program/service delivery, resource, and data sharing relationships providers shared with particular community-based partners (e.g. patient referrals, shared staff, memorandum of understanding). Focused coding allowed for the grouping of codes into broader categories. Analytic and methodological memos were maintained to continuously document thoughts, experiences, questions, and observations throughout the data collection and analysis process.

Two members of the research team performed the initial sorting of responses by the type of community-based partner. A third researcher joined in the coding process for initial and focused coding. Co-analysis provided a mechanism for recognizing the role of personal perspectives and addressing discrepancies until mutual agreement in an attempt to reduce the effect of potential bias on the interpretation of the results. Credibility of the process was maintained by prolonged engagement, peer debriefing, and deviant case 
analysis, which helps to both build and improve rigor (Charmaz, 2014; Creswell, 2013). It should be noted that while such studies have the potential to provide rich, qualitative information, the findings cannot be generalized to the wider population because the nature of the information is very much context specific. There is potential for interviewer bias, but appropriate steps can be taken in advance to avoid such issues during data collection and analysis. Additionally, qualitative data collection and analysis is a time intensive process and time and resources should be allocated appropriately to this process.

\section{Limitations}

As is the case for any methodology, there are limitations of using social network analysis, particularly as it relates to this study. Social network analysis is a timeconsuming process. Relationships explored within this study often assume trust and access. In health services delivery, building trust with and acquiring access to reliable partners can be somewhat challenging. Unlike other network studies, this study was longitudinal by design, allowing a period of four years for relationship building to occur (if relationships had not already existed between organizations).

Networks in this study varied in size and composition. Relationships within some networks can be complex and sometimes difficult to understand. As a result, there is a possibility that connectivity between and among organizations can be overestimated in ways that impact the accuracy of the nature of an actual relationship.

Whole network analyses are particularly sensitive to non-response or missing data. According to the final evaluation report submitted to the Centers for Medicare and Medicaid Services, non-response is not ideal for network analysis because of the 
presence of unconfirmed relationships between actors, which has the potential to bias the structural properties of social networks severely. This sample had an overall response rate of 84 percent during data collection for $\mathrm{T}_{0} / \mathrm{T}_{1}$ and 76 percent during data collection for $\mathrm{T}_{2}$, both of which are acceptable within the existing literature. Missing data on unconfirmed relationships were accommodated by symmetrizing the data.

The lower response rate for $\mathrm{T}_{2}$ data collection could artificially indicate a decrease in outcome measures in some RHPs where relationships did not end but, rather, were not reported. On the contrary, respondents may have experienced issues with recalling relationships and/or possibly exaggerating ties with those perceived to have authority or power within each RHP (e.g. anchor institution).

A majority of telephone-based surveys were completed by a single respondent at each organization. While anchor institutions worked directly with member organizations to identify an appropriate respondent who would be knowledgeable of the relationships asked about in the survey, it is unrealistic to assume that one individual alone would be knowledgeable about all the collaborative activities occurring throughout and across an organization—-particularly for the larger organizations.

As described in the final evaluation report to the Centers for Medicare and Medicaid Services, the types of respondents changed for the second round of data collection for some organizations. As such, differences in institutional knowledge between executives who responded $T_{0} / T_{1}$ versus project managers at $T_{2}$, likely affected the extensiveness of the relationships reported. In some cases, this issue was addressed by having several individuals at the same organization participate in the telephone-based survey simultaneously (e.g. conference calls). In other cases, respondents had the option 
to answer "I don't know" to certain questions and the research team followed up with an appropriate representative at the organization to obtain accurate information. There were also a few cases where unusual staff turnover within organizations resulted in a significant loss of institutional memory, and the historical relationships remained unknown, which was captured in the data as no relationship. Moreover, the data likely underrepresents the relationships that actually exist, thereby making the conclusions very conservative.

Like many other social network designs, this research design is limited by the absence of a comparison or control group, which has the potential to improve the internal validity of the study. Lack of a comparison group makes it impossible to assess causality or apply observed changes to the demonstration project. Although a control group design is ideal, there were no available controls (e.g. geographic, service delivery focused networks of healthcare providers and public funding entities that were not participating in the Waiver) to include in this study and nor was it realistic to create comparable groups for each of the 20 RHPs. With this understanding, the longitudinal study design allowed the evaluation team to assess how collaboration between organizations participating in the DSRIP might change over time.

There are a number of different measures that can be used to assess centrality (e.g. closeness) and homophily (e.g. E-I index), but this study selected a few specific measures to keep the analysis focused. Measures that were not included in this study may be equally important in answering our research questions, but the literature suggests that some network measures were simply not appropriate for our study because the data are 
not directed, and some measures are specifically intended to assess relationships based on reciprocity.

A final limitation, highlighted particularly by survey respondents, was that the sampling frame failed to include other organizations that may have been key collaborators in DSRIP activities. While an additional set of questions were added in the $\mathrm{T}_{2}$ survey to accommodate participant concerns, corresponding data from $\mathrm{T}_{0} / \mathrm{T}_{1}$ was not available to be able to assess changes over time. This is also a limitation of using secondary data because the data were not necessarily collected to answer the research questions proposed above. 


\section{CHAPTER IV}

\section{ASSESSING THE IMPACT OF THE TEXAS MEDICAID 1115 TRANSFORMATION WAIVER ON COMMUNITY MENTAL HEALTH CENTERS: AN APPLICATION OF NETWORK ANALYSIS}

\section{Introduction}

An overall national ranking for the prevalence of mental illness by state indicates that Texas ranks 36 (out of 51 states), yet it has one of the lowest rates of access to mental health care services (Mental Health America, 2015). In fact, the annual per capita mental health spending in Texas was nearly $\$ 40.65$ as compared to the national average of \$119.62 for fiscal year 2013 (Kaiser Family Foundation [KFF], 2017). Many Texans continue to face barriers related to effective and efficient delivery of mental health care as a result of fragmented service delivery and lack of coordination among multiple organizations responsible for delivering health services across the continuum of care (Hogg Foundation for Mental Health [HFMH], 2014). This results in unnecessary hospital utilization, something community mental health centers (CMHCs) can influence or prevent. Despite the support CMHCs provide to hospitals serving indigent and uninsured populations, their role remains largely unrecognized by the Texas Medicaid system (Texas Council of Community Centers, 2016). Not surprisingly, inadequate access to mental health services, supports, and treatment continue to be one of the most demanding policy issues in Texas (HFMH, 2014). 
In 2011, Texas received approval from the Centers for Medicare and Medicaid Services (CMS) for a five-year 1115 Medicaid Waiver Demonstration Project (Waiver) aimed to increase access to health care, improve quality of care, and reduce costs of care (Triple Aim strategies). Under the waiver, mental health services were significantly expanded, providing a window of opportunity to integrate behavioral health services with primary health care as a way of addressing existing gaps in health services delivery. In fact, community mental health centers (CMHCs) were allotted at least 10 percent of the total available funds in each RHP under the Delivery System Reform Incentive Payment (DSRIP) Program, one component of the Waiver providing financial incentives to eligible providers implementing one or more evidence-based projects, as approved by the Texas Health and Human Services Commission (HHSC) and CMS (Gates, Rudowitz, \& Guyer, 2014). Transformation projects focus on infrastructure development and program innovation and redesign, while requiring measurement of quality improvements and outcomes (HHS, n.d.). Unlike a traditional grant, funds for DSRIP were directly tied to meeting performance metrics and achieving specific outcomes (Gates et al., 2014).

The state of Texas is geographically vast, and the populations are diverse; therefore, different regions in the state have unique health needs. As such, the HHSC chose to implement DSRIP in Texas by creating 20 Regional Healthcare Partnerships (RHPs). The RHPs represented organizational networks comprised of relationships within sectors (i.e., hospitals, community mental health centers, public health departments), as well as relationships across sectors (i.e. relationships between hospitals and governmental entities, community mental health centers and public health departments, or other public-private partnerships). RHPs served as a mechanism to plan, 
implement, and monitor DSRIP activities (Texas Health and Human Services [HHSC], n.d.). The composition of RHPs varied, but at minimum included the anchor institution (administratively responsible for coordination), participating intergovernmental transfer (IGT) entities, and DSRIP performing providers. What was particularly unique about the way Texas chose to implement DSRIP is the fact that the state expanded the pool of providers eligible for DSRIP funds, which had previously only been available to public hospitals for California's waiver. As such, participation in an RHP expanded access to the pool of providers that could collectively work with CMHCs to implement innovative and effective solutions for addressing behavioral health needs in each region. This provided CMHCs with unique opportunities to maximize development of and improve access to quality behavioral health services in transforming the health care delivery system in Texas (HFMH, 2014). This is particularly valuable because it presents flexibility for networks to expand behavioral health services without having to conform to the narrow eligibility requirements of state-funded services in CMHCs (HFMH, 2014).

In the context of networks, traditional methods for assessing partnerships tend to focus on gathering data on characteristics of partners to draw comparisons and conclusions about social connections. Given that the RHPs under the Waiver exist as distinct networks, interorganizational network analysis can assess how the role of CMHCs evolved in each RHP over the implementation period. Network analysis focuses primarily on collecting relational data between actors where information on actor characteristics is often collected as secondary data. A large number of network studies in health service delivery focus on whole network analysis (Morrissey, 1992; Provan \& Milward, 1995; Provan, Fish, \& Sydow, 2007; Provan \& Lemaire, 2012). While 
measures about the whole network, such as network density inform current thought on the structure of the network, its evolution, and the impact this has on participating organizations, fewer studies focus on the role of organizations within service delivery networks and the potential impact this may have on collaboration. This information is particularly relevant given the emergence of more integrated models of care, providing opportunities to consider how best to integrate otherwise unintegrated or less central organizations, like CMHCs.

Therefore, DSRIP presented a unique window of opportunity for CMHCs to work in conjunction with other providers (e.g. hospitals, public health departments) to achieve the Triple Aim strategies. The purpose of this study is to characterize the role of CMHCs within each RHP over time based on their structural position, intersectoral connections, and strength of ties. We hypothesize that CMHCs became more central, had more intersectoral partnerships, and had stronger ties with participating members compared to the other participating organizations over the implementation period. This information may increase our understanding about the opportunities presented and the constraints imposed on CMHCs as society increasingly recognizes how integral behavioral health is within broader population health.

\section{Methods}

\section{Study Design}

In terms of the methodology, the data were collected as part of an evaluation of Texas’ Waiver, conducted by Texas A\&M University, the University of Texas, and the University of Louisville under contract by the Texas Health and Human Services Commission (HHSC). Thus, it is being presented as secondary data. 
Each RHP represents a distinct implementation structure through which transformation was assumed to be taking place; therefore, it is important to examine each network as a whole (e.g. network characteristics and network outcomes of each RHP) (Creel, Wendel, \& Ali, 2016). The most effective way to assess the RHP-level networks is through interorganizational network analysis where each participating organization reports on links with each of the other participating organizations within the defined network (Provan, Fish, and Sydow 2007). As such, a non-randomized, pre-post interorganizational network study design was used to assess collaboration for the RHPlevel networks. Data collection focused on gathering information about interorganizational ties during three time periods:

1. Twelve (12) months prior to the creation of the RHPs, Calendar year $2011\left(\mathrm{~T}_{0}\right)$

2. Demonstration Year 2 of the Waiver, Calendar year $2013\left(\mathrm{~T}_{1}\right)$; and

3. Demonstration Year 4 of the Waiver, Calendar year $2015\left(\mathrm{~T}_{2}\right)$

\section{Data Collection}

Interorganizational network data for $\mathrm{T}_{0}$ and $\mathrm{T}_{1}$ were collected between January and May of 2014. There was no possibility of collecting $\mathrm{T}_{0}$ data as the RHPs were forming, but information prior to the creation of RHPs is important in understanding changes in relational data among network members. Thus, $\mathrm{T}_{0}$ data were collected in the same survey immediately after $T_{1}$ data was gathered. Details using this method to mitigate response-shift bias have been described elsewhere (Howard and Dailey, 1979). Data for $T_{2}$ were collected between January and mid-July of 2016.

The sampling frame for this study was all organizations participating in DSRIP across 19 RHPs (Creel \& Wendel, 2016). The research question posed assumes that each network includes at least two or more CMHCs; RHP 15 only includes one CMHC and 
thus was excluded. Data were collected at the organizational level (sampling frame: $n=380$ participating organizations for all 19 RHPs at $T_{0} / T_{1}$, and $n=398$ participating organizations for all 19 RHPs at $\left.T_{2}\right)$. The unit of analysis is at the RHP level $(n=19)$. A single key informant approach was used to collect information about the range of interorganizational exchanges in each RHP via computer-assisted telephone surveys (Creel \& Wendel, 2016; Foster-Fishman, Salem, Allen, \& Fahrbach, 2001). Additional details about the data collection process are reported elsewhere (Creel \& Wendel, 2016).

\section{Measures}

The network survey was structured so that respondents answered a series of yes/no questions about their organization's relationship with other organizations in their RHP (Provan and Milward 1995). Key measures are presented in Table 3 (Creel \& Wendel, 2016). 


\section{Table 3. Survey Measures}

\begin{tabular}{|c|c|c|c|}
\hline Construct & $\mathrm{T}_{0}$ (Pre-Waiver) Measures & $\mathrm{T}_{1}(2013) \& \mathrm{~T}_{2}(2015)$ Measures & Source \\
\hline $\begin{array}{c}\text { Any } \\
\text { Collaboration* }\end{array}$ & $\begin{array}{l}\text { "In the year prior to the } \\
\text { establishment of RHP [\#], did } \\
\text { your organization work with [x } \\
\text { organization] at all?" }\end{array}$ & $\begin{array}{l}\text { "Does your organization } \\
\text { currently work with [x } \\
\text { organization]?" }\end{array}$ & $\begin{array}{c}\text { Provan \& Milward, } \\
1995\end{array}$ \\
\hline $\begin{array}{l}\text { Joint Service } \\
\text { Delivery }\end{array}$ & $\begin{array}{l}\text { "In the year prior to the } \\
\text { establishment of RHP [\#], did } \\
\text { your organization collaborate } \\
\text { with [x organization] to deliver } \\
\text { services?" }\end{array}$ & $\begin{array}{c}\text { "Does your organization } \\
\text { currently collaborate with [x } \\
\text { organization] to deliver services? }\end{array}$ & $\begin{array}{c}\text { Foster-Fishman et } \\
\text { al., 2001; Provan \& } \\
\text { Milward, } 1995\end{array}$ \\
\hline $\begin{array}{c}\text { Resource } \\
\text { Sharing }\end{array}$ & $\begin{array}{c}\text { "In the year prior to the } \\
\text { establishment of RHP [\#], did } \\
\text { your organization share } \\
\text { tangible resources with [x } \\
\text { organization] for the purpose } \\
\text { of increasing access to services? }\end{array}$ & $\begin{array}{c}\text { "Does your organization } \\
\text { currently share tangible resources } \\
\text { with [x organization] for the } \\
\text { purpose of increasing access to } \\
\text { services?" }\end{array}$ & $\begin{array}{l}\text { Provan, Nakama, } \\
\text { Veazie, Teufel- } \\
\text { Shone \& } \\
\text { Huddleston, } 2003\end{array}$ \\
\hline Data Sharing & $\begin{array}{l}\text { "In the year prior to the } \\
\text { establishment of RHP [\#], did } \\
\text { your organization have an } \\
\text { agreement in place to share } \\
\text { patient data with [x } \\
\text { organization]?" }\end{array}$ & $\begin{array}{c}\text { "Does your organization } \\
\text { currently have a data sharing } \\
\text { agreement with [x organization]? }\end{array}$ & $\begin{array}{c}\text { Johnsen, Morrissey, } \\
\text { \& Calloway, } 1996\end{array}$ \\
\hline
\end{tabular}

\section{Analysis}

Responses for each of the three time periods were arranged into a square adjacency matrix using network software Ucinet 6 (Borgatti, Everett, \& Freeman, 2002), where 0 indicated no tie and 1 indicated the presence of a tie. Each RHP had four separate matrices for each tie type (any collaboration, joint program/service delivery, resource sharing, and data sharing) as well as a matrix that combined the responses from these matrices to assess multiplexity. Whole network data is particularly sensitive to missing data, so the data were symmetrized to reflect relationships between organizations if one of the responding organizations indicated collaboration. Additional details about 
this process and its effectiveness can be found elsewhere (Bolland and Wilson, 1994; Foster-Fishman et al. 2001).

Additionally, a number of different network measures were used to explore how the role of CMHCs evolved over time within the RHPs. For each RHP overall and for each type of tie (all collaboration, joint program/service delivery, tangible resource sharing, formal data sharing), responses from $\mathrm{T}_{0}, \mathrm{~T}_{1}$, and $\mathrm{T}_{2}$ were analyzed for centrality, homophily, and the average number of ties for CMHCs and non-CMHCs where applicable. The Ucinet 6 software package, a network analysis tool, was used to calculate these measures. Each measure is presented in detail below with a description of what it is intended to capture and why it is relevant to this study.

\section{Centrality}

In networks, structural position can impact or be influenced by the amount of power an organization possesses, an organization's ability to control and influence others, the extent to which an organization can serve in a broker role for other organizations in the network, and the potential to serve as a hub for information or resource exchange (Borgatti, Everett, \& Johnson, 2013; Hanneman \& Riddle, 2005). While it is useful to look at various measures of centrality, the focus of this study is two specific measures of centrality to assess how central CMHCs are within the networks and in what types of relationships they play a more central role. Degree centrality is the number of links an organization has with other organizations at a certain point in time, which implies that organizations with the most number of ties to other organizations are the most central. Betweenness centrality measures the extent to which an organization falls along the shortest path (geodesic path) between two other organizations. Betweenness centrality 
can indicate opportunities for gatekeeping, brokering, and controlling flows of network content (Borgatti et al., 2013). Examining the extent to which organizations are central to the network provides useful information about the constraints and opportunities available to an organization within the network (Hanneman \& Riddle, 2005).

While the Ucinet 6 output generates degree and betweenness scores for every organization in the network, only centrality scores for CMHCs were reported and compared over time for each type of tie across the 19 networks. The average of the point centrality measures for CMHC in an RHP were reported.

\section{Homophily}

In order to understand how homophily is measured in network analysis, it is important to understand ego networks. Ego networks are comprised of an ego (focal node) and the nodes to whom the ego is directly connected (alters) as well as the ties among the alters (Borgatti et al., 2013). Hanneman and Riddle (2005) clarify that "a network has as many egos as it has nodes.” In an ego network, each organization has a unique set of characteristics (attributes). That can play an important role in determining whether or not a tie forms between two organizations. The presence or absence of a tie can impact opportunities (e.g. access to novel information or resources) to which an organization may be exposed (Borgatti et al., 2013). In network analysis, homophily is a measure of whether two actors are likely to be connected. Simply put, homophily is the extent to which organizations form ties with other organizations based on similarity.

Homophily refers to the phenomenon that two organizations who share some key characteristic (e.g. two hospitals) are more likely to form ties than two organizations who do not share that characteristic (e.g. a hospital and a public health department) 
(Hanneman \& Riddle, 2005). Selection and social influence are two mechanisms by which homophily can emerge. While selection focuses on organizational characteristics that can drive the formation of ties, social influence focuses on how existing ties in the network can impact characteristics of organizations (Borgatti et al., 2013; Hanneman \& Riddle, 2005). As such, homophily provides a meaningful way to assess a network's surrounding context and composition in ways that influence the formation of ties.

Homophily is used in this study to evaluate the extent to which CMHCs are forming ties with organizations different from themselves. This can help to provide meaningful information about the position of CMHCs within the networks based on who they are forming ties with and how that changes over the implementation period. If CMHCs only form ties with other CMHCs, we assume that the Waiver has not necessarily accomplished system transformation because CMHCs are not working to integrate their services with other organizations and vice versa. If CMHCs form ties with other types of organizations, this implies that there is scope for service coordination and integration in ways that may promote improved health. Percent homophily is generated via the ego networks function in Ucinet 6 and reported at the organizational-level (each organization within the RHP has a score for the homophily measure). Essentially, this measure reports the percentage of ego's ties that have same attribute (in this case the attribute is organization type). While the Ucinet 6 output generates percent homophily scores for every organization in the network, this study is specifically interested in scores for CMHCs over time for each type of tie across the 19 networks. Since each CMHC has a different service area and provides services to a different number of counties, the percent homophily scores for each CMHC across the three time periods are multiplied by 
the number of counties it serves. Since there are multiple CMHCs within an RHP, the sum of all their scores were calculated and divided by the total number of counties all CMHCs' serve within a particular RHP. This number was reported for the results.

\section{Average Strength of Ties}

Relationships among organizations are generally complex; organizations within a network are connected in many ways simultaneously (Hanneman \& Riddle, 2005).

Network multiplexity is a measure of the strength of relationships between organizations. An organization connected to other organizations in multiple ways (e.g. client referrals, resource sharing, data sharing) may suggest a more complex, collaborative partnership, an indicator of relationship strength. Provan and colleagues (2007) suggest that multiplex ties between two organizations suggest stronger relationships because if one of those ties were to erode, there are other ties that would still keep the two organizations connected. Network multiplexity is expressed as the mean number of ties between two organizations; the strength of ties score for this study can range between one and three (Isett \& Provan, 2005). Strength of tie is directly associated with multiplexity, where a higher multiplexity score indicates a stronger tie. We are particularly interested in exploring how CMHCs' average strength of ties evolved over the implementation period as compared to nonCMHCs.

Using the $\mathrm{NxN}$ multiplexity matrices created in Ucinet 6, each of the 19 RHP matrices were pasted into SPSS to generate univariate statistics for each organization's strength of tie in the network. An average strength of tie was calculated for each organization and a corresponding standard deviation (SD) was used to assess the amount of variation that exists. If there were multiple CMHCs within an RHP, a single average 
strength of tie score was reported across all CMHCs within an RHP. In order to compare the average strength of tie for CMHCs within a network to another group within the network, an average strength of tie score and a SD was also calculated for all of the other types of organizations (non-CMHC organizations). Results at the state-level will present an average strength of tie score and ranges to illustrate variation.

\section{Results}

For $\mathrm{T}_{0} / \mathrm{T}_{1}$, a total of 329 of the 388 organizations participated in the survey. The overall response rate was 84 percent, but response rates varied by RHP (range: $67 \%$ to $100 \%$ ). Between $\mathrm{T}_{0} / \mathrm{T}_{1}$ and $\mathrm{T}_{2}$, an additional 18 organizations were added to the sampling frame to accommodate performing providers and IGT entities for new 3-year projects. The overall response rate at $\mathrm{T}_{2}$ was 74 percent and, again, varied by RHP (range: $63 \%$ to 96\%) (Creel et al., 2016).

\section{Centrality}

Table 4 presents the mean, point change, and percent change to determine changes in the centrality measures (degree centrality and betweenness centrality) of CMHCs between $\mathrm{T}_{0}, \mathrm{~T}_{1}$, and $\mathrm{T}_{2}$ for each type of tie. Point centrality scores for tangible resource sharing and formal data sharing are lower compared to the other types of ties, which suggests that CMHCs, on average, tend to be least central in those tie types. Joint program/service delivery tends to have the highest degree centrality scores after the all collaboration tie type, providing opportunities for $\mathrm{CMHCs}$ to assume more central roles across networks. For all collaboration and joint program/service delivery relationships, the mean degree centrality tends to decrease over time, indicating that CMHCs tend to have fewer ties with organizations over the implementation period. For tangible resource 
sharing and formal data sharing, we see a decrease in mean degree centrality from $\mathrm{T}_{0}$ to $T_{1}$ and $T_{0}$ to $T_{2}$ but a slight increase from $T_{1}$ to $T_{2}$. It appears that degree scores were highest at $\mathrm{T}_{0}$ for all types of ties, possibly indicating that organizations assumed more central roles prior to the formation of the RHPs. Across all CMHCs, we see a decrease in mean degree from $T_{0}$ to $T_{2}$ for all tie types. Interestingly, we see an increase in mean betweenness from $\mathrm{T}_{0}$ to $\mathrm{T}_{2}$ for all but the formal data sharing tie. For mean betweenness, there is an increase from $T_{0}$ to $T_{1}$, a decrease from $T_{1}$ to $T_{2}$, and an increase from $T_{0}$ to $T_{2}$ for all collaboration and joint program/service delivery ties. 
Table 4. Changes in Degree and Betweenness Centrality of Community Mental Health Centers

\begin{tabular}{|c|c|c|c|c|c|c|c|c|c|c|c|c|}
\hline \multicolumn{13}{|l|}{ CENTRALITY } \\
\hline & \multicolumn{2}{|c|}{$\begin{array}{c}T_{0} \\
\text { (Pre-Waiver) }\end{array}$} & \multicolumn{2}{|r|}{$\begin{array}{c}T_{1} \\
-2013\end{array}$} & \multicolumn{2}{|c|}{$\begin{array}{c}T_{2} \\
-2015\end{array}$} & \multicolumn{2}{|c|}{$\begin{array}{l}\text { Change } \\
T_{0} \text { to } T_{1}\end{array}$} & \multicolumn{2}{|c|}{$\begin{array}{l}\text { Change } \\
T_{1} \text { to } T_{2}\end{array}$} & \multicolumn{2}{|c|}{$\begin{array}{l}\text { Change } \\
T_{0} \text { to } T_{2}\end{array}$} \\
\hline & DEGREE & BETWEENNESS & DEGREE & BETWEENNESS & DEGREE & BETWEENNESS & DEGREE & BETWEENNESS & DEGREE & BETWEENNESS & DEGREE & BETWEENNESS \\
\hline & MEAN & MEAN & MEAN & MEAN & MEAN & MEAN & $\begin{array}{l}\text { Point Change } \\
\text { ( } \% \text { Change) }\end{array}$ & $\begin{array}{c}\text { Point Change } \\
\text { ( } \% \text { Change) }\end{array}$ & $\begin{array}{l}\text { Point Change } \\
\text { (\% Change) }\end{array}$ & $\begin{array}{c}\text { Point Change } \\
(\% \text { Change) }\end{array}$ & $\begin{array}{l}\text { Point Change } \\
\text { ( } 6 \text { Change) }\end{array}$ & $\begin{array}{c}\text { Point Change } \\
\text { (\% Change) }\end{array}$ \\
\hline All Collaboration & 8.72 & 10.02 & 820 & 19.02 & 7.72 & 13.12 & $-0.51(-696)$ & 9(9096) & $-0.49(-696)$ & $-5.91(-3196)$ & $-1(-1196)$ & $3.1(3196)$ \\
\hline Program and Service Delivery & 7.37 & 11.92 & 6.88 & 20.69 & 6.35 & 15.32 & $-0.49(-796)$ & $8.77(7496)$ & $-0.53(-896)$ & $-5.37(-2696)$ & $-1.02(-1496)$ & $3.41(2996)$ \\
\hline Sharing Tangible Resources & 3.81 & 13.86 & 248 & 13.54 & 292 & 13.96 & $-1.33(-35 \%)$ & $-0.32(-296)$ & $0.44(1896)$ & $0.42(396)$ & $-0.89(-2396)$ & $0.1(196)$ \\
\hline Formal Data Sharing & 4.17 & 16.00 & 2.33 & 8.45 & 2.73 & 12.16 & $-1.85(-4496)$ & $-7.55(-4796)$ & $0.4(1796)$ & $3.71(4496)$ & $-1.45(-35 \%)$ & $-3.84(-2496)$ \\
\hline
\end{tabular}

*The point change is the percentage point change in the measure across time periods, calculated by subtracting the yalue of the measure from the furthest time period from the value of the measure from the most recent time

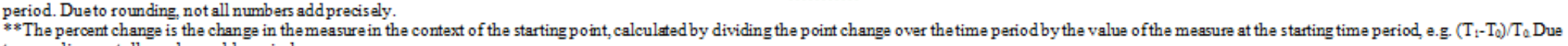
to rounding, notall numbers add precisely. 


\section{Homophily}

Given the fact that each CMHC has a different service area and provides services to a different number of counties, the percent homophily scores for each CMHC across the three time periods are multiplied by the number of counties it serves. Since there are multiple CMHCs within an RHP, the sum of all their scores was calculated and divided by the total number of counties all CMHCs' serve within a particular RHP. This number was reported as the final percent homophily score for each RHP. Table 5 presents the state-wide mean, point change, and percent change to determine changes in percent homophily of CMHCs between $\mathrm{T}_{0}, \mathrm{~T}_{1}$, and $\mathrm{T}_{2}$ for each type of tie. Percent homophily is expressed as a percent ranging from 0 to 100 , where 0 percent indicates that CMHCs are not working with any other CMHCs and 100 percent suggests that CMHCs are only working with other CMHCs. An increase in homophily indicates more ties with CMHCs and less with other types of organizations and a decrease in homophily suggests more ties with other types of organizations and less ties with CMHCs. For all but the all collaboration and the joint program/service delivery ties, we see an overall decrease in homophilous ties among CMHCs over the implementation period. CMHCs were unique in that they could put up own IGT; therefore, perhaps they found it more beneficial to keep money early on during the implementation period. However, CMHCs are working with other types of organizations to share resources and data across the DSRIP implementation period. For the all collaboration and joint program/service delivery ties, we see a decrease in homophilous ties from $T_{0}$ to $T_{1}$ and $T_{0}$ to $T_{2}$ but a slight increase from $T_{1}$ to $T_{2}$. This is because they belong to a statewide data network, thus an initial tie would have to exist. Decreases in percent changes for homophily are most noticeable for 
the tangible resource sharing ( $\mathrm{T}_{0}$ to $\mathrm{T}_{1}:-10 \%, \mathrm{~T}_{1}$ to $\mathrm{T}_{2}:-46 \%, \mathrm{~T}_{0}$ to $\mathrm{T}_{2}:-52 \%$ ) and formal data sharing ties $\left(\mathrm{T}_{0}\right.$ to $\mathrm{T}_{1}:-14 \%, \mathrm{~T}_{1}$ to $\mathrm{T}_{2}:-45 \%, \mathrm{~T}_{0}$ to $\left.\mathrm{T}_{2}:-52 \%\right)$, particularly from $\mathrm{T}_{0}$ to $\mathrm{T}_{2}$. In fact, across all RHPs, homophily for formal data sharing decreased in 10 RHPs (range of percent change from $\mathrm{T}_{0}$ to $\mathrm{T}_{2}:-100 \%$ to $67 \%$ ). DSRIP provided opportunities for CMHCs to obtain additional resources to support data sharing efforts with other organizations as part of a project. In the context of data sharing, these findings suggest that CMHCs may be working more formally with other types of organizations, possibly to ensure coordination and continuity of services. 
Table 5. Changes in Percent Homophily of Community Mental Health Centers

\begin{tabular}{|c|c|c|c|c|c|c|c|c|c|}
\hline \multicolumn{10}{|l|}{ HOMOPHILY } \\
\hline & $\begin{array}{c}\mathrm{T}_{0} \\
\text { (Pre-Waiver) }\end{array}$ & $\begin{array}{c}T_{1} \\
-2013\end{array}$ & $\begin{array}{c}T_{2} \\
-2015\end{array}$ & \multicolumn{2}{|c|}{$\begin{array}{l}\text { Change } \\
\mathrm{T}_{0} \text { to } \mathrm{T}_{1}\end{array}$} & \multicolumn{2}{|c|}{$\begin{array}{l}\text { Change } \\
\mathrm{T}_{1} \text { to } \mathrm{T}_{2}\end{array}$} & \multicolumn{2}{|c|}{$\begin{array}{c}\text { Overall Change } \\
\qquad T_{0} \text { to } T_{2}\end{array}$} \\
\hline & $\begin{array}{c}\text { Percent } \\
\text { Homophilous }\end{array}$ & $\begin{array}{c}\text { Percent } \\
\text { Homophilous }\end{array}$ & $\begin{array}{c}\text { Percent } \\
\text { Homophilous }\end{array}$ & $\begin{array}{c}\text { Point } \\
\text { Change* }^{*}\end{array}$ & $\begin{array}{c}\% \\
\text { Change**}\end{array}$ & $\begin{array}{c}\text { Point } \\
\text { Change* }^{*}\end{array}$ & $\begin{array}{c}\% \\
\text { Change }^{* *}\end{array}$ & $\begin{array}{c}\text { Point } \\
\text { Change* }^{*}\end{array}$ & $\begin{array}{c}\% \\
\text { Change }^{* *}\end{array}$ \\
\hline All Collaboration & $32 \%$ & $27 \%$ & $30 \%$ & -5 & $-17 \%$ & 3 & $11 \%$ & -2 & $-7 \%$ \\
\hline Program and Service Delivery & $30 \%$ & $25 \%$ & $29 \%$ & -5 & $-16 \%$ & 3 & $14 \%$ & -1 & $-5 \%$ \\
\hline Sharing Tangible Resources & $46 \%$ & $42 \%$ & $22 \%$ & -5 & $-10 \%$ & -19 & $-46 \%$ & -24 & $-52 \%$ \\
\hline Formal Data Sharing & $52 \%$ & $45 \%$ & $25 \%$ & -8 & $-14 \%$ & -20 & $-45 \%$ & -28 & $-53 \%$ \\
\hline
\end{tabular}

*The point change is the percentage point change in the measure across time periods, calculated by subtracting the value of the measure from the furthest time period from the value of the measure from the most recent time period. Due to rounding, not all numbers add precisely.

**The percent change is the change in the measure in the context of the starting point, calculated by dividing the point change over the time period by the value of the measure at the starting time period, e.g. $\left(\mathrm{T}_{1}-\mathrm{T}_{0}\right) / \mathrm{T}_{0}$. Due to rounding, not all numbers add precisely. 


\section{Average Strength of Ties}

Table 6 presents the statewide multiplexity means and ranges over the implementation period, indicating an overall increase in multiplexity for both CMHCs and non-CMHCs. The findings show that the mean average strength of ties for CMHCs and non-CMHCs was highest in $\mathrm{T}_{2}$ (CMHC: 1.87 , non-CMHC: 1.80$)$, indicating that on average $\mathrm{CMHCs}$ and non-CMHCs are both experiencing an increase in the complexity of their collaboration with other organizations. Interestingly, CMHCs had higher average strength of ties scores as compared to non-CMHCs across all time periods. The greatest point and percent changes appear to have occurred from $\mathrm{T}_{0}$ to $\mathrm{T}_{2}$ for both groups $(\mathrm{CMHC}$ : $0.23(14 \%)$, Non-CMHC: $0.23(15 \%))$. On average, we also noted greater variation in the ranges of CMHCs when compared to non-CMHCs. Point and percent changes for nonCMHCs increase progressively while we observe a different pattern for CMHCs. The results indicate that there is an 8 percent increase (0.12 point change) in CMHCs average strength of tie scores from $T_{0}$ to $T_{1}$, but these changes are not as strong for $T_{1}$ to $T_{2}(6 \%$ increase, 0.11 point change). Across RHPs, the range from $\mathrm{T}_{0}$ to $\mathrm{T}_{2}$ varied for both CMHCs and non-CMHCs, with 5 RHPs having a slight decrease in tie strength and all others seeing an increase (range of percent change, CMHC: $-21 \%$ to $46 \%$, range of percent change, non-CMHC: $-11 \%$ to $42 \%)$. 
Table 6. Changes in Average Strength of Ties of Community Mental Health Centers

\begin{tabular}{|c|c|c|c|c|c|c|c|c|c|c|c|c|}
\hline & \multicolumn{2}{|c|}{$\begin{array}{c}T_{0} \\
\text { (Pre-Waiver) }\end{array}$} & \multicolumn{2}{|c|}{$\begin{array}{c}T_{1} \\
-2013 \\
\end{array}$} & \multicolumn{2}{|c|}{$\begin{array}{c}T_{2} \\
-2015 \\
\end{array}$} & \multicolumn{2}{|c|}{$\begin{array}{l}\text { Change } \\
T_{0} \text { to } T_{1}\end{array}$} & \multicolumn{2}{|c|}{$\begin{array}{l}\text { Change } \\
T_{1} \text { to } T_{2}\end{array}$} & \multicolumn{2}{|c|}{$\begin{array}{l}\text { Change } \\
T_{0} \text { to } T_{2}\end{array}$} \\
\hline & $\mathrm{CMHC}$ & $\begin{array}{l}\text { Non- } \\
\text { CMHC }\end{array}$ & $\mathrm{CMHC}$ & $\begin{array}{l}\text { Non- } \\
\text { CMHC }\end{array}$ & $\mathrm{CMHC}$ & $\begin{array}{l}\text { Non- } \\
\text { CMHC }\end{array}$ & $\mathrm{CMHC}$ & Non-CMHC & $\mathrm{CMHC}$ & Non-CMHC & $\mathrm{CMHC}$ & Non-CMHC \\
\hline & MEAN & MEAN & MEAN & MEAN & MEAN & MEAN & $\begin{array}{l}\text { Point Change } \\
\text { (\% Change) }\end{array}$ & $\begin{array}{l}\text { Point Change } \\
\text { (\% Change) }\end{array}$ & $\begin{array}{l}\text { Point Change } \\
\text { (\% Change) }\end{array}$ & $\begin{array}{l}\text { Point Change } \\
\text { (\% Change) }\end{array}$ & $\begin{array}{l}\text { Point Change } \\
\text { (\% Change }\end{array}$ & $\begin{array}{l}\text { Point Change } \\
\text { (\% Change) }\end{array}$ \\
\hline Mean & 1.64 & 1.57 & 1.76 & 1.66 & 1.87 & 1.80 & $0.12(8 \%)$ & $0.10(6 \%)$ & $0.11(6 \%)$ & $0.13(8 \%)$ & $0.23(14 \%)$ & $0.23(15 \%)$ \\
\hline Range & $1.20-2.25$ & $1.16-1.88$ & $1.25-2.5$ & $1.24-1.97$ & $1.21-2.56$ & $1.49-2.12$ & $\begin{array}{c}-0.54-0.9 \\
(-24 \%-56 \%)\end{array}$ & $\begin{array}{l}-0.16-0.57 \\
(-9 \%-49 \%)\end{array}$ & $\begin{array}{c}-0.4-0.78 \\
(-23 \%-44 \%)\end{array}$ & $\begin{array}{c}-0.24-0.55 \\
(-14 \%-44 \%)\end{array}$ & $\begin{array}{c}-0.36-0.76 \\
(-21 \%-46 \%)\end{array}$ & $\begin{array}{c}-0.21-0.53 \\
(-11 \%-42 \%)\end{array}$ \\
\hline
\end{tabular}

*The point change is the percentage point change in the measure across time periods, calculated by subtracting the value of the measure from the furthest time period from the value of the measure from themost recent time period. Due to rounding, not all numbers add precisely.

* The percent change is the change in the measure in the context of the starting point, calculated by dividing the point change over the time period by the value of the measure at the starting time period, e.g. $\left(T_{1}-T_{0}\right) / T_{0}$ to rounding not all numbers add precisaly. 


\section{Discussion}

Behavioral health services were significantly expanded under the 1115 Waiver. As such, DSRIP changed the landscape for CMHCs by providing unique opportunities for them to work with other organizations in addressing the mental health needs of Texans. This study characterizes how the role of CMHCs has evolved based on structural position, intersectoral connections, and strength of ties.

Our first hypothesis: CMHCs become more central over the implementation period, was partially supported. Increases in mean betweenness scores from $T_{0}$ to $T_{1}$ and $\mathrm{T}_{0}$ to $\mathrm{T}_{2}$ for all collaboration and joint program/service delivery ties indicate that CMHCs tend to fall along the shortest path between two other organizations within the RHPs, particularly as it relates to joint program/service delivery. This suggests that over the implementation period, CMHCs assumed structurally advantaged positions within the RHPs in ways that allow them to influence what types of content enters the group, control flows of program/service delivery, and facilitate exchange of information and resources among other participating organizations in the RHP. Because the Waiver prioritized behavioral health by allocating 10 percent of DSRIP funds for CMHCs, it seems reasonable for them to leverage this funding in securing a more central role within the RHPs, inviting collaboration in the form of integrated behavioral and primary health to occur. This is especially true from $\mathrm{T}_{0}$ to $\mathrm{T}_{1}$ where the increase in percent change for mean betweenness is a lot more pronounced.

Contrastingly, it appears that mean degree scores were highest at $\mathrm{T}_{0}$ for all types of ties, possibly indicating that participation in dense networks reduced centrality because of the presence of more ties among organizations in the RHP. As such, CMHCs did not 
necessarily become more central based on the number of direct ties they had with other organizations, particularly for tangible resource sharing and data sharing ties. In addition to providing behavioral health services as performing providers, CMHCs could also serve as IGT entities who could contribute local dollars to draw down federal matching funds, another source of increased power within the RHP. Taken as a whole, information on centrality is particularly relevant because it has implications for expanding the role of CMHCs as a recognized health service delivery organization within the Texas Medicaid system to improve behavioral health outcomes.

The findings suggest that CMHCs assume more central roles in the joint program/service delivery ties likely due to the fact that there was increased funding for mental health efforts and CMHCs were eligible to offer intergovernmental transfer funds to match the federal DSRIP funds. This elevated the position of CMHCs within the networks, providing them with increased power, potentially making them desirable partners for other organizations, particularly hospitals who were seeking to integrate primary care with behavioral health. This power also allowed them to control flows of program/service delivery and possibly facilitate the exchange of other types of network content, particularly given the number of behavioral health projects that were available to choose from within the menu of options.

Second, our hypothesis that CMHCs would have more intersectoral partnerships over time, was also supported by the data. The results suggest that CMHCs were less likely to only work with other CMHCs over the implementation period, particularly as it relates to tangible resource sharing and formal data sharing. This could, in part, be attributed to the fact that CMHCs were eligible to offer IGT funds. In fact, we find that 
the percent change is most pronounced for those two types of ties over the three time periods. There may be a few reasons why we observe a substantial increase for the formal data sharing tie. First, the nature of the projects supported by the Waiver either required or encouraged data sharing among members to ensure coordination and continuity of services between organizations. Second, a few RHPs leveraged available resources through DSRIP projects to create local or regional health information exchanges (HIEs) (Creel et al., 2016).

As hypothesized, we find that both CMHCs and non-CMHCs experienced an increase in the complexity of their collaboration with other organizations. CMHCs had higher strength of tie scores than non-CMHCs, possibly suggesting that the Waiver helped them to build and sustain meaningful partnerships over time. Taken together, the structural position, intersectoral collaborations, and strength of ties of CMHCs across the RHPs indicate that the Waiver has significantly shaped the role of CMHCs in Texas and possibly the availability and accessibility of behavioral health services within the state.

There are some limitations associated with this study. There are a number of different measures that can be used to assess centrality (e.g. closeness) and homophily (e.g. E-I index), but we chose to focus on specific measures to keep the analysis focused. Measures that were not included in this study may be equally important in answering our research questions, but the literature suggests that some network measures were simply not appropriate for our study because our data were not directed, and some measures are specifically intended to assess relationships based on reciprocity. A majority of the surveys were completed by a single respondent at each organization. While anchor institutions worked directly with member organizations to identify an appropriate 
respondent who would be knowledgeable of the relationships asked about in the survey, it is unrealistic to assume that one individual alone would be knowledgeable about all the collaborative activities occurring throughout and across an organization - especially for the larger organizations. Additionally, the types of respondents changed for the second round of data collection for some organizations. As such, differences in institutional knowledge between executives who responded $T_{0} / T_{1}$ versus project managers at $T_{2}$, likely affected the extensiveness of the relationships reported.

Whole network analyses are particularly sensitive to non-response or missing data. Missing data on unconfirmed relationships were accommodated by symmetrizing the data. Since missing data were apparent in almost all RHPs, an absence of a tie between two organizations could be misleading if neither of the two organizations participated in the survey, as this may have failed to capture an actual tie that exists between the two organizations. The lower response rate for $\mathrm{T}_{2}$ data collection could artificially indicate a decrease in outcome measures in some RHPs where relationships did not end but, rather, were not reported. On the contrary, respondents may have experienced issues with recalling relationships and/or possibly exaggerating ties with those perceived to have authority or power within each RHP (e.g. anchor institution). A final limitation, highlighted particularly by survey respondents, was that the sampling frame failed to include other organizations that may have been key collaborators in DSRIP activities. While an additional set of questions were added in the $\mathrm{T}_{2}$ survey to accommodate participant concerns, corresponding data from $\mathrm{T}_{0} / \mathrm{T}_{1}$ was not available to be able to assess changes over time. This is also a limitation of using secondary data 
because the data were not necessarily collected to answer the research questions proposed above.

Mental health is fundamental to overall health and well-being. However, Texas has one of the lowest rates of access to mental health services (Mental Health America, 2015 ) and the annual per capita spending for mental health is nearly a third of the national average (KFF, 2017). Health care delivery systems have frequently relied on siloed approaches to address complex health care needs, placing increased burden on a fragmented system. In fact, CMHCs have largely been peripheral to the health care delivery system with mental health being perceived as distinct from physical health. Fortunately, the waiver presented opportunities to prioritize mental health, foster collaboration, and allow CMHCs to offer IGT funds, factors that enhanced the position and power of CMHCs within their RHPs. In doing so, CMHCs assumed more central roles for service integration with other types of organizations, allowing them to develop multiple, meaningful relationships with an organization in ensuring coordinated and continuous care. Given the state of mental health in Texas, the Waiver intentionally focused on integrating non-traditional service delivery organizations, such as CMHCs for health care delivery system reform. This is important because it has significantly expanded behavioral health services in Texas, and rightfully acknowledged that CMHCs are essential health service delivery organizations that can contribute to the Triple Aim strategies for system transformation and population health improvement. In incorporating CMHCs, otherwise unintegrated organizations, to the health service delivery system, future policies should consider the expansion of network boundaries to include the range 
of other organizations that are critical to maintaining the health status of low-income populations. 


\section{CHAPTER V \\ EXAMINING OPPORTUNITIES FOR SUSTAINED INTERSECTORAL PARTNERSHIPS THROUGH THE TEXAS MEDICAID 1115 TRANSFORMATION WAIVER}

\section{Introduction}

Over the course of an individual's life span, there are a range of health services he or she may seek out, which are categorized across a continuum of care (Olden, 2011). One challenge to achieving optimal health is that the systems tasked with the responsibility of providing care across this continuum often operate in silos, missing opportunities to provide quality, coordinated care. The problems faced by health service delivery systems are complex and multifaceted (Shi \& Singh, 2014). In 2015, the United States (US) spent approximately $\$ 3.2$ trillion on health care (Centers for Medicare and Medicaid Services [CMS], 2015). Despite high health care spending, however, efforts to improve health are lacking as evidenced by deficiencies in access to care, health system quality, and equity among other issues (Davis, Stremikis, Squires, \& Schoen, 2014). One of the pivotal features that differentiates the US from most other industrialized countries is the absence of universal health insurance coverage (Davis et al., 2014). Universal coverage systems are shown to promote the Triple Aim strategies, an approach to increase access to care, enhance quality of care, reduce costs, and improve population 
health (The Institute for Healthcare Improvement, 2009; World Health Organization, 2012).

The Patient Protection and Affordable Care Act (ACA), a comprehensive health reform law, was intended to expand coverage, reduce health care costs, and improve health care delivery systems within the US (Obama, 2016). Under the ACA, millions of Americans were able to obtain health insurance coverage; however, concerns related to access and cost of care (e.g. increased premiums) persist (Davis et al., 2014; Obama, 2016). These issues have serious economic consequences which are often passed on to consumers and taxpayers. Under the new Presidential administration and Congress, a wave of uncertainty overshadows the future of health care. Many question what a "repeal [ACA] and replace" would look like. Others question whether "replace" is even on the agenda (Obama, 2017). Some are fearful as they consider the potential implications of these changes on their ability to prevent and manage existing health conditions (Obama, 2017). Bearing in mind the potential implications of a new health care system, it is crucial to consider the ways in which systems that deliver health services can work with each other to fill existing gaps in the continuum of care. Collaborative, intersectoral partnerships provide an opportunity to conserve capital and make effective use of limited resources. The Texas 1115 Medicaid Waiver provides an opportunity to explore how a state policy change can incentivize and affect collaboration.

The Texas 1115 Medicaid Waiver, known as the Healthcare Transformation and Quality Improvement Program (Waiver) was approved by the Centers for Medicare and Medicaid Services (CMS) in 2011 and allowed the state to test changes in coverage, benefits, provider payments, and cost-sharing over a span of five years (Artiga, 2011). 
The Waiver aimed to catalyze system transformation through collaboration and integration of services that increased efficiency of service delivery, improved quality of care, and reduced costs. Implementation of the Waiver consisted of three elements, which included expansion of Medicaid managed care, redesign of the uncompensated care payment structure for hospitals, and transformation of health care delivery through the Delivery System Reform Incentive Payment (DSRIP) Program. This study focuses on the organizations that participated in DSRIP, which was designed to incentivize activities that support organizations collaborative efforts with other organizations to address the Triple Aim strategies (Gates, Rudowitz, \& Guyer, 2014; HHS, n.d.).

Given the geographic vastness of the state and the diversity of the populations within the state, 20 Regional Healthcare Partnerships (RHPs) were created across the state as a structure for planning, implementing, and tracking DSRIP activities. The RHPs represent networks comprised of organizations within and across sectors, including hospitals, community mental health centers (CMHCs), public health departments, and academic health science centers among other organizations. Each RHP varies with respect to composition, but each includes an anchor institution (administratively responsible for coordination), participating intergovernmental transfer (IGT) entities (responsible for providing local match to draw down federal funds), and performing providers. RHPs could be characterized as mandated partnerships since CMS and the Texas Health and Human Services Commission (HHSC) required the formation of RHPs with clear financial incentives at stake for participating organizations.

While the establishment of RHPs created some new relationships, many RHPs were built upon a core group of interorganizational relationships that already existed. 
Through the RHPs, the Waiver sought to create collaborative environments for providers to achieve improved system performance. Establishing and strengthening relationships among organizations across sectors within these regions was intended to improve capacity to collaborate and deliver health services more efficiently and effectively, particularly to the uninsured and those covered by Medicaid. Promoting collaboration among organizations engages them in relationships with a broader range of organizations that can facilitate exchange (Glisson \& James, 1992). Networks such as these RHPs can aid service providers in coordinating service delivery functions and activities, thereby improving the quality, effectiveness, or efficiency of services to clients (Isett \& Provan, 2005). In fact, such DSRIP activity is expected to improve access to preventive care; improve quality, health, and cost outcomes for populations served by specific projects; and improve regional health and human service delivery capacity through enhanced collaboration.

Under the Waiver, Texas uniquely expanded eligibility of providers for the DSRIP funding pool, making it possible for a range of providers beyond public hospitals to receive financial incentives for participating in delivery system reform. This provides a formal mechanism to identify relationships that exist between organizations in different sectors of the health care delivery system, known as intersectoral ties. Assessing such relationships can shift the paradigm about the ways in which human, social, intellectual, and financial capital can be pooled to improve efficiency and increase capability to address the complex issues of the current health system.

The literature suggests that the creation of networks does not always result in collaboration (Foster-Fishman, Salem, Allen, \& Fahrbach, 2001). When collaboration is 
reported, the literature points to a number of common types of ties that can exist between organizations that deliver health services (e.g. joint service delivery, resource sharing) (Borgatti \& Foster, 2003; Huerta, Caebeer, VanderPlatt, 2006; Isett et al., 2011; Luke \& Harris, 2007; Milward and Provan; 2006; Popp et al., 2014; Provan et al., 2007). Yet, there is relatively little discussion about the specific nature of relationships (based on structure and content exchanged) and how those relationships can be used to drive delivery system reform, specifically when networks are created in response to a policy change. Delivery system reform is predicated on the idea that innovative service delivery models will be used to address quality of care, access to care, and cost of care. The Waiver provides an opportunity to assess how collaboration among organizations between and across sectors evolved over time. As such, the purpose of this study is to evaluate the extent to which formation of the RHPs impacted intersectoral collaboration under DSRIP. Based on existing literature, we would expect the formation of RHPs to increase intersectoral ties over time.

\section{Methods}

\section{Study Design}

For the purposes of this study, the data were collected as part of an evaluation of Texas' Waiver that was conducted by Texas A\&M University, the University of Texas, and the University of Louisville under contract by the Texas Health and Human Services Commission (HHSC). Therefore, the data are being presented here as secondary data.

Since each RHP represents a distinct network, interorganizational network analysis was used to assess the RHP-level networks where each RHP member organization report on ties with each of the other organizations within the RHP (Provan, 
Fish, and Sydow 2007). Interorganizational network analysis is a powerful tool for examining patterns of relationships among organizations (Morrissey, 1992; Provan \& Milward, 1995). Popp and colleagues (2014) suggest that there are multiple benefits of interorganizational networks some of which include access to resources and efficient use of resources, an increased ability to share risk in pursing innovative endeavors, ability to provide coordinated, high quality services across the continuum of care, engage in knowledge and information exchange, or an opportunity to share responsibility. The actors in interorganizational networks are organizations and the ties are the relationships that exist between organizations. Therefore, a non-randomized, pre-post interorganizational network study design was used to evaluate intersectoral collaboration in the RHP-level networks. Information about interorganizational ties was gathered during three time periods:

1. Twelve (12) months prior to the creation of the RHPs, Calendar year $2011\left(\mathrm{~T}_{0}\right)$

2. Demonstration Year 2 of the Waiver $\left(\mathrm{T}_{1}\right)$, Calendar year 2013; and

3. Demonstration Year 4 of the Waiver, Calendar year $2015\left(\mathrm{~T}_{2}\right)$

Since it was not possible to collect data prior to the establishment of the RHPs $\left(\mathrm{T}_{0}\right)$, data for $\mathrm{T}_{0}$ and $\mathrm{T}_{1}$ were collected in the same survey between January and May of 2014. It was important to capture relationships at $\mathrm{T}_{0}$ because this provides baseline information about the evolution of relationships throughout the implementation period. In order to mitigate the effects of response-shift bias, $\mathrm{T}_{0}$ data were collected immediately after $\mathrm{T}_{1}$ data in the same survey. A more detailed description of this approach is published elsewhere (Howard \& Dailey, 1979). Data for $\mathrm{T}_{2}$ were collected between January and mid-July of 2016. 
The sampling frame for the study included all organizations participating in DSRIP across the 20 RHPs (Creel \& Wendel, 2016). Data were collected at the organizational level (sampling frame: $n=388$ participating organizations for all 20 RHPs at $T_{0} / T_{1}$, and $n=406$ participating organizations for all 20 RHPs at $T_{2}$ ). For many network studies, the unit of analysis is the network itself (Borgatti, Everett, \& Johnson, 2013; Hanneman \& Riddle, 2005; Isett \& Provan, 2005; Provan \& Milward, 1995; Provan, Fish, \& Sydow, 2007; Provan \& Lemaire, 2012). In line with this approach, the unit of analysis for this study is at the RHP level $(n=20)$, with each RHP comprising a distinct network. Data on interorganizational exchanges were collected in each RHP using a key informant approach via computer-assisted telephone surveys (Creel \& Wendel, 2016; Foster-Fishman et al. 2001). A more in-depth discussion on data collection can be found published elsewhere (Creel \& Wendel, 2016).

\section{Measures}

In the network survey, respondents were asked to answer a series of yes/no questions about their organization's relationship with other organizations in their RHP (Provan and Milward 1995). Key survey measures are presented in Table 7. The survey instrument drew questions and constructs from previously published studies (Creel \& Wendel, 2016; Foster-Fishman et al, 2001; Johnsen, Morrissey, \& Calloway, 1996; Provan \& Milward, 1995; Provan, Nakama, Veazie, Teufel-Shone \& Huddleston, 2003). 


\section{Table 7. Survey Measures}

\begin{tabular}{|c|c|c|}
\hline Construct & $\mathrm{T}_{0}$ (Pre-Waiver) Measures & $\begin{array}{c}\mathrm{T}_{1}(2013) \& \mathrm{~T}_{2}(2015) \\
\text { Measures }\end{array}$ \\
\hline $\begin{array}{c}\text { Any } \\
\text { Collaboration* }\end{array}$ & $\begin{array}{l}\text { "In the year prior to the establishment of RHP [\#], } \\
\text { did your organization work with [x organization] at } \\
\text { all?" }\end{array}$ & $\begin{array}{l}\text { "Does your organization currently } \\
\text { work with [x organization]?" }\end{array}$ \\
\hline $\begin{array}{l}\text { Joint Service } \\
\text { Delivery }\end{array}$ & $\begin{array}{l}\text { "In the year prior to the establishment of RHP [\#], } \\
\text { did your organization collaborate with [x } \\
\text { organization] to deliver services?" }\end{array}$ & $\begin{array}{l}\text { "Does your organization currently } \\
\text { collaborate with [x organization] to } \\
\text { deliver services?" }\end{array}$ \\
\hline $\begin{array}{l}\text { Resource } \\
\text { Sharing }\end{array}$ & $\begin{array}{l}\text { "In the year prior to the establishment of RHP [\#], } \\
\text { did your organization share tangible resources } \\
\text { with [x organization] for the purpose of increasing } \\
\text { access to services?" }\end{array}$ & $\begin{array}{l}\text { "Does your organization currently } \\
\text { share tangible resources with [x } \\
\text { organization] for the purpose of } \\
\text { increasing access to services?" }\end{array}$ \\
\hline Data Sharing & $\begin{array}{l}\text { "In the year prior to the establishment of RHP [\#], } \\
\text { did your organization have an agreement in place } \\
\text { to share patient data with [x organization]?" }\end{array}$ & $\begin{array}{l}\text { "Does your organization currently } \\
\text { have a data sharing agreement } \\
\text { with [x organization]?" }\end{array}$ \\
\hline
\end{tabular}

\section{Analysis}

Using network software Ucinet 6 , survey data across the three time periods $\left(\mathrm{T}_{0}\right.$, $\mathrm{T}_{1}$, and $\mathrm{T}_{2}$ ) were arranged into a square adjacency matrix, where 0 indicated no tie and 1 indicated the presence of a tie within each cell (Borgatti, Everett, \& Freeman, 2002). A total of four matrices were generated for each RHP by type of relationship (any collaboration, joint program/service delivery, tangible resource sharing, and formal data sharing). Network data can be biased if missing data are not accounted for appropriately; therefore, the data were symmetrized to reflect relationships between organizations if one organizatiom indicated collaboration. A more in-depth description of this approach and its effectiveness can be found elsewhere (Borgatti et al., 2013; Creel \& Wendel, 2016; Hanneman \& Riddle, 2005). 


\section{Intersectoral Connections}

Since the state expanded eligibility of providers for the DSRIP funding pool, it was possible for a broad range of providers beyond public hospitals to participate in delivery system reform. This provided a unique opportunity to identify ties that exist between organizations in different sectors of the health care delivery system. Intersectoral partnerships offer a number of benefits:

1. Provide organizations with the opportunities to strengthen limited resources and make more efficient use of resources (Bryson et al., 2006; Provan \& Lemaire, 2012).

2. In the delivery system reform context, such partnerships provide opportunities to provide coordinated care and improve the quality of services provided across the continuum of care (Provan \& Lemaire, 2012).

3. Such collaborations have an increased potential for creating opportunities for innovation (Provan \& Lemaire, 2012).

While such relationships can be difficult to create and sustain over time, they provide meaningful opportunities for organizations to fulfill their directional strategies in meeting the needs of the populations they serve (Bryson et al, 2006). For the purposes of this study, we chose to aggregate all RHP-level changes across the four tie types and present statewide changes for each type of tie (all collaboration, joint program/service delivery, tangible resource sharing, formal data sharing) from $\mathrm{T}_{0}$ to $\mathrm{T}_{2}$.

Ucinet 6 is capable of analyzing both relational data and nodal (organization) attribute data, which are both essential to address this research question. The examination of intersectoral connections within network analysis requires a firm understanding of a key characteristic of networks: network density. Network density is the number of existing connections among network organizations as a proportion of the total possible connections (Wasserman \& Faust, 1994). Network density provides critical information about the connectedness of a network, which can influence the flow of information, the 
exchange of resources, and accessibility of novel information. While denser networks provide more opportunities to share information and exchange resources, networks that are sparsely connected may provide improved access to different types of actors and novel resources (Borgatti et al., 2013). However, the impact of density on a network is contingent on both the characteristics of organizations that make up the network and the type of relation being studied (Borgatti et al., 2013).

In Ucinet 6, the density-by-groups function was used to assess intersectoral connections for each type of tie (e.g. joint program/service delivery, tangible resource sharing, formal data sharing). The resulting output generated densities by sector that vary from zero to one. These densities were multiplied by 100 to express the percentage of ties found within sectors (e.g. among hospitals) and also between sectors (e.g. hospitals' ties with CMHCs) within a network for each type of tie. In order to assess sector-level patterns for intersectoral connections, the point and percent change for density of connections within and between members of all sectors was examined for $T_{0}$ to $T_{2}$. This information can offer a critical perspective on the nature of intersectoral ties at the state level, the types of ties in which intersectoral connections are more likely to form, the ways in which intersectoral ties evolve over time, and the implications for health service delivery in Texas.

\section{Results}

Of the 388 organizations that were eligible to participate in the survey for $\mathrm{T}_{0} / \mathrm{T}_{1}$, 329 organizations participated. The overall response rate was 84 percent, but response rates varied by RHP (range: $67 \%$ to $100 \%$ ). Eighteen organizations were added to the sampling frame between $\mathrm{T}_{0} / \mathrm{T}_{1}$ and $\mathrm{T}_{2}$ to accommodate organizations who added new 3- 
year projects. The overall response rate at $\mathrm{T}_{2}$ was 74 percent and varied by RHP (range: $63 \%$ to $96 \%$ ) (Creel et al., 2016). Tables 8 through 11 present changes in collaboration by tie type, where an increase represents an increase in collaboration and no increase represents a decrease or no change in collaboration. Both mean point and percent changes for the density of connections from $\mathrm{T}_{0}$ to $\mathrm{T}_{2}$ are reported within and between sectors by tie type. A gray shaded area represents either the absence of collaboration or a zero as the starting density for $\mathrm{T}_{0}$, which yields an undefined value for percent change. Each sector has an $\mathrm{n}$, which represents the number of RHPs that include organizations falling within that particular type of sector. Results focus on capturing changes in collaboration that the majority of RHPs report within a particular sector for all tie types; however, in cases where the magnitude of the change is substantial regardless of the number of RHPs, the change was reported. 
Table 8. Within sector and intersectoral ties, All Collaboration

\begin{tabular}{|c|c|c|c|c|c|c|c|}
\hline & \multirow[b]{2}{*}{$\begin{array}{l}\text { Change in } \\
\text { collaboration }\end{array}$} & \multicolumn{3}{|c|}{ Within Sector } & \multicolumn{3}{|c|}{ Intersectoral } \\
\hline & & $\begin{array}{l}\text { \# of } \\
\text { RHPs }\end{array}$ & $\begin{array}{c}\text { Mean } \\
\text { point } \\
\text { change* }\end{array}$ & $\begin{array}{c}\text { Mean \% } \\
\text { change** }^{\star *}\end{array}$ & $\begin{array}{l}\text { \# of } \\
\text { RHPs }\end{array}$ & $\begin{array}{c}\text { Mean } \\
\text { point } \\
\text { change* }\end{array}$ & $\begin{array}{l}\text { Mean \% } \\
\text { change** }^{*}\end{array}$ \\
\hline Hospital & Increase & 8 & 0.26 & $109 \%$ & 13 & 0.12 & $41 \%$ \\
\hline$(n=20)$ & No Increase & 12 & -0.17 & $-43 \%$ & 7 & -0.15 & $-33 \%$ \\
\hline $\begin{array}{l}\text { Hospital/ } \\
\text { Health District or } \\
\text { Hospital Authority }\end{array}$ & Increase & 2 & 0.30 & $80 \%$ & 10 & 0.15 & $102 \%$ \\
\hline$(n=16)$ & No Increase & 7 & -0.03 & $-31 \%$ & 6 & -0.05 & $-26 \%$ \\
\hline County & Increase & 2 & 0.82 & $317 \%$ & 7 & 0.17 & $94 \%$ \\
\hline$(n=11)$ & No Increase & 2 & -0.08 & $-25 \%$ & 4 & -0.15 & $-27 \%$ \\
\hline City & Increase & 0 & & & 2 & 0.08 & $27 \%$ \\
\hline$(n=3)$ & No Increase & 0 & & & 1 & -0.16 & $-54 \%$ \\
\hline School District & Increase & 0 & & & 1 & 0.51 & $765 \%$ \\
\hline$(n=1)$ & No Increase & 0 & & & 0 & & \\
\hline EMS District & Increase & 0 & & & 1 & 0.88 & $1051 \%$ \\
\hline$(n=1)$ & No Increase & 0 & & & 0 & & \\
\hline $\begin{array}{l}\text { Community } \\
\text { Mental Health } \\
\text { Center }\end{array}$ & Increase & 0 & & & 8 & 0.09 & $30 \%$ \\
\hline$(n=20)$ & No Increase & 17 & -0.28 & $-29 \%$ & 12 & -0.11 & $-24 \%$ \\
\hline $\begin{array}{l}\text { Academic Health } \\
\text { Science Center }\end{array}$ & Increase & 0 & & & 8 & 0.13 & $42 \%$ \\
\hline$(n=15)$ & No Increase & 2 & 0.00 & $0 \%$ & 7 & -0.10 & $-25 \%$ \\
\hline $\begin{array}{l}\text { Health } \\
\text { Department }\end{array}$ & Increase & 0 & & & 7 & 0.22 & $80 \%$ \\
\hline$(n=11)$ & No Increase & 4 & -0.25 & $-33 \%$ & 4 & -0.10 & $-22 \%$ \\
\hline Physician Practice & Increase & 0 & & & 4 & 0.20 & $52 \%$ \\
\hline$(n=6)$ & No Increase & 1 & 0.00 & & 2 & -0.06 & $-26 \%$ \\
\hline $\begin{array}{l}\text { Community } \\
\text { Collaborative }\end{array}$ & Increase & 0 & & & 1 & 0.23 & $65 \%$ \\
\hline$(n=1)$ & No Increase & 0 & & & 0 & & \\
\hline
\end{tabular}

*The point change is the percentage point change in the measure across time periods, calculated by subtracting the value of the measure from the furthest time period from the value of the measure from the most recent time period. Due to rounding, not all numbers add precisely.

**The percent change is the change in the measure in the context of the starting point, calculated by dividing the point change over the time period by the value of the measure at the starting time period, e.g. $\left(T_{2}-T_{0}\right) / T_{0}$. Due to rounding, not all numbers add precisely. When the value of the measure at the starting time period is zero, percent changes are not reported.

***Within an RHP, if there was only one organization within a particular sector, within sector results were not reported. 
Table 9. Within sector and intersectoral ties, Joint Program/Service Delivery

\begin{tabular}{|c|c|c|c|c|c|c|c|}
\hline & \multirow[b]{2}{*}{$\begin{array}{c}\text { Change in } \\
\text { Collaboration }\end{array}$} & \multicolumn{3}{|c|}{ Within Sector } & \multicolumn{3}{|c|}{ Intersectoral } \\
\hline & & $\begin{array}{c}\text { \# of } \\
\text { RHP } \\
s\end{array}$ & $\begin{array}{c}\text { Mean } \\
\text { point } \\
\text { change* }\end{array}$ & $\begin{array}{c}\text { Mean \% } \\
\text { change }^{\star *}\end{array}$ & $\begin{array}{l}\text { \# of } \\
\text { RHPs }\end{array}$ & $\begin{array}{c}\text { Mean } \\
\text { point } \\
\text { change* }\end{array}$ & $\begin{array}{c}\text { Mean \% } \\
\text { change** }\end{array}$ \\
\hline Hospital & Increase & 5 & 0.29 & $45 \%$ & 4 & 0.11 & $14 \%$ \\
\hline$(\mathrm{n}=20)$ & No Increase & 15 & -0.14 & $-14 \%$ & 16 & -0.06 & $-7 \%$ \\
\hline $\begin{array}{l}\text { Hospital/ } \\
\text { Health District or } \\
\text { Hospital } \\
\text { Authority }\end{array}$ & Increase & 0 & & & 3 & 0.21 & $31 \%$ \\
\hline$(n=16)$ & No Increase & 3 & -0.04 & $-4 \%$ & 13 & -0.15 & $-15 \%$ \\
\hline County & Increase & 0 & & & 1 & 0.11 & $12 \%$ \\
\hline$(n=11)$ & No Increase & 2 & 0.00 & $0 \%$ & 10 & -0.04 & $-4 \%$ \\
\hline City & Increase & 0 & & & 1 & 0.17 & $20 \%$ \\
\hline$(n=3)$ & No Increase & 0 & & & 2 & 0.00 & $0 \%$ \\
\hline School District & Increase & 0 & & & 0 & & \\
\hline$(n=1)$ & No Increase & 0 & & & 1 & 0.00 & $0 \%$ \\
\hline EMS District & Increase & 0 & & & 0 & & \\
\hline$(n=1)$ & No Increase & 0 & & & 1 & -0.25 & $-25 \%$ \\
\hline $\begin{array}{l}\text { Community } \\
\text { Mental Health } \\
\text { Center }\end{array}$ & Increase & 5 & 0.29 & $51 \%$ & 2 & 0.16 & $21 \%$ \\
\hline$(n=20)$ & No Increase & 10 & -0.01 & $-1 \%$ & 18 & -0.10 & $-10 \%$ \\
\hline $\begin{array}{l}\text { Academic Health } \\
\text { Science Center }\end{array}$ & Increase & 0 & & & 1 & 0.01 & $1 \%$ \\
\hline$(n=15)$ & No Increase & 1 & 0.00 & $0 \%$ & 14 & -0.20 & $-20 \%$ \\
\hline $\begin{array}{l}\text { Health } \\
\text { Department }\end{array}$ & Increase & 0 & & & 1 & 0.61 & $155 \%$ \\
\hline$(n=11)$ & No Increase & 2 & -0.17 & $-17 \%$ & 10 & -0.04 & $-4 \%$ \\
\hline $\begin{array}{l}\text { Physician } \\
\text { Practice }\end{array}$ & Increase & 0 & & & 2 & 0.60 & $25 \%$ \\
\hline$(n=6)$ & No Increase & 0 & & & 4 & 0.00 & $0 \%$ \\
\hline $\begin{array}{l}\text { Community } \\
\text { Collaborative }\end{array}$ & Increase & 0 & & & 0 & & \\
\hline$(n=0)$ & No Increase & 0 & & & 0 & & \\
\hline
\end{tabular}

*The point change is the percentage point change in the measure across time periods, calculated by subtracting the value of the measure from the furthest time period from the value of the measure from the most recent time period. Due to rounding, not all numbers add precisely. **The percent change is the change in the measure in the context of the starting point, calculated by dividing the point change over the time period by the value of the measure at the starting time period, e.g. $\left(\mathrm{T}_{2}-\mathrm{T}_{0}\right) / \mathrm{T}_{0}$. Due to rounding, not all numbers add precisely. When the value of the measure at the starting time period is zero, percent changes are not reported.

***Within an RHP, if there was only one organization within a particular sector, within sector results are not presented. 
Table 10. Within sector and intersectoral ties, Tangible Resource Sharing

\begin{tabular}{|c|c|c|c|c|c|c|c|}
\hline \multirow{2}{*}{\multicolumn{2}{|c|}{$\begin{array}{l}\text { INTERSECTORAL TIES, STA } \\
\qquad \begin{array}{c}\text { Change in } \\
\text { collaboratio } \\
n\end{array}\end{array}$}} & \multicolumn{3}{|c|}{ Within Sector } & \multicolumn{3}{|c|}{ Intersectoral } \\
\hline & & $\begin{array}{c}\text { \# of } \\
\text { RHP } \\
s\end{array}$ & $\begin{array}{c}\text { Mean } \\
\text { point } \\
\text { change* }\end{array}$ & $\begin{array}{l}\text { Mean } \% \\
\text { change }^{\star \star}\end{array}$ & $\begin{array}{l}\text { \# of } \\
\text { RHPs }\end{array}$ & $\begin{array}{c}\text { Mean } \\
\text { point } \\
\text { change* }\end{array}$ & $\begin{array}{l}\text { Mean \% } \\
\text { change }^{\star *}\end{array}$ \\
\hline \multirow{2}{*}{$\begin{array}{l}\text { Hospital } \\
(n=20)\end{array}$} & Increase & 8 & 0.31 & $108 \%$ & 10 & 0.29 & $107 \%$ \\
\hline & No Increase & 12 & -0.16 & $-38 \%$ & 10 & -0.18 & $-39 \%$ \\
\hline $\begin{array}{l}\text { Hospital/ } \\
\text { Health District or } \\
\text { Hospital } \\
\text { Authority }\end{array}$ & Increase & 0 & & & 7 & 0.27 & $123 \%$ \\
\hline$(n=16)$ & No Increase & 3 & -0.21 & $-38 \%$ & 9 & -0.15 & $-44 \%$ \\
\hline County & Increase & 0 & & & 5 & 0.30 & $79 \%$ \\
\hline$(n=11)$ & No Increase & 2 & 0.00 & $0 \%$ & 6 & -0.18 & $-49 \%$ \\
\hline City & Increase & 0 & & & 3 & 0.37 & $106 \%$ \\
\hline$(n=3)$ & No Increase & 0 & & & 0 & & \\
\hline School District & Increase & 0 & & & 1 & 0.42 & $125 \%$ \\
\hline$(n=1)$ & No Increase & 0 & & & 0 & & \\
\hline EMS District & Increase & 0 & & & 1 & 0.50 & \\
\hline$(n=1)$ & No Increase & 0 & & & 0 & & \\
\hline $\begin{array}{l}\text { Community } \\
\text { Mental Health } \\
\text { Center }\end{array}$ & Increase & 5 & 0.26 & $125 \%$ & 12 & 0.33 & $225 \%$ \\
\hline$(n=20)$ & No Increase & 10 & -0.33 & $-54 \%$ & 8 & -0.18 & $-38 \%$ \\
\hline $\begin{array}{l}\text { Academic Health } \\
\text { Science Center }\end{array}$ & Increase & 1 & 1.00 & & 3 & 0.14 & $22 \%$ \\
\hline$(n=15)$ & No Increase & 0 & & & 12 & -0.29 & $-40 \%$ \\
\hline $\begin{array}{l}\text { Health } \\
\text { Department }\end{array}$ & Increase & 0 & & & 4 & 0.27 & $76 \%$ \\
\hline$(n=11)$ & No Increase & 2 & 0.00 & & 7 & -0.30 & $-47 \%$ \\
\hline $\begin{array}{l}\text { Physician } \\
\text { Practice }\end{array}$ & Increase & 0 & & & 5 & 0.27 & $43 \%$ \\
\hline$(n=6)$ & No Increase & 0 & & & 1 & -0.13 & $-44 \%$ \\
\hline $\begin{array}{l}\text { Community } \\
\text { Collaborative }\end{array}$ & Increase & 0 & & & 0 & & \\
\hline$(n=0)$ & No Increase & 0 & & & 0 & & \\
\hline
\end{tabular}

*The point change is the percentage point change in the measure across time periods, calculated by subtracting the value of the measure from the furthest time period from the value of the measure from the most recent time period. Due to rounding, not all numbers add precisely. **The percent change is the change in the measure in the context of the starting point, calculated by dividing the point change over the time period by the value of the measure at the starting time period, e.g. $\left(T_{2}-T_{0}\right) / T_{0}$. Due to rounding, not all numbers add precisely. When the value of the measure at the starting time period is zero, percent changes are not reported.

***Within an RHP, if there was only one organization within a particular sector, within sector results are not presented. 
Table 11. Within sector and intersectoral ties, Formal Data Sharing

\begin{tabular}{|c|c|c|c|c|c|c|c|}
\hline & \multirow[b]{2}{*}{$\begin{array}{l}\text { Change in } \\
\text { collaboration }\end{array}$} & \multicolumn{3}{|c|}{ Within Sector } & \multicolumn{3}{|c|}{ Intersectoral } \\
\hline & & $\begin{array}{l}\text { \# of } \\
\text { RHPs }\end{array}$ & $\begin{array}{c}\text { Mean } \\
\text { point } \\
\text { change* }\end{array}$ & $\begin{array}{c}\text { Mean \% } \\
\text { change* } \\
\text { * }\end{array}$ & $\begin{array}{l}\text { \# of } \\
\text { RHPs }\end{array}$ & $\begin{array}{c}\text { Mean } \\
\text { point } \\
\text { change* }\end{array}$ & $\begin{array}{l}\text { Mean \% } \\
\text { change }^{\star *}\end{array}$ \\
\hline \multirow{2}{*}{$\begin{array}{l}\text { Hospital } \\
(n=20)\end{array}$} & Increase & 11 & 0.29 & $112 \%$ & 13 & 0.23 & $320 \%$ \\
\hline & No Increase & 9 & -0.19 & $-22 \%$ & 7 & -0.11 & $-32 \%$ \\
\hline $\begin{array}{l}\text { Hospital/ } \\
\text { Health District or } \\
\text { Hospital Authority }\end{array}$ & Increase & 1 & 0.17 & $50 \%$ & 8 & 0.25 & $121 \%$ \\
\hline$(n=16)$ & No Increase & 2 & 0.00 & $0 \%$ & 8 & -0.17 & $-36 \%$ \\
\hline \multirow{2}{*}{$\begin{array}{l}\text { County } \\
(n=11)\end{array}$} & Increase & 0 & & & 6 & 0.32 & $146 \%$ \\
\hline & No Increase & 2 & -0.5 & $-100 \%$ & 5 & -0.07 & $-85 \%$ \\
\hline City & Increase & 0 & & & 2 & 0.23 & $50 \%$ \\
\hline$(n=3)$ & No Increase & 0 & & & 1 & 0.00 & \\
\hline \multirow{2}{*}{$\begin{array}{l}\text { School District } \\
(n=1)\end{array}$} & Increase & 0 & & & 1 & 0.17 & $50 \%$ \\
\hline & No Increase & 0 & & & 0 & & \\
\hline \multirow{2}{*}{$\begin{array}{l}\text { EMS District } \\
(n=1)\end{array}$} & Increase & 0 & & & 0 & & \\
\hline & No Increase & 0 & & & 1 & 0.00 & \\
\hline $\begin{array}{l}\text { Community } \\
\text { Mental Health } \\
\text { Center }\end{array}$ & Increase & 6 & 0.13 & $22 \%$ & 15 & 0.26 & $497 \%$ \\
\hline$(n=20)$ & No Increase & 9 & -0.22 & $-43 \%$ & 5 & -0.17 & $-51 \%$ \\
\hline $\begin{array}{l}\text { Academic Health } \\
\text { Science Center }\end{array}$ & Increase & 0 & & & 8 & 0.38 & $157 \%$ \\
\hline$(n=15)$ & No Increase & 1 & 0.00 & & 7 & -0.13 & $-41 \%$ \\
\hline $\begin{array}{l}\text { Health } \\
\text { Department }\end{array}$ & Increase & 1 & 0.33 & & 6 & 0.34 & $233 \%$ \\
\hline$(n=11)$ & No Increase & 1 & 0.00 & & 5 & -0.30 & $-45 \%$ \\
\hline Physician Practice & Increase & 0 & & & 1 & 0.43 & $340 \%$ \\
\hline$(n=6)$ & No Increase & 0 & & & 5 & -0.28 & $-53 \%$ \\
\hline $\begin{array}{l}\text { Community } \\
\text { Collaborative }\end{array}$ & Increase & 0 & & & 0 & & \\
\hline$(n=0)$ & No Increase & 0 & & & 0 & & \\
\hline
\end{tabular}

*The point change is the percentage point change in the measure across time periods, calculated by subtracting the value of the measure from the furthest time period from the value of the measure from the most recent time period. Due to rounding, not all numbers add precisely. **The percent change is the change in the measure in the context of the starting point, calculated by dividing the point change over the time period by the value of the measure at the starting time period, e.g. $\left(\mathrm{T}_{2}-\mathrm{T}_{0}\right) / \mathrm{T}_{0}$. Due to rounding, not all numbers add precisely. When the value of the measure at the starting time period is zero, percent changes are not reported.

***Within an RHP, if there was only one organization within a particular sector, within sector results are not presented. 
Overall, where collaboration is observed, we primarily see a decrease or no change for within sector collaboration across all tie types. The majority of RHPs in the all collaboration tie type, saw a decrease or no change in within-sector collaboration (range: $-33 \%$ to $0 \%$ ) and an increase in intersectoral collaboration (range: $27 \%$ to $1051 \%$ ).

Within-sector and intersectoral collaboration decreased for most RHPs in the joint program/service delivery tie type. The majority of RHPs collaborating to share tangible resources saw a decrease or no change in within-sector collaboration. We see variation in changes to intersectoral collaboration for the tangible resource sharing tie type, where some RHPs see an increase in intersectoral collaboration and some a decrease or no change. Several RHPs in the formal data sharing tie type saw a decrease or no change in within-sector collaboration (range: $-100 \%$ to $0 \%$ ) and an increase in intersectoral collaboration (range: $50 \%$ to $497 \%$ ). Our hypothesis was partially supported in that increases in intersectoral collaboration across RHPs; however, there is variation in intersectoral connections by tie type. A closer examination of tie type by sector illustrates variations in within-sector and intersectoral connections.

\section{All Collaboration}

For the all collaboration tie type, intersectoral collaboration increased for all sectors but CMHCs (17 RHPs saw no increase, mean percent change: -29\%). From a within-sector perspective, CMHCs across the state are inherently connected to one another. Although their service regions are purposefully distinct, regional networks exist, and a statewide database that houses all client data ensures availability of current information on clients regardless of their movement between regions. As such, it makes sense that CMHCs saw decreases or no changes in within-sector collaboration because 
there was already a high level of connection. School districts and EMS districts

experienced, on average, very large increases in intersectoral collaboration. These percent changes may be superficially high due to the fact that there was only one school district and one EMS district across all RHPs.

\section{Joint Program/Service Delivery}

Interestingly, although joint program/service delivery was the most frequently reported type of tie, we see that these ties were not as persistent and seemed to serve a temporary purpose, disappearing over time. In fact, where within-sector and intersectoral collaboration was observed, the majority of RHPs reported decreases or no changes for this particular type of tie (range for mean percent changes: $-17 \%$ to $0 \%$ ). Intersectoral collaboration for health departments was unusually high compared to the other sectors within one RHP, potentially indicating a preliminary shift of understanding about the importance of and need for service integration efforts inclusive of population health activities (range for mean percent change: 155\%).

\section{Tangible Resource Sharing}

Hospital/health districts, counties, academic health science centers, and health departments all had a higher number of RHPs reporting a decrease or no change in intersectoral collaboration for tangible resource sharing (range for mean percent changes: $-49 \%$ to $-40 \%$ ). With that said, those RHPs that indicated increases in intersectoral collaboration for tangible resource sharing reported significant increases (range for mean percent changes: $22 \%$ to $123 \%$ ). This suggests that resource sharing ties across sectors within some RHPs allowed organizations to sustain partnerships for integrated service delivery. For hospitals, there were an equal number of RHPs reporting 
increases and decreases/no changes in collaboration to share tangible resources. The mean percent change for CMHCs appeared to be most striking for increased intersectoral collaboration around tangible resource sharing as compared to the other sectors (mean percent change: $225 \%$ ). This suggests that intersectoral collaboration to share resources improved drastically for CMHCs between $\mathrm{T}_{0}$ and $\mathrm{T}_{2}$.

\section{Formal Data Sharing}

The data indicate increased within-sector and intersectoral collaboration as it relates to formal data sharing among hospitals, hospital/health districts, and CMHCs (range of percent changes for within-sector collaboration: $22 \%$ to $112 \%$; range of percent changes for intersectoral collaboration: $121 \%$ to $497 \%$ ). Additionally, an equal number of RHPs reported an increase and a decrease/no change in collaboration where collaboration to share data was occurring among health departments. We observe that the EMS district and physician practice sectors had a higher number of RHPs reporting decreases or no changes in formal data sharing ties; however, the RHP with a physician practice reporting increased intersectoral connections indicated substantial increases (mean percent change: $340 \%)$. For hospital/health district, there were an equal number of RHPs reporting increases and decreases/no changes in collaboration to share data, but the increase in intersectoral collaboration is substantial (mean percent change: 121\%). Interestingly, the mean percent change for $\mathrm{CMHCs}^{\prime}$ intersectoral collaborations around data sharing as compared to the other sectors (mean percent change: 497\%) increased substantially. This suggests that $\mathrm{CMHCs}$ are sharing data with other types of organizations for care coordination and continuity, a particular goal of the Waiver. We also see within-sector 
data sharing increased for CMHCs, highlighting the fact that CMHCs are inherently connected through the state and their collective data system.

We also find that there is an increase in collaboration among organizations that traditionally would not be considered part of the health service delivery system, such as local governments (cities, counties) and municipal districts (school districts) as new collaborators within DSRIP, particularly as it relates to formal data sharing.

Network diagrams help visualize the evolution of within-sector and intersectoral collaboration over time (Creel, Wendel, \& Ali, 2016). For this study, network diagrams for RHP 15 are used to illustrate how some organizations gained more collaborative partners than others. Figures 1 and 2 present network diagrams for the all collaboration tie type. Organizations within each network are coded by shape and color (see legend). We see that there are more ties, shown by lines connecting organizations, present at $\mathrm{T}_{2}$ than $\mathrm{T}_{0}$. As it relates to intersectoral collaboration, we see that a hospital (right corner) that was otherwise unconnected to other types of organizations during $T_{0}$ forms relationships with an academic health science center and a health department by $\mathrm{T}_{2}$. We also observe a great deal of within-sector collaboration among hospitals for this particular tie type.

Figures 3 and 4 include network diagrams to capture changes in intersectoral collaboration to share tangible resources. The number of ties from $\mathrm{T}_{0}$ to $\mathrm{T}_{2}$ decreases significantly where many of the resource sharing ties are no longer present at $\mathrm{T}_{2}$. For example, the academic health science center went from sharing tangible resources with all but one organization in $\mathrm{T}_{0}$ to almost half of that amount in $\mathrm{T}_{2}\left(\mathrm{~T}_{0}: 6\right.$ ties, $\mathrm{T}_{2}: 3$ ties). The academic health science center also experience a decrease in intersectoral 
collaboration to share tangible resources from $\mathrm{T}_{0}$ to $\mathrm{T}_{2}$, where it is no longer working with the CMHC to share resources by $\mathrm{T}_{2}$. From $\mathrm{T}_{0}$ to $\mathrm{T}_{2}$, health departments also experienced a decrease in intersectoral collaboration since they are no longer collaborating with hospitals to share resources at $\mathrm{T}_{2}$.

Figures 5 and 6 present network diagrams for the formal data sharing connections. There are more formal data sharing agreements between organizations from $\mathrm{T}_{0}$ to $\mathrm{T}_{2}$. Health departments, CMHCs, and hospitals are all collaborating with at least one organization in another sector by $\mathrm{T}_{2}$, which reflects the results presented in table 5 on intersectoral connections by tie type and sector. 


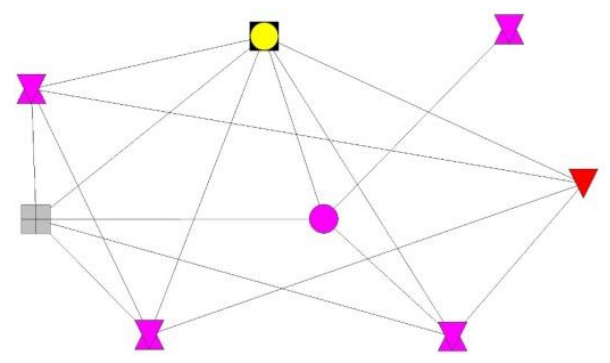

Figure 1. Network Diagram To, RHP 15, All Collaboration

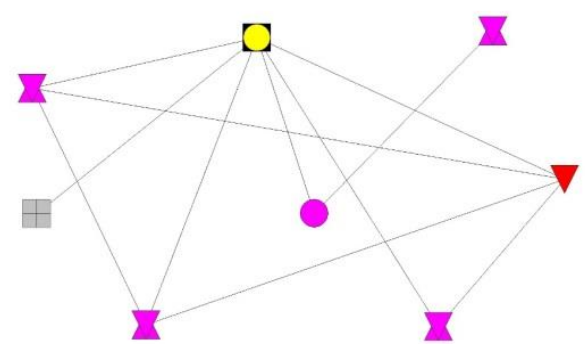

Figure 3. Network Diagram $T_{0}$, RHP 15, Tangible Resource Sharing

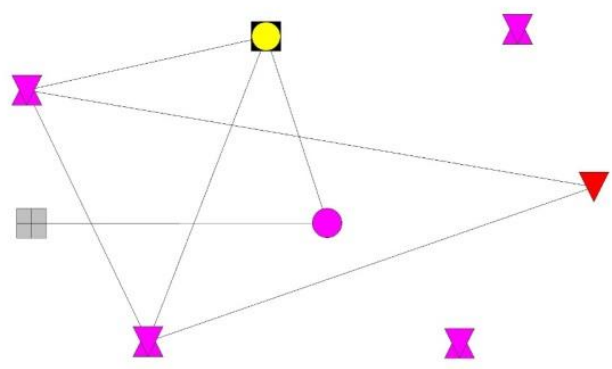

Figure 5. Network Diagram $T_{0}$, RHP 15, Formal Data Sharing Agreements

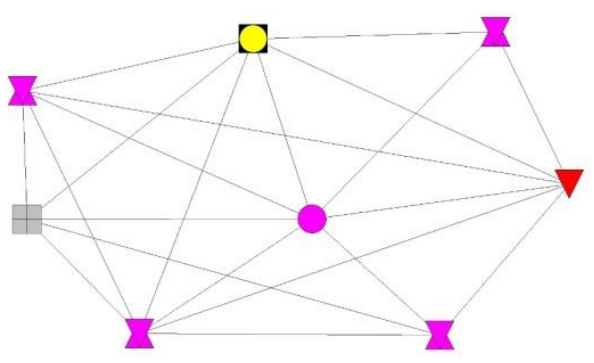

Figure 2. Network Diagram T2, RHP 15, All Collaboration

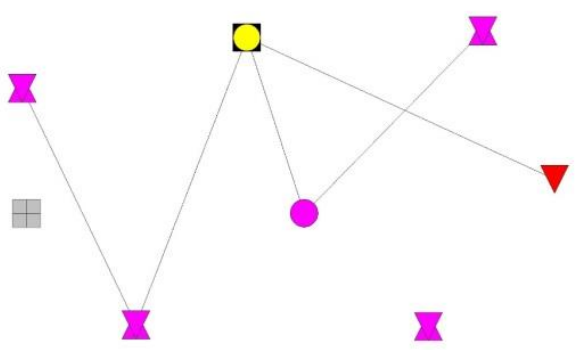

Figure 4. Network Diagram $T_{2}$, RHP 15, Tangible Resource Sharing

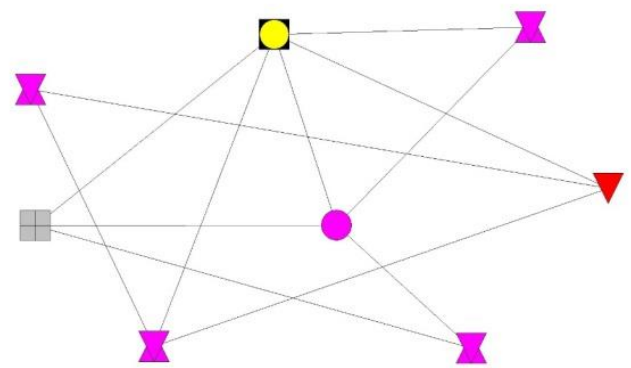

Figure 6. Network Diagram $T_{2}$, RHP 15, Formal Data Sharing Agreements

$$
\begin{array}{|l}
\hline \text { Organization Role in RHP (shape) } \\
\text { Anchor } \\
\square \text { IGT only } \\
\triangle \text { IGT + Performing Provider (Hospital) } \\
\text { IGT + Performing Provider (CMHC) } \\
\nabla \text { IGT + Performing Provider (Health Department) } \\
\text { DIGT + Performing Provider (HSC) } \\
\text { IGT + Performing Provider (Health District) } \\
\square \text { Performing Provider only } \\
\text { Organization Trpe (color) } \\
\text { Hospital } \\
\text { Hospital / Health District or Hospital Authority } \\
\text { County Government } \\
\text { City Government } \\
\text { School District } \\
\text { EMS District } \\
\text { CMHC } \\
\text { Health Science Center } \\
\text { Health Department } \\
\text { Physician Practice } \\
\text { Health District \& Hospital Partnership }
\end{array}
$$




\section{Discussion}

This study was intended to examine the extent to which the Waiver promoted intersectoral collaboration among organizations participating in DSRIP over time. The data indicate an overall decrease or no change in within-sector collaboration as it relates to joint program/service delivery, tangible resource sharing, and formal data sharing. However, there were increases in intersectoral collaboration for tangible resource sharing and formal data sharing as compared to joint program/service delivery, where a consistent decrease in intersectoral collaboration for all sectors was observed.

The most noticeable improvements in intersectoral collaboration were around formal data sharing, likely because this type of relationship was the least likely to be reported, and the percent change was sensitive to small numbers. Data sharing might include formal agreements to transfer patient information electronically, joint participation in a regional health information exchange, or sharing the same electronic medical record system within health systems. As such, an increase in formal data sharing ties for intersectoral collaboration may be attributed to a few key factors. Formal data sharing was low within all regions prior to the establishment of the RHPs, which provided room for growth. The nature of DSRIP projects either necessitated or encouraged data sharing among members to ensure coordination and continuity of services between organizations. In fact, data sharing enabled organizations to efficiently coordinate activities when serving the same population to reduce duplication of specific services. Several RHPs leveraged the opportunity of having resources available through DSRIP projects to develop local or regional health information exchanges, which has implications for improving the coordination and quality of care for consumers of the 
health care system. In fact, Foster-Fishman and colleagues (2001) suggest that intersectoral ties may indicate a higher likelihood of service integration, which can combat issues of fragmentation in health care delivery.

Additionally, increases in intersectoral collaboration around resource and data sharing were most noticeable for hospitals and CMHCs. There may be a few reasons for these findings. First, each RHP has at least one hospital and one CMHC, the only two types of organizations that can be found in every RHP. Second, CMHCs were allotted at least 10 percent of the total available funds in each RHP under DSRIP. This is important to recognize because these funds purposefully expanded development of and access to quality behavioral health care services. The available resources increased opportunities for CMHCs to partner with organizations across sectors to address the behavioral health and other needs of the low-income or underserved populations. In fact, CMHCs often partnered with hospitals on projects focused on integrated primary and behavioral health care, and they partnered with other organizations for additional crisis intervention response and the establishment of campuses for children with emotional problems and developmental delays (HHSC, 2014). Presumably, many of these efforts necessitate resource and data sharing to ensure that the goals of coordination and continuity for integrated service delivery are realized.

Although joint program/service delivery ties were the most frequent type of relationship observed among organizations, they did not appear to be persistent and dissolved fairly quickly compared to some of the other tie types. Several factors can explain this finding. First, when DSRIP was initiated, it incentivized early experimentation and enthusiasm about collaboration within RHPs. Second, at the onset of 
the Waiver, there were many collaborations linked to organizations getting their DSRIP projects to be fully operational. Over time, however, the pressure of meeting metrics and responding to required monitoring reduced the capacity and resources available for collaboration and organizations likely recalibrated their efforts to focus on meeting their metrics in order to receive payments. As such, the projects that ultimately survived were likely those that organizations implemented primarily on their own. Finally, performing providers also eligible to offer IGT funds did not have to collaborate because they could put up IGT for their own projects.

This study has several limitations. First, many of the surveys were completed by a single representative at each organization. While all attempts were made to identify an appropriate respondent who would have knowledge of the relationships asked about in the survey, it is unreasonable to expect that one individual alone would be knowledgeable about all the collaborative activities occurring throughout and across an organizationespecially for the larger organizations. Additionally, respondents changed for the second round of data collection for some organizations. Differences in organizational knowledge between executives who responded $T_{0} / T_{1}$ versus project managers at $T_{2}$, likely affected the nature of the relationships reported.

Finally, a 100 percent response rate is ideal for network analysis in order to confirm relationships and assess directionality within a relationship. We observed missing data in almost all RHPs, but relied on a common approach in network analysis, data symmetrization, as a technique to mitigate the effects of missing data (Borgatti et al., 2013). Additionally, the lower response rate for $T_{2}$ data collection could artificially 
indicate a decrease in outcome measures in some RHPs where relationships did not end but, rather, were not reported.

Despite these limitations, this study contributes several important findings to the literature. Organizations that are responsible for delivering health care often operate in silos, jeopardizing the quality of care individuals receive and perpetuating systemic inefficiencies within an existing fragmented system. This approach seldom addresses the complex health needs of low-income, underserved populations and fails to meet the quality and cost demands of health service delivery reform. In terms of health coverage, Texas continues to struggle with the highest uninsured population (16\% compared to a national average of $9 \%$ ). As such, the burden of caring for the low-income and uninsured falls primarily on hospitals. Hospitals alone cannot deliver the range of services such populations may seek out on the continuum of care.

Historically, CMHCs and public health agencies have been peripheral to health service delivery, often unrecognized in their roles within health system transformation. The Waiver presented a unique opportunity for organizations across sectors, including those who have otherwise been excluded, to participate in service integration. In doing so, HHSC rightfully acknowledged that CMHCs and public health agencies are critical to achieving the Triple Aim strategies. This study indicates increased intersectoral collaboration between hospitals, CMHCs, and health departments among others for tangible resource sharing and formal data sharing ties over time. This is promising in that organizations across sectors are forming more formal types of ties to integrate services and potentially sustain those services over time in combatting fragmentation and promoting coordination of services. While the Waiver fostered intersectoral collaboration 
between organizations, future policies must consider including and structurally designing incentives for other key players that have traditionally been peripheral to the system, but are integral to transforming the health care delivery system. 


\section{CHAPTER VI \\ IDENTIFYING AND EXPLICATING PARTNERSHIPS WITH KEY \\ COLLABORATORS BEYOND ESTABLISHED NETWORKS THROUGH THE TEXAS MEDICAID 1115 TRANSFORMATION WAIVER}

\section{Introduction}

In the United States (US), efforts to improve health have traditionally been dependent on the health care system (Heiman, \& Artiga, 2015). US health care spending totaled approximately \$3.2 trillion in 2015 (Centers for Medicare and Medicaid Services [CMS], 2015). Some of the primary drivers of health care costs include an aging population, an increase in prevalence of chronic illness, for-profit health insurance, technology, pharmaceuticals, and consumer demand (Mack, 2016). Despite high health care spending, deficiencies in access to care, health system quality, and equity continue to persist (Davis, Stremikis, Squires, \& Schoen, 2014). Life expectancy is one of the most universally accepted indicators of health status. The National Research Council, Committee on Population (2013) found that the US has one of the lowest life expectancies compared to other industrialized countries.

Additionally, the absence of universal health insurance coverage differentiates the US from many other industrialized countries (Davis et al., 2014). Some of the most prominent features of a universal coverage system include elements such as acknowledgment of the idea that health care is a fundamental right of individuals 
(inclusion of everyone), investment in social service provision, public financing, public accountability, and public stewardship (World Health Organization [WHO], 2012). What makes these systems incredibly effective is their ability to achieve the Triple Aim strategies of increasing access to care, improving quality of care and reducing costs of care while limiting the profitability of health care (The Institute for Healthcare Improvement, 2009; WHO, 2012).

The Patient Protection and Affordable Care Act (ACA) allowed millions of Americans to access health care while providing opportunities to transform the existing health care delivery system in ways that improve health (Obama, 2016). In fact, "the number of uninsured individuals in the United Sates has declined from 49 million in 2010 to 29 million in 2015" (Obama, 2016, p. 527). Despite these efforts, however, concerns related to access and cost of care as well as health equity remain. In fact, a study aimed at examining how the US health care system compares to other countries suggests that the US ranks last among 11 other industrialized countries on indicators of efficiency, equity, healthy lives, and cost-related problems as it relates to access (Davis et al., 2014). Improving population health requires a comprehensive approach contingent on addressing the social, economic, and environmental factors that impact health (Heiman, \& Artiga, 2015). Systems are starting to recognize the importance of the social determinants of health in conceptualizing health more broadly. As health care delivery systems reflect on this shift, particularly as it relates to low-income, underserved populations, initiatives are emerging at multiple levels to integrate social determinants into the health care system (Heiman, \& Artiga, 2015). In order to understand the value of 
such integration, it is essential to understand the diverse and complex needs of lowincome, underserved populations.

There are various challenges that low-income populations face on a daily basis, many relating to structural barriers in society (Hastings, Taylor, \& Austin, 2006), such as:

- Persistence of poverty or near-poverty;

- Lack of education;

- Chronic health problems;

- Limited access to social services; and

- Unmet needs for food, clothing, shelter, health care, and other basic goods.

As a result of our nation's deteriorating social safety net, low-income populations are often tasked with an enormous burden to choose between fundamental needs, such as food and health care (Davis, 2015; Hastings et al., 2006). As such, it may be worthwhile to consider the ways in which health care delivery systems and social service organizations can maximize their efficiencies by integrating or at least coordinating services for low-income, underserved populations.

The Organisation for Economic Co-operation and Development (OECD) provides evidence suggesting social services significantly improve population health outcomes and reduce costs of health care (Davis, 2015). In many ways, social services ensure that individuals have their fundamental needs met, which contributes to health improvement. The US lags behind other countries as it relates to investment in social services, such as access to adequate nutrition, shelter, and income (Davis, 2015). Thus, the burden often falls on hospitals to make such investments for uninsured, indigent populations since many low-income clients enter the health care delivery system with complex needs requiring extensive and extended care. This eventually translates to increased costs for hospitals and society as a whole (Davis, 2015). One way of overcoming these challenges 
is to promote collaboration across organizations and entities that can connect such

populations to the appropriate services, both health and otherwise, in a timely manner.

Collaborative partnerships provide an opportunity to conserve capital and make

effective use of limited resources. In general terms, to collaborate with others is to work with them in achieving some type of shared goal or objective (Mitchell, 2008).

Collaboration is also often mutually beneficial and well-defined by those engaged

(Mitchell, 2008). What makes collaboration important is that it plays a key role in

meeting community-wide goals, particularly as it relates to meeting fundamental and

complex needs. The National Association of County and City Health Officials

(NACCHO) (2017) suggests several benefits of collaboration:

- Cost and effort are not duplicated;

- Fragmentation among services, programs, and initiatives is reduced;

- High-quality, more integrated outcomes for end users;

- Integration of diverse perspectives among agencies;

- Improved communication among agencies;

- Increased trust and understanding among individuals and organizations;

- Potential for organizational and individual learning; and

- Better ability to achieve key outcomes (para. 5).

Equipped with preliminary knowledge about the benefits of collaboration, it is

worthwhile to explore the contexts in which there is potential for collaboration to occur.

The 1115 Medicaid Transformation Waiver provides such an opportunity.

In 2011, the Centers for Medicare and Medicaid Services (CMS) approved Texas for a five-year Medicaid waiver demonstration project, also referred to as the Healthcare Transformation and Quality Improvement Program (Waiver). Section 1115 waivers have traditionally been used to test and implement coverage approaches outside the scope of existing federal program rules (CMS, 2013). One of the fundamental goals of the Waiver was to transform health care delivery systems through collaboration and integration of 
services in ways that address the Triple Aim strategy of increasing access to care, improving quality of care, and reducing costs of care (Gates, Rudowitz, \& Guyer, 2014; Texas Health and Human Services [HHSC], n.d.). The Waiver focused on three primary aspects: expansion of Medicaid managed care, redesign of the uncompensated care reimbursement structure, and transformation of the health care delivery system through the Delivery System Reform Incentive Payment (DSRIP) Program. This study focuses on organizations that participated in DSRIP.

DSRIP provided financial support to service providers for successfully implementing CMS-approved projects focused on achieving the Triple Aim strategies (Gates et al., 2014; Institute for Healthcare Improvement, 2009). The state chose to implement DSRIP through the creation of 20 Regional Healthcare Partnerships (RHPs), which served as a mechanism to plan, implement, and monitor DSRIP efforts (HHSC, n.d.) RHPs varied in size and composition, but all included an anchor institution (administratively responsible for coordination), participating intergovernmental transfer (IGT) entities (responsible for providing local match to draw down federal funds), and performing providers. Since CMS and HHSC required the formation of RHPs with financial incentives at stake for participating organizations, RHPs could be characterized as mandated partnerships. However, organizations were not required to participate in an RHP; participation was voluntary (HHSC, n.d.).

A unique feature in Texas' waiver was expansion of the pool of providers who could participate in DSRIP to include public/private hospitals, community mental health centers, counties, and public health departments among other organizations. A key aspect of eligibility was the ability to either bill Medicaid (e.g. hospital) or offer money for 
Medicaid match (e.g. county) (HHSC, n.d.). Those who provided the local match through intergovernmental transfer of city or county tax dollars allowed performing providers to draw down DSRIP federal funds based on their achieving certain outcomes or milestones (HHSC, n.d.). While these networks were intended to promote intersectoral collaboration among a diverse pool of participating organizations, it is important to examine the extent to which these networks were comprehensive in ways that contribute to achieving the Triple Aim strategies.

By expanding eligibility for participating organizations, the Waiver provided a unique opportunity to promote intersectoral collaboration among organizations tasked with the responsibility of providing key health services on the continuum of care. This network of participating organizations, however, does not comprise the full network of organizations that are necessary for serving low-income, high need populations. The purpose of this study is to explore collaborations that DSRIP providers perceived as critical with community-based partners not eligible to participate in DSRIP.

\section{Methods}

In terms of the methodology, the data used for this study were collected as part of an evaluation of Texas' Waiver that was conducted by Texas A\&M University, the University of Texas, and the University of Louisville under contract by the Texas Health and Human Services Commission (HHSC). As such, it is used as secondary data for this research.

Since each RHP represents a distinct network through which collaboration was assumed to be occurring, an interorganizational network survey was used to capture each participating organization's relationship(s) with each of the other participating 
organizations in the defined network (Provan, Fish, and Sydow 2007). A nonrandomized, pre-post interorganizational network study design was initially used to assess collaboration within each RHP, where data were collected during three time periods:

1. Twelve (12) months prior to the creation of the RHPs, Calendar year $2011\left(\mathrm{~T}_{0}\right)$

2. Demonstration Year 2 of the Waiver, Calendar year $2013\left(\mathrm{~T}_{1}\right)$; and

3. Demonstration Year 4 of the Waiver, Calendar year $2015\left(\mathrm{~T}_{2}\right)$

Network data for $\mathrm{T}_{0}$ were collected in the same survey immediately after $\mathrm{T}_{1}$ data was gathered. Data for $\mathrm{T}_{2}$ were collected between January and mid-July of 2016. During the $T_{0 /} T_{1}$ data collection phase, however, participants expressed concern about not being asked to report on relationships with community-based partners who are not formal participants in the RHP (e.g. those organizations excluded from the sampling frame). This was identified as a gap during data collection since several participants reported working closely with other non-member organizations on DSRIP-related activities. Including these non-member organizations in the sampling frame for each RHP was impossible given the vast number of other organizations that could exist.

In an attempt to address and accommodate participant feedback from the $\mathrm{T}_{0 /} \mathrm{T}_{1}$ data collection phase, the $\mathrm{T}_{2}$ survey included a new question about other organizational partners. Respondents were asked to list up to three other organizations with whom they worked the most on activities to target the underserved population in their community. For each new organization listed, the survey included the same yes/no questions about types of ties that were asked about RHP member organizations. Table 12 provides the key measures relevant to this study. Open-ended, qualitative questions were added as a follow up to each quantitative question to contextualize the nature of relationships. This 
study focuses exclusively on data obtained from this $\mathrm{T}_{2}$ cross-sectional measure. As such, a non-randomized, cross-sectional study design was used to evaluate collaboration between RHP members and other organizational partners.

\section{Table 12. Survey Measures}

\begin{tabular}{|c|c|}
\hline Construct & $\mathrm{T}_{2}(2015)$ Measures \\
\hline Additional Organizations & $\begin{array}{l}\text { "Other than the organizations I have asked you about, can you tell me the } \\
\text { names of up to } 3 \text { other organizations with which you work the most on activities } \\
\text { that target improved access or services for the underserved?" }\end{array}$ \\
\hline Joint Service Delivery & $\begin{array}{l}\text { "Does your organization currently collaborate with [x organization] to deliver } \\
\text { services?" }\end{array}$ \\
\hline Resource Sharing & $\begin{array}{l}\text { "Does your organization currently share tangible resources with [x } \\
\text { organization] for the purpose of increasing access to services?" }\end{array}$ \\
\hline Data Sharing & $\begin{array}{l}\text { "Does your organization currently have a data sharing agreement with [x } \\
\text { organization]?" }\end{array}$ \\
\hline
\end{tabular}

This study uses a primarily qualitative research design to explore and analyze the relationships DSRIP providers perceived as critical with community-based partners who are not eligible to participate in DSRIP.

As responses were examined within this study, an inductive approach was used to identify conceptual categories that capture the relevance and nature of critical relationships as they emerge from the data. Additionally, descriptive statistics were calculated at the RHP- and state-wide level to describe the composition of the sample and characterize the frequency with which the three major types of relationships between RHP-member organizations and other community-based organizations occurred. This information also helps contextualize themes that emerged through qualitative data analysis. Content analysis was conducted using an iterative thematic approach to coding in order to identify key themes that help to provide contextual information about the nature of relationships pursued by RHP member organizations. Themes were compared 
within and across cases, paying particular attention to deviant cases and possible reasons for differences.

With respect to the nature of the data, responses were not audio-recorded and thus not transcribed verbatim; however, interviewers documented interview responses within the survey. Qualitative responses were then extracted from the survey, color-coded by the type of DSRIP organization, and sorted by the type of community-based partner.

Responses were generally brief and focused on a specific type of tie. Each response was treated as a segment of text and included the type of relationship (e.g. joint program/service delivery, tangible resource sharing, and formal data sharing), the nature of that relationship (the content of the response), and the RHP number of the organization reporting the relationship. Since part of the research question strives to understand which community-based partners were critical for DSRIP collaboration, three tables were created to map out the type of community-based partners with whom DSRIP providers are working with to deliver joint programs/services, share tangible resources, and share data. Based on those tables, certain relationships between particular DSRIP providers and community-based partners were selected for closer examination.

Data about each relationship were coded in two phases: initial and focused coding. Initial/line-by-line coding was used to characterize the nature of each relationship by tie type, specifically focused on capturing the various types of program/service delivery, resource, and data sharing relationships providers shared with particular community-based partners (e.g. patient referrals, shared staff, memorandum of understanding). Focused coding allowed for the grouping of codes into broader categories. Analytic and methodological memos were maintained to continuously 
document thoughts, experiences, questions, and observations throughout the data collection and analysis process.

Two members of the research team performed the initial sorting of responses by the type of community-based partner reported. A third researcher joined in the coding process for initial and focused coding. Co-analysis provided a mechanism for recognizing the role of personal perspectives and addressing discrepancies until mutual agreement in an attempt to reduce the effect of potential bias on the interpretation of the results.

Credibility of the process was maintained by prolonged engagement, peer debriefing, and deviant case analysis, which can help to both build and improve rigor (Charmaz, 2014; Creswell, 2013).

\section{Results}

A total of 534 additional organizations were reported as key community-based partners. These partners included non-profit and social service organizations, hospitals either not participating in DSRIP or not in the same RHP, health clinics, law enforcement and criminal justice agencies, behavioral health organizations, federally qualified health centers, county and city governments, school districts, faith-based organizations, health departments, private practice physicians, academic institutions, and other organizations. A number of DSRIP-participating organizations reported partners that did not fit into existing categories of community-based organizations; therefore, they were grouped into a category of "other organizations. Table 13 presents a list of community-based partners with whom RHP members reported collaborating with for DSRIP activities. Non-profit and social service organizations as well as hospitals are among the most frequently 
reported community-based partners, while private practices and academic institutions are among the least reported partners by DSRIP participating organizations.

Table 14 presents characteristics of collaboration with community-based partners. On average, respondents reported at least two community-based partners with whom they work (range: 1.4 to 3), and the majority of those ties were around joint program/service delivery (88\%). Compared to joint program/service delivery, collaboration to share tangible resources and formally share data were not as frequent (resource sharing: 52\% and data sharing: 47\%).

Average tie strengths refers to the strength of relationships between DSRIPparticipating organizations and their community-based partners. In this study, average tie strength was assessed by aggregating the three types of ties (collaboration to deliver joint programs and services, sharing tangible resources, and formal data sharing agreements), ranging between one and three. Organizations that share more than one type of tie are considered to have more complex collaborative partnerships. Statewide, the mean strength of ties between DSRIP participating organizations and their community-based partners was 1.6, ranging from a low of 1.2 in RHP 4 to a high of 2.6 in RHPs 14 and 15 . A closer examination of collaboration by community-based partner provides additional information about the types of organizations DSRIP participating organizations are working with most frequently. 


\section{Table 13. Other Organizational Partners Reported by DSRIP Participants}

\begin{tabular}{|l|c|}
\hline Categories & \# Reported \\
\hline Non-profit/Social Services Organization & 94 \\
\hline Hospital & 90 \\
\hline Health Clinic & 46 \\
\hline Law Enforcement/Criminal Justice & 48 \\
\hline Behavioral Health Organization & 41 \\
\hline Federally Qualified Health Center (FQHC) & 28 \\
\hline County/Municipality & 25 \\
\hline School District & 23 \\
\hline Faith-Based Organization & 11 \\
\hline Health Department & 11 \\
\hline Private Practice & 6 \\
\hline Academic Institution & \\
\hline $\begin{array}{l}\text { Other (e.g. Pharmacy, home healthcare agencies, } \\
\text { community health workers, nutrition centers, local nursing } \\
\text { homes, community coalitions/collaboratives, Mexican } \\
\text { consulate, prescription assistance programs, ambulance } \\
\text { transportation services, imaging services for diagnostic } \\
\text { work, cities, other RHP, dental clinic, prenatal clinic, } \\
\text { consulting group) }\end{array}$ & 52 \\
\hline
\end{tabular}


Table 14. Characteristics of Collaboration with Other Organizational Partners by RHP

\begin{tabular}{|c|c|c|c|c|c|c|}
\hline & $\begin{array}{c}\text { Total \# of } \\
\text { Other } \\
\text { Organizations } \\
\text { Reported }\end{array}$ & $\begin{array}{l}\text { Average \# of } \\
\text { Other } \\
\text { Organizations } \\
\text { Reported }\end{array}$ & $\begin{array}{c}\text { Other } \\
\text { Organization } \\
\text { Program and } \\
\text { Service Delivery } \\
\text { Collaborations }\end{array}$ & $\begin{array}{c}\text { Other } \\
\text { Organization } \\
\text { Tangible } \\
\text { Resource } \\
\text { Sharing } \\
\text { Collaborations* }\end{array}$ & $\begin{array}{c}\text { Other } \\
\text { Organization } \\
\text { Formal Data } \\
\text { Sharing } \\
\text { Collaborations* }\end{array}$ & $\begin{array}{c}\text { Average } \\
\text { Tie } \\
\text { Strength }\end{array}$ \\
\hline RHP 1 & 44 & 2.6 & $98 \%$ & $55 \%$ & $45 \%$ & 1.5 \\
\hline RHP 2 & 18 & 2.6 & $94 \%$ & $67 \%$ & $61 \%$ & 1.4 \\
\hline RHP 3 & 60 & 2.7 & $93 \%$ & $40 \%$ & $32 \%$ & 1.8 \\
\hline RHP 4 & 15 & 1.9 & $100 \%$ & $80 \%$ & $73 \%$ & 1.2 \\
\hline RHP 5 & 11 & 2.8 & $100 \%$ & $27 \%$ & $45 \%$ & 1.7 \\
\hline RHP 6 & 49 & 2.7 & $57 \%$ & $41 \%$ & $63 \%$ & 1.9 \\
\hline RHP 7 & 20 & 2.5 & $100 \%$ & $75 \%$ & $65 \%$ & 1.3 \\
\hline RHP 8 & 30 & 2.7 & $93 \%$ & $47 \%$ & $43 \%$ & 1.6 \\
\hline RHP 9 & 44 & 2.2 & $100 \%$ & $70 \%$ & $50 \%$ & 1.4 \\
\hline RHP 10 & 33 & 1.7 & $100 \%$ & $58 \%$ & $33 \%$ & 1.6 \\
\hline RHP 11 & 15 & 1.5 & $100 \%$ & $53 \%$ & $40 \%$ & 1.6 \\
\hline RHP 12 & 38 & 2.0 & $100 \%$ & $68 \%$ & $34 \%$ & 1.5 \\
\hline RHP 13 & 38 & 2.5 & $50 \%$ & $29 \%$ & $63 \%$ & 2.1 \\
\hline RHP 14 & 17 & 2.1 & $24 \%$ & $35 \%$ & $59 \%$ & 2.6 \\
\hline RHP 15 & 17 & 2.4 & $71 \%$ & $12 \%$ & $35 \%$ & 2.6 \\
\hline RHP 16 & 12 & 1.4 & $92 \%$ & $58 \%$ & $17 \%$ & 1.8 \\
\hline RHP 17 & 31 & 2.4 & $97 \%$ & $55 \%$ & $45 \%$ & 1.5 \\
\hline RHP 18 & 12 & 2.4 & $100 \%$ & $42 \%$ & $50 \%$ & 1.6 \\
\hline RHP 19 & 15 & 2.1 & $100 \%$ & $87 \%$ & $33 \%$ & 1.4 \\
\hline RHP 20 & 15 & 3.0 & $100 \%$ & $33 \%$ & $53 \%$ & 1.6 \\
\hline $\begin{array}{l}\text { State- } \\
\text { wide }\end{array}$ & 534 & 2.3 & $88 \%$ & $52 \%$ & $47 \%$ & 1.6 \\
\hline
\end{tabular}

*Because organizations can have more than one type of tie, percentages do not add to 100 .

Tables 15 through 17 present DSRIP participating organizations that are working with different community-based partners for each type of tie. Overall, we see that distribution of collaboration with community-based partners by tie type varies for the different types of DSRIP participating organizations. Among the DSRIP participating organizations, hospitals and community mental health centers (CMHCs) appear to be 
collaborating with almost all of the different types of community-based partners, particularly to deliver programs/services.

Hospitals are working with all types of community-based partners for program/service delivery and tangible resource sharing; however, they are sharing data with all community-based partners but school districts and health departments. CMHCs are working with all organizations but academic institutions for program/service delivery, and all organizations but faith-based organizations, academic institutions, and other organizations for tangible resource sharing. With respect to data sharing, CMHCs report working with all organizations but faith-based organizations, private practices, and academic institutions. Among the different types of DSRIP participating organizations, we notice that physician practices, school districts, community collaborative, and cities are working with only certain types of community-based partners, such as non-profit and social service organizations and FQHCs.

Based on Tables 15 through 17, specific relationships warrant additional in-depth exploration across the different tie types. Since hospitals and CMHCs most frequently reported working with the different community-based partners, our analysis focuses on specific ties these organizations share with two community-based organizations. In terms of identifying the most appropriate community-based partners to focus on for the qualitative analysis, we found that non-profit and social services organizations are the most prominent community-based partners. Additionally, one of the more interesting and unexpected collaborations observed through this study was the relationship DSRIP participating organizations reported with law enforcement/criminal justice. This relationship with law enforcement/criminal justice emerged several times across 
organizations within RHPs. Compared to the other community-based partners identified through this study, we found that law enforcement/criminal justice did not fall in the typical health care realm much like the others. Therefore, we chose to examine both nonprofit/social service organizations as an example of organizations we expected to find in the survey and law enforcement/criminal justice organizations as examples of organizations that were unexpected in terms of collaboration. As such, we focused on exploring the following relationships in-depth across all tie types: non-profit/social service-hospital, non-profit/social service-CMHC, law enforcement/criminal justicehospital, and law enforcement/criminal justice-FQHC.

\section{Program/Service Delivery}

CMHCs collaborated with non-profit organizations for referrals to health providers and the provision of clinical services. However, hospitals reported collaborating with non-profit organizations more extensively to provide a range of different programs and services, including preventive, disease management, social, clinical, and navigation services. In characterizing the nature of a frequent type of collaboration between hospitals and non-profit and social service organizations, one organization reported referring many of their charity and indigent clients for assistance with utilities and transportation to and from appointments to non-profit and social service organizations. Another hospital again characterized the importance of social services in meeting health needs by emphasizing that they worked with non-profit and social service organizations to allow their chronic disease patients to access healthy foods. Additionally, some hospitals reported providing financial support to sustain ongoing activities and initiatives at non-profit and social service organizations. 
Overall, hospitals and CMHCs frequently reported working with law enforcement/criminal justice organizations to conduct screenings for jail diversion and to provide mental health services to either those in jail or those discharged from jail to ensure continuity of care. One CMHC described how they contract with trained mental health deputies, employees of the sheriff's department to divert people from jails and the ER. One hospital noted a joint collaboration with both law enforcement/criminal justice organization as well as a local mental health authority (CMHC) where they all collaborated on crisis intervention response teams and chronic consumer stabilization initiatives to help chronic, mentally ill clients who are at risk of recycling through the justice system and ER. Other hospitals emphasized the delivery of navigation services through mental health clinics. They characterized such relationships by the provision of services and resources to those who are released from jail in order to improve behavioral health and prevent them from re-entering the justice system or ER.

Some CMHCs reported having a crisis hotline that law enforcement officers could contact if they identify individuals in any sort of mental health crisis, primarily to divert those at risk from the criminal justice system. Additionally, many CMHCs reported collaboration with law enforcement/criminal justice organizations to transport clients who are in crisis to their clinics or the Emergency department. In rare cases, we found that hospitals referred clients to lawyers and other legal services for Medicaid and for assistance filing for social security disability benefits.

\section{Tangible Resource Sharing}

Across all of the relationships, collaboration to share tangible resources focused primarily on the provision of supplies and equipment for medical and/or telemedicine 
services, shared staff for program/service delivery, and space, both for the purposes of housing staff (office space) and to deliver programs/services. Among these resources, staff was reported as the most frequently shared resource, likely due to the fact that DSRIP-participating organizations were collaborating with community-based partners to deliver programs/services that required greater workforce capacity for improved availability of and access to services for the low-income, underserved populations in each region. This also allowed DSRIP-participating organizations to share the burden of sustainability, which was identified as a key concern. For collaborations involving law enforcement/criminal justice organizations, staff often included trained deputies of the Sheriff's department as well as trained police officers.

\section{Formal Data Sharing}

Across all of the relationships, organizations shared data primarily to ensure continuity of care. Broadly, we find that organizations share either project-specific or patient-level data. Non-profit organizations reported sharing patient-level data via Business Associate Agreements (BAA) or a Memorandum of Understanding (MOU), where MOUs were more common among CMHCs. A BAA is an "agreement that the privacy regulations require all covered entities have with their vendors that provide a service for them involving protected health information (PHI)" (University of Michigan Health System, 2003).

Law enforcement/criminal justice organizations reported various means of sharing data to ensure continuity of care, such as contracts, BAAs, MOUs and local agreements to share patient-level data. Additionally, they reported data sharing with county jails and crisis intervention teams to identify ex-inmates who have previously been in the mental 
health system and those at risk of entering the criminal justice system to provide appropriate mental health services. 
Table 15. Distribution of Collaboration with other Organizational Partners, Joint Program/Service Delivery

\begin{tabular}{|c|c|c|c|c|c|c|c|c|c|c|c|c|c|}
\hline $\begin{array}{l}\text { DSRIP- } \\
\text { Participating } \\
\text { Organization }\end{array}$ & $\begin{array}{l}\text { Non-profit/ } \\
\text { Social } \\
\text { Service } \\
\text { Organization }\end{array}$ & Hospital & $\begin{array}{l}\text { Health } \\
\text { Clinic }\end{array}$ & $\begin{array}{l}\text { Law } \\
\text { Enforcement/ } \\
\text { Criminal } \\
\text { Justice }\end{array}$ & $\begin{array}{l}\text { Behavioral } \\
\text { Health } \\
\text { Organization }\end{array}$ & $\begin{array}{l}\text { Federally } \\
\text { Qualified } \\
\text { Health } \\
\text { Center }\end{array}$ & $\begin{array}{l}\text { County/ } \\
\text { Municipality }\end{array}$ & $\begin{array}{l}\text { School } \\
\text { District }\end{array}$ & $\begin{array}{l}\text { Faith-based } \\
\text { Organization }\end{array}$ & $\begin{array}{l}\text { Health } \\
\text { Department }\end{array}$ & $\begin{array}{l}\text { Private } \\
\text { Practice }\end{array}$ & $\begin{array}{l}\text { Academic } \\
\text { Institution }\end{array}$ & Other \\
\hline Hospital & $x$ & $x$ & $x$ & $x$ & $x$ & $x$ & $x$ & $x$ & $x$ & $x$ & $x$ & $x$ & $x$ \\
\hline $\begin{array}{l}\text { Hospital/ } \\
\text { Health } \\
\text { District }\end{array}$ & $x$ & $x$ & $x$ & $x$ & $x$ & $x$ & $x$ & $x$ & $x$ & $x$ & & & $x$ \\
\hline $\begin{array}{l}\text { Academic } \\
\text { Health } \\
\text { Science } \\
\text { Center }\end{array}$ & $x$ & $x$ & $x$ & $x$ & $x$ & $x$ & $x$ & $x$ & $x$ & $x$ & & & $x$ \\
\hline $\begin{array}{l}\text { Health } \\
\text { Department }\end{array}$ & $x$ & $x$ & & $x$ & $x$ & $x$ & & $x$ & $x$ & $x$ & $x$ & & $x$ \\
\hline $\begin{array}{l}\text { Community } \\
\text { Mental } \\
\text { Health } \\
\text { Center }\end{array}$ & $x$ & $x$ & $x$ & $x$ & $x$ & $x$ & $x$ & $x$ & $x$ & $x$ & $x$ & & $x$ \\
\hline $\begin{array}{l}\text { County/ } \\
\text { Municipality }\end{array}$ & $x$ & $x$ & $x$ & $x$ & & $x$ & & & $x$ & & & & $x$ \\
\hline $\begin{array}{l}\text { Physician } \\
\text { Practice }\end{array}$ & $x$ & $x$ & $x$ & & & $x$ & $x$ & & & & & $x$ & $\times$ \\
\hline $\begin{array}{l}\text { School } \\
\text { District }\end{array}$ & $x$ & & & & & & & & & & & & \\
\hline $\begin{array}{l}\text { Community } \\
\text { Collaborative }\end{array}$ & & & & & & $x$ & & & & & & & \\
\hline City & $\times$ & & & & $\times$ & & & & & & & & $x$ \\
\hline
\end{tabular}


Table 16. Distribution of Collaboration with other Organizational Partners, Tangible Resource Sharing

\begin{tabular}{|c|c|c|c|c|c|c|c|c|c|c|c|c|c|}
\hline $\begin{array}{l}\text { DSRIP- } \\
\text { Participating } \\
\text { Organization }\end{array}$ & $\begin{array}{l}\text { Non-profit/ } \\
\text { Social } \\
\text { Service } \\
\text { Organization }\end{array}$ & Hospital & $\begin{array}{l}\text { Health } \\
\text { Clinic }\end{array}$ & $\begin{array}{l}\text { Law } \\
\text { Enforcement/ } \\
\text { Criminal } \\
\text { Justice }\end{array}$ & $\begin{array}{l}\text { Behavioral } \\
\text { Health } \\
\text { Organization }\end{array}$ & $\begin{array}{l}\text { Federally } \\
\text { Qualified } \\
\text { Health } \\
\text { Center }\end{array}$ & $\begin{array}{l}\text { County/ } \\
\text { Municipality }\end{array}$ & $\begin{array}{l}\text { School } \\
\text { District }\end{array}$ & $\begin{array}{l}\text { Faith-based } \\
\text { Organization }\end{array}$ & \begin{tabular}{l|} 
Health \\
Department
\end{tabular} & $\begin{array}{l}\text { Private } \\
\text { Practice }\end{array}$ & $\begin{array}{l}\text { Academic } \\
\text { Institution }\end{array}$ & Other \\
\hline Hospital & $x$ & $x$ & $x$ & $x$ & $x$ & $x$ & $x$ & $x$ & $x$ & $x$ & $x$ & $x$ & $\times$ \\
\hline $\begin{array}{l}\text { Hospital/Health } \\
\text { District }\end{array}$ & $\times$ & $\times$ & $\times$ & $\times$ & & $\times$ & $\times$ & & & & & & $\times$ \\
\hline $\begin{array}{l}\text { Academic } \\
\text { Health Science } \\
\text { Center }\end{array}$ & $x$ & $x$ & $\times$ & $x$ & $x$ & $x$ & $x$ & & $x$ & $x$ & & & $x$ \\
\hline $\begin{array}{l}\text { Health } \\
\text { Department }\end{array}$ & $x$ & $x$ & & $x$ & & $x$ & & $x$ & & $x$ & & & $x$ \\
\hline $\begin{array}{l}\text { Community } \\
\text { Mental Health } \\
\text { Center }\end{array}$ & $x$ & $x$ & $x$ & $x$ & $x$ & $x$ & $x$ & $x$ & & $x$ & $x$ & & \\
\hline County & & & $x$ & $x$ & & & & & $x$ & & & & $\times$ \\
\hline $\begin{array}{l}\text { Physician } \\
\text { Practice }\end{array}$ & $x$ & $x$ & $x$ & & & $x$ & $x$ & & & & & $x$ & $\times$ \\
\hline School District & $x$ & & & & & & & & & & & & \\
\hline $\begin{array}{l}\text { Community } \\
\text { Collaborative }\end{array}$ & & & & & & & & & & & & & \\
\hline City & $\times$ & & & & $x$ & & & & & & & & $x$ \\
\hline
\end{tabular}


Table 17. Distribution of Collaboration with other Organizational Partners, Formal Data Sharing

\begin{tabular}{|c|c|c|c|c|c|c|c|c|c|c|c|c|c|}
\hline $\begin{array}{l}\text { DSRIP- } \\
\text { Participating } \\
\text { Organization }\end{array}$ & $\begin{array}{l}\text { Non-profit/ } \\
\text { Social } \\
\text { Service } \\
\text { Organization }\end{array}$ & Hospital & $\begin{array}{l}\text { Health } \\
\text { Clinic }\end{array}$ & $\begin{array}{l}\text { Law } \\
\text { Enforcement// } \\
\text { Criminal } \\
\text { Justice }\end{array}$ & $\begin{array}{l}\text { Behavioral } \\
\text { Health } \\
\text { Organization }\end{array}$ & $\begin{array}{l}\text { Federally } \\
\text { Qualified } \\
\text { Health } \\
\text { Center }\end{array}$ & $\begin{array}{l}\text { County/ } \\
\text { Municipality }\end{array}$ & $\begin{array}{l}\text { School } \\
\text { District }\end{array}$ & $\begin{array}{l}\text { Faith-based } \\
\text { Organization }\end{array}$ & $\begin{array}{l}\text { Health } \\
\text { Department }\end{array}$ & $\begin{array}{l}\text { Private } \\
\text { Practice }\end{array}$ & $\begin{array}{l}\text { Academic } \\
\text { Institution }\end{array}$ & Other \\
\hline Hospital & $x$ & $x$ & $x$ & $x$ & $x$ & $x$ & $x$ & & $x$ & & $x$ & $x$ & $x$ \\
\hline $\begin{array}{l}\text { Hospital/Health } \\
\text { District }\end{array}$ & & $\times$ & $x$ & & & $x$ & $x$ & & & $x$ & & & $x$ \\
\hline $\begin{array}{l}\text { Academic } \\
\text { Health Science } \\
\text { Center }\end{array}$ & $x$ & $x$ & $x$ & & & $x$ & $x$ & & & $x$ & & & \\
\hline $\begin{array}{l}\text { Health } \\
\text { Department }\end{array}$ & $x$ & $x$ & & & & $x$ & & $x$ & & $x$ & $x$ & & $x$ \\
\hline $\begin{array}{l}\text { Community } \\
\text { Mental Health } \\
\text { Center }\end{array}$ & $x$ & $x$ & $x$ & $x$ & $x$ & $x$ & $x$ & $x$ & & $x$ & & & $x$ \\
\hline County & $x$ & $x$ & $x$ & $x$ & & $x$ & & & $x$ & & & & $x$ \\
\hline $\begin{array}{l}\text { Physician } \\
\text { Practice }\end{array}$ & $x$ & $x$ & $x$ & & & $x$ & & & & & & $x$ & \\
\hline School District & $x$ & & & & & & & & & & & & \\
\hline $\begin{array}{l}\text { Community } \\
\text { Collaborative }\end{array}$ & & & & & & $x$ & & & & & & & \\
\hline City & & & & & $x$ & & & & & & & & \\
\hline
\end{tabular}




\section{Discussion}

Overall, we find that DSRIP-participating organizations are not only working collaboratively with other participating organizations, but also working extensively with community-based partners outside the RHPs. There may be a few reasons for this. First, participating organizations were required to select projects from a menu of options that may not necessarily encompass the services other community-based partners are responsible for providing to the low-income, underserved populations (e.g. social services). In fact, many non-profit and social service organizations receive an influx of referrals from DSRIP participating organizations and are expected to provide substantial social services for the low-income, underserved population, often without financial support. However, these services are still critical in the continuum of care. Second, eligibility for participation in DSRIP was not open to all types of organizations even though Texas chose to expand eligibility to include a more diverse pool of providers compared to California. Thus, organizations providing some of these services were excluded from DSRIP but still necessary in delivery system reform. Finally, all participating organizations could in theory bill Medicaid or offer a local match for Medicaid; however, some low-income, underserved populations required services that are not necessarily eligible expenditures under Medicaid (CMS, 2017).

Relationships between organizations, such as service delivery, are more common and more likely to be sustained because they require less negotiation when compared to system-level planning activities (Bryson, Crosby, \& Stone, 2006). Thus, a preliminary examination of these exchanges suggests that organizations are uniquely attempting to integrate services and programing with each other, integrating the social determinants of 
health with the health care system. Although less frequent, data sharing ties in many ways suggest a commitment to ensuring coordination and continuity of services between organizations.

The qualitative analysis revealed unique insight about the nature of collaborations with two types of community-based organizations, non-profit and social service organizations and law enforcement/criminal justice organizations. We focused on these organizations because they were the most prevalent and least expected, respectively. The majority of non-profit organizations provided substantial social services that helped individuals meet basic needs to improve overall health and well-being, such as access to food, which has a well-established relationship with health (Davis, 2015).

In Texas, access to mental health services is a major concern, particularly when the annual per capita spending for mental health is nearly a third of the national average (KFF, 2017). In recognizing the importance of mental health, the Waiver significantly expanded mental health services allowing participating organizations to engage in unique partnerships with critical organizations. One such partnership emerged between providers and law enforcement/criminal justice organizations.

Those with mental illness and substance abuse disorders are overrepresented in the criminal justice system (Henderson, 2006). As such, there is a recognized need for targeted services that divert these high-risk individuals, when appropriate, from the criminal justice system toward community-based services that provide the necessary support and treatment for recovery. Law enforcement/criminal justice partners worked with hospitals and $\mathrm{CMHCs}$, to some extent, on such diversion efforts, striving to connect 
those at-risk of entering (or re-entering in some cases) the criminal justice system with the appropriate services to prevent recidivism and improve access to care.

Unfortunately, both community-based partners were not eligible to participate in DSRIP as a performing provider because they are not health delivery organizations who could bill Medicaid. For example, hospital/health districts were eligible to participate in DSRIP because they were offering up the local match to draw down federal funding for DSRIP activities, even if they are not directly delivering services. Without hospital/health districts, service delivery would not be possible since the provision of a local match is mandatory for participation. Community-based partners in the non-profit and social service organizations category do not bill Medicaid since most of these organizations provide social services (e.g. food) and do not include non-profit hospitals, organizations that can bill Medicaid (CMS, 2017). Under Medicaid, food is not an eligible expenditure; however, this transformation waiver has allowed the state to test new delivery models that include services that were not otherwise eligible as expenditures under Medicaid, such as navigation services (CMS, 2017; HHSC, n.d.). In fact, some regions have directed DSRIP funds to provide support services for both Medicaid-enrolled and indigent populations in supportive housing or those experiencing homelessness and mental illness (Heinman \& Artiga, 2015).

Under the Waiver, Texas expanded eligibility for the pool of participating organizations for DSRIP, but even so that pool does not comprise the full network of providers that are obviously necessary for serving the complex needs of low-income populations. Transforming the delivery system and improving population health require broad participation of stakeholders that might not fit neatly into the health care realm. In 
order for system transformation to occur, policies must acknowledge that siloed approaches to addressing health are inefficient and costly. A broad definition of health must be considered in examining ways to address the unique needs of low-income, underserved populations. This definition acknowledges the significant role nontraditional organizations play in helping to integrate the social determinants of health more effectively with the health care system. In fact, the inclusion of CMHCs in these collaborative provider networks has provided a prime example of the fact that there are a wide range of other organizations beyond hospitals that are critical to maintaining the health status for such populations. More inclusive networks provide greater opportunities for service integration and coordinated efforts, which can help to accomplish the Triple Aim strategies more holistically.

There are some limitations of this study. First, no baseline data for the same measure were collected to be able to assess changes in collaboration with communitybased partners over time. This is also an inherent limitation of using secondary data, as these data were not collected to answer our research question. Second, respondents were limited to report on relationships with three organizations, even though some of the respondents were collaborating with more than three organizations outside of their established RHP network. Third, it should be noted that while qualitative studies have the potential to provide rich, qualitative information, the findings cannot be generalized to the wider population because the nature of the information is very much context specific. Fourth, some respondents may have experienced recall bias in recollecting the types of relationships shared with community-based partners and the nature of those relationships. There is also potential for interviewer bias, but appropriate steps were taken in advance to 
avoid such issues during data collection and analysis. Fifth, the scope of this qualitative analysis is not as in-depth due to an inclination for capturing the most frequent and most unexpected relationships. Finally, there may be overlap among organizations in the way categories for additional community-based partners were created; however, this appeared to be the most effective way to categorize additional partners since respondents were asked to identify the type of organization with whom they collaborated.

In summary, this research highlights a need to integrate more forcefully the social determinants of health with health care, specifically as it relates to addressing the needs of low-income, underserved populations. Achieving optimal health requires fundamental needs to be met, often in the form of social services. Promoting and incentivizing collaboration that values a health in all policies approach can help to advance health equity goals. Future waivers should consider the inclusion of social service and nontraditional partners in achieving the Triple Aim strategies, as they provide many of the services critical to improving population health outcomes and reducing health care costs (Heiman \& Artiga, 2015). 


\section{CHAPTER VII \\ DISCUSSION AND CONCLUSIONS}

Interorganizational network analysis is a powerful tool that allows researchers to examine network structure by capturing relationships that exist between organizations. Network structure can provide useful information about the development and growth of relationships over time, emphasizing aspects of the network that allow it to thrive and achieve intended objectives (Popp et al., 2014). Previous studies have utilized interorganizational network analysis to map and measure collaboration within networks and to show changes in collaboration over time to demonstrate the effectiveness of network structure or development (Provan and Milward, 1995; Provan \& Milward, 2001; Provan and Lemaire, 2012; Ramanadhan et al., 2012; Valente, \& Celentano, 2001; Valente, Coronges, Stevens, \& Cousineau, 2008). A large number of network studies in health service delivery focus on whole network analysis (Borgatti \& Foster, 2003; Huerta, Caebeer, VanderPlatt, 2006; Isett et al., 2011; Luke \& Harris, 2007; Milward and Provan; 2006; Popp, MacKean, Casebeer, Milward, \& Lindstrom, 2014; Provan, Fish, \& Sydow, 2007). Health and human services networks are often developed to strengthen service delivery systems and to manage population health across the continuum of care (Foster-Fishman, Salem, Allen, \& Fahrbach, 2001; Greenhalgh, Robert, Macfarlane, Bate, \& Kyriakidou, 2004; Provan \& Milward, 1995). 
In Texas, community mental health centers (CMHCs) have traditionally operated in isolation from other organizations responsible for health service delivery, such as primary care (HFMH, 2014). In a study comparing the integrated and coordinated nature of four different networks of CMHCs, the following ties were reported among organizations: patient referrals sent and received, case coordination, joint programs, and service contracts (Provan \& Milward, 1995). Certain relationships between organizations, such as service delivery are more common and more likely to be sustained because they require less negotiation when compared to system-level planning activities (Bryson, Crosby, \& Stone, 2006). In comparison to service delivery ties, the literature has focused very little on the extent to which more formal types of ties (e.g. resource and data sharing) are impacted within mandated networks. Additionally, the complexity of relationships is likely to increase as interorganizational relationships mature, which results in strengthened relationships and sustained collaboration (Provan \& Milward, 2001). With this knowledge, various network measures (e.g. centrality, homophily, multiplexity) can be used to identify organizations that occupy important positions within networks (Cook \& Emerson, 1978). This is important because power is a critical element of social structures and structural position can impact the amount of power an organization possesses to control and influence others, providing valuable information about the constraints and opportunities available to an organization within a particular network (Hanneman \& Riddle, 2005). 
While measures about whole networks provide valuable insight on network structure, evolution, and the impact it has on participating organizations, fewer studies focus on the role of organizations within service delivery networks and the potential impact this may have on collaboration. Complexity of relationships is likely to increase as interorganizational ties mature (Provan \& Milward, 2001), but the literature does not necessarily point to the types of ties that are strengthened and sustained over time.

The literature also indicates the types of ties that exist between networks of CMHCs; however, there is little information about the ways in which CMHCs work with other types of organizations responsible for health service delivery and the impact this may have on their role within diverse networks. In fact, there appears to be no literature on the extent to which CMHCs are central to integrated health service delivery networks. Currently, the knowledge base for the characteristics of CMHCs that make them central to a network is limited. This information is particularly relevant as the shift to more integrated models of care are emerging, providing opportunities to consider how best to integrate otherwise unintegrated or less central organizations. Similarly, it is unclear to what extent intersectoral partnerships are sustained in health services delivery over time.

Additionally, there is relatively little discussion about the specific nature of relationships (based on structure and content exchanged) and how those relationships can be used to drive delivery system reform, specifically when networks are created for the purpose of policy implementation. Currently, the organizations responsible for delivering health care operate relatively distinctly from one other, attempting to address complex health needs with siloed approaches. Delivery system reform is predicated on the idea that innovative service delivery models rely on collaborative networks to address quality 
of care, access to care, and costs of care. Thus, the Waiver provided an opportunity to assess how collaboration among organizations between and across sectors evolves over time. Capturing the nature of relationships both within and beyond mandated networks provides a unique opportunity to assess the nature and impact of collaborative provider networks as it relates to delivery system reform.

\section{Research Questions}

Based on gaps in the literature, it was worthwhile to extend network analysis in understanding the extent to which the Waiver promoted collaboration for health service delivery reform in Texas, the nature of that collaboration and what Texas' experience can tell policy-makers about how to shape related efforts in the future.

Research Question 1 focused on examining measures of centrality at the organization-level for community mental health centers (CMHCs). Under the waiver, mental health services were expanded significantly providing CMHCs with unique opportunities for service integration with other organizations that provide key services on the continuum of care, an opportunity that is not otherwise readily available. This increased focus on mental health within the context of collaborative provider networks presents an opportunity to assess the ways in which CMHCs have been impacted under this policy. Interorganizational network analysis was used to characterize changes in the position and role of CMHCs across 19 Regional Healthcare Partnerships (RHPs) in Texas over time.

Research Question 2 focused on understanding the extent to which the formation of RHPs under DSRIP have been successful in promoting intersectoral collaboration among participating organizations. Organizations that provide services across the 
continuum of care often operate in isolation, perpetuating deficiencies in the fragmented health care system. Such fragmentation results in lack of access to care, increased costs of care, poor health outcomes, and health inequities among other things (Davis et al., 2014; Robert Wood Johnson Foundation, 2011). Delivery system reform focuses on improving access to care and managing population health, which requires organizations across sectors to form strategic alliances for integrated and coordinated service delivery. Interorganizational network analysis was used to map and characterize changes in intersectoral collaboration within each RHP over time.

Research Question 3 focused on identifying key community partners critical to serving low-income, underserved populations beyond the mandated partnerships and on characterizing the nature of relationships that participating organizations pursued with such organizations. The Waiver expanded the pool of providers who could participate in DSRIP to address the needs of low-income populations; however, this network failed to include some organizations that are critical to serving such populations. Low-income, underserved populations constantly struggle to choose between fundamental needs, such as food and health care (Davis, 2015; Hastings et al., 2006). Population health improvement requires a holistic approach in addressing the social, economic, and environmental factors that impact health (Heiman, \& Artiga, 2015). As such, this research question focuses on the way health care organizations collaborated with key community-based partners to meet the unique needs of the low-income, underserved populations. Qualitative analysis was used to identify organizations with whom RHP member organizations collaborated with outside of the RHP and to characterize the nature of those relationships. 


\section{Key Findings}

\section{Role of community mental health centers in RHPs}

Centrality is a measure that identifies the sources and distribution of power within a network (Hanneman \& Riddle, 2005). The findings indicate that the point centrality scores for tangible resource sharing and formal data sharing ties are lower compared to the other types of ties, suggesting that CMHCs, on average, tend to be least central in those tie types. Joint program/service delivery tends to have the highest degree centrality scores after the all collaboration tie type, allowing CMHCs to assume more central roles across networks. For joint program/service delivery relationships, the mean degree centrality tends to decrease over time, indicating that CMHCs tend to have fewer ties with organizations over the implementation period. It appears that degree centrality scores were highest at $\mathrm{T}_{0}$ for all types of ties, possibly indicating that organizations assumed more central roles prior to the formation of the RHPs. Across all CMHCs, we see a decrease in mean degree centrality from $T_{0}$ to $T_{2}$ for all tie types and an increase in mean betweenness centrality for all but the formal data sharing tie.

Thus, the findings indicate that $\mathrm{CMHCs}$ tend to be more central in joint program/service delivery ties are likely due to the fact that there was increased funding for mental health efforts and CMHCs were also allowed to offer intergovernmental transfer funds to match the federal DSRIP funds. This provided CMHCs with increased power within networks, potentially making them desirable partners for other organizations, particularly hospitals who were seeking to integrate primary care with behavioral health. This power also positioned them to control flows of program/service delivery and possibly facilitate the exchange of other types of network content. An 
overall decrease for degree centrality in joint program/service delivery could indicate that collaboration was no longer necessary after respective projects had been launched.

Homophily was used to measure the extent to which CMHCs were collaborating with similar others (e.g. CMHCs). An increase in homophily indicates more ties with CMHCs or less with other types of organizations, and a decrease in homophily represents more ties with other types of organizations or less ties with CMHCs. For all but the all collaboration and the joint program/service delivery ties, we see an overall decrease in homophilous ties among CMHCs over the implementation period. This suggests that CMHCs were working with other types of organizations across the DSRIP implementation period. Since CMHCs could put up their own intergovernmental transfer (local match to draw down federal funds), this may also reflect that they found it beneficial to keep more funds early on during implementation. For the all collaboration and joint program/service delivery ties, we see a decrease in homophilous ties from $\mathrm{T}_{0}$ to $T_{1}$ and $T_{0}$ to $T_{2}$ but a slight increase from $T_{1}$ to $T_{2}$. Decreases in percent changes for homophily are most noticeable for the tangible resource sharing and formal data sharing ties, particularly from $\mathrm{T}_{0}$ to $\mathrm{T}_{2}$. Based on these findings, it seems the Waiver was successful in integrating CMHCs with other organizations that deliver health care services because CMHCs appear to be engaging in increased intersectoral collaboration as it relates to tangible resource sharing and formal data sharing. The fact that CMHCs worked with other types of organizations to share resources and data emphasizes the fact that mental health is an integral part of overall health and well-being and must be integrated with more traditional forms of health care. 
Multiplexity is the extent to which an organization shares multiple types of ties with another organization. The mean average strength of ties for CMHCs and nonCMHCs was highest in $\mathrm{T}_{2}$, indicating that on average CMHCs and non-CMHCs were both experiencing an increase in the complexity of their collaboration with other organizations over time. CMHCs had higher average strength of ties scores compared to non-CMHCs across all time periods meaning that they collaborated with organizations in multiple ways.

\section{Intersectoral Collaboration}

Within the context of this study, intersectoral ties are those ties that exist between organizations in different sectors of the health care delivery system (e.g. a hospital has a tie with a CMHC). Where collaboration is observed, we primarily see a decrease or no change for within-sector collaboration across all tie types. The majority of RHPs in the all collaboration tie type saw a decrease or no change in within-sector collaboration and an increase in intersectoral collaboration for all sectors but CMHCs. This may reflect the inherent interconnection of CMHCs initially through the state and their collective data system.

Where within-sector and intersectoral collaboration was observed, there were only decreases or no changes reported for the joint program/service delivery tie type. The majority of RHPs collaborating to share tangible resources saw a decrease or no change in within-sector collaboration. We see variation in changes to intersectoral collaboration for the tangible resource sharing tie type, where some RHPs saw an increase in intersectoral collaboration and some a decrease or no change. Several RHPs in the formal data sharing tie type saw a decrease or no change in within-sector collaboration and an 
increase in intersectoral collaboration. A critical aspect of delivery system reform is increased intersectoral collaboration. These results suggest that the Waiver was successful in expanding the provider pool to include a diverse mix of providers and promoted collaboration among organizations across sectors, particularly as it relates to service integration via data sharing. This is important because such efforts promote coordination of services and continuity of care.

\section{Collaboration with Community-Based Partners}

A total of 534 additional organizations were reported as key community-based partners. These partners included non-profit and social service organizations, hospitals either not participating in DSRIP or not in the same RHP, health clinics, law enforcement and criminal justice agencies, behavioral health organizations, federally qualified health centers, county and city governments, school districts, faith-based organizations, health departments, private practice physicians, academic institutions, and other organizations. Non-profit and social service organizations as well as hospitals were the most frequently reported community-based partners while private practices and academic institutions were the least reported partners by DSRIP participating organizations. On average, respondents reported at least two community-based partners with whom they work, and the majority of those ties were around joint program/service delivery. Among DSRIPparticipating organizations, hospitals and community mental health centers (CMHCs) seem to be collaborating with almost all of the different types of community-based partners, particularly to deliver joint programs/services.

Two specific community-based organizations were identified and their relationships with the most engaged DSRIP participating organizations, hospitals and 
CMHCs was explored through an in-depth qualitative analysis. In terms of identifying the most appropriate community-based partners on which to focus for the qualitative analysis, the most prominent community-based partner, non-profit and social service organizations and the most unexpected, law enforcement/criminal justice were central to the analysis. The majority of joint program/service delivery collaboration with non-profit and social service organizations focused on the provision of social services while collaboration with law enforcement/criminal justice revolved around crisis screenings for jail diversion and the provision of mental health services. Partnerships were supported by shared tangible resources, such as staff, supplies, and space as well as formal data agreements, many of which took the form of memorandum of agreements and Business Associate Agreements to share patient-level information.

\section{Practice and Policy Implications}

These findings have various practice and policy implications.

\section{Role of community mental health centers in RHPs}

In Texas, CMHCs have traditionally operated in isolation from the rest of the health service delivery system. Behavioral health services were significantly expanded under the 1115 Waiver. Therefore, DSRIP changed the landscape for CMHCs by providing unique opportunities for them to work with other organizations in addressing the mental health needs of Texans. This allowed CMHCs to maximize development of and improve access to quality behavioral health services without having to conform to the narrow eligibility requirements of state-funded services in CMHCs (HFMH, 2014).

Over the implementation period, CMHCs assumed structurally advantaged positions within the RHPs in ways that allowed them to influence what types of content 
entered the group, controlled flows of program/service delivery, and facilitated exchange of information and resources among other participating organizations in the RHP. Because the Waiver prioritized behavioral health by allocating 10 percent of DSRIP funds for CMHCs, it seemed reasonable for them to leverage this funding in securing a more central role within the RHPs, fostering collaboration in the form of integrated behavioral and primary health to occur. In addition to providing behavioral health services as performing providers, CMHCs could also serve as IGT entities who could contribute local dollars to draw down federal matching funds, another source of increased power within the RHP.

With an increased emphasis on ensuring coordination and continuity of services between organizations, CMHCs had increased opportunities to engage in intersectoral collaboration over the implementation period, particularly as it relates to tangible resource sharing and formal data sharing. CMHCs had higher strength of tie scores than non-CMHCs, possibly suggesting that the Waiver helped them to build and sustain multiple, meaningful partnerships over time. In considering the fragmentation of the current health care system and acknowledging the presence of silos in the system, Texas recognized that access to mental health was critical to population health improvement and must be prioritized. The Waiver intentionally focused on incorporating behavioral health within this delivery system transformation integrating CMHCs to a diverse pool of providers. Future policies should be cognizant of integrating otherwise unintegrated or less central organizations, such as CMHCs in the health service delivery system. 


\section{Intersectoral Collaboration}

Since the state expanded eligibility of providers for the DSRIP funding pool, it was possible for a broad range of providers beyond public hospitals to participate in delivery system reform. This allowed organizations in different sectors of the health care delivery system to collaborate with one another in addressing issues of fragmentation in the current health care system. This information has helped to provide valuable insight about the ways in which human, social, intellectual, and financial capital were pooled to improve efficiency and coordinate services for the low-income, underserved population in Texas.

The most noticeable improvements in intersectoral collaboration were around formal data sharing. Data sharing might include formal agreements to transfer patient information electronically, joint participation in a regional health information exchange, or sharing the same electronic medical record system within health systems. The nature of DSRIP projects either necessitated or encouraged data sharing among members to ensure coordination and continuity of services between organizations. In fact, data sharing enabled organizations to efficiently coordinate activities when serving the same population to reduce duplication of specific services. Several RHPs leveraged the opportunity of having resources available through DSRIP projects to develop local or regional health information exchanges, which has implications for improving the coordination and quality of care for consumers of the health care system. In fact, FosterFishman and colleagues (2001) suggest that intersectoral ties may indicate a higher likelihood of service integration, which can combat issues of fragmentation in health care delivery. 
More specifically, increases in intersectoral collaboration around resource and data sharing were most noticeable for hospitals and CMHCs, the only two types of organizations that participated in every RHP. Increased funding for CMHCs purposefully expanded development of and access to quality behavioral health care services and provided increased opportunities for CMHCs to partner with organizations across sectors to address the behavioral health and other needs of the low-income or underserved populations. In fact, CMHCs often partnered with hospitals on projects focused on integrated primary and behavioral health care, and they partnered with other organizations for additional crisis intervention. Presumably, many of these efforts necessitate resource and data sharing to ensure service coordination and integration are realized, quality of care improved, and costs reduced.

Although joint program/service delivery ties were the most frequent type of relationship observed among organizations, they did not appear to be enduring and dissolved fairly quickly compared to some of the other tie types. At the onset of the Waiver, there were many collaborations linked to organizations getting their DSRIP projects to be fully operational. Over time, however, the pressure of meeting metrics and responding to required monitoring reduced the capacity and resources available for collaboration and organizations likely recalibrated their efforts to focus on meeting their metrics in order to receive payments. Thus, the projects that ultimately survived were likely those that organizations implemented primarily on their own and for those organizations that were eligible for offering their own intergovernmental transfer funds. Moreover, policies concerned with health service delivery reform must be inclusive of 
multiple organizations across the continuum of care and find ways to incentivize service integration in combatting fragmentation in the current health care system.

\section{Collaboration with community-based partners}

During the $\mathrm{T}_{0 /} \mathrm{T}_{1}$ data collection phase, participants expressed concern about not being asked to report on relationships with community-based partners they work with who are not formal participants in the RHP (e.g. those organizations excluded from the sampling frame). In an attempt to address and accommodate participant feedback from the $\mathrm{T}_{0 /} \mathrm{T}_{1}$ data collection phase, the $\mathrm{T}_{2}$ survey included a new question about collaboration with other organizational partners.

DSRIP-participating organizations are not only working collaboratively with other participating organizations, but also working extensively with community-based partners outside RHPs. There may be a few reasons for this. First, participating organizations were required to select projects from a menu of options that may not necessarily encompass the services other community-based partners are responsible for providing to the low-income, underserved populations (e.g. social services). However, these services are still critical in the continuum of care. Second, eligibility for participation in DSRIP was not open to all types of organizations even though Texas chose to expand eligibility to include a more diverse pool of providers compared to California. As such, organizations providing some of these services were excluded for DSRIP but still necessary in delivery system reform. Finally, all participating organizations could in theory bill Medicaid or offer a local match for Medicaid; however, some low-income, underserved populations required services that are not necessarily eligible expenditures under Medicaid (CMS, 2017). 
A preliminary examination of exchanges between DSRIP-participating organizations and community-based partners suggests that organizations are uniquely attempting to integrate services and programing with each other, integrating the social determinants of health with the health care system. Although less frequent, data sharing ties in many ways suggest a commitment to ensuring coordination and continuity of services between organizations. A closer examination of relationships with specific community-based partners revealed that the majority of non-profit organizations provided substantial social services that helped individuals meet basic needs to improve overall health and well-being, such as access to food, which has a well-established relationship with health.

Texas has one of the lowest rates of access to mental health care services (Mental Health America, 2015). Given the expanded funding for behavioral health services under the Waiver, there were increased opportunities to promote behavioral health with community-based partners. For example, law enforcement/criminal justice partners worked with hospitals and CMHCs on diversion efforts, striving to connect those at-risk of entering (or re-entering in some cases) the criminal justice system with the appropriate behavioral health services to prevent recidivism and improve access to care. Furthermore, future waiver programs should consider expanding the pool of providers to include and incentivize some of these community-based partners providing essential social, behavioral, and other appropriate services that may not fall directly within the health care sector. 


\section{Conclusion}

Holistically, these studies provide a number of policy and practice implications. First, mental health is a critical aspect of overall health and well-being. Unfortunately, inadequate access to mental health services, supports, and treatment continue to be one of the most demanding policy issues in Texas (HFMH, 2014). CMHCs have largely been peripheral to health service delivery systems with mental health seen as distinct from physical health. Despite the support CMHCs provide to hospitals serving indigent and uninsured populations, their role remains largely unrecognized by the Texas Medicaid system (Texas Council of Community Centers, 2016). The Waiver presented opportunities to prioritize mental health, promote collaboration, and allow CMHCs to provide intergovernmental transfer funds, all of which elevated the role and power of CMHCs in their RHPs. In doing so, CMHCs assumed more central roles in integrated service delivery with other types of organizations, allowing them to develop multiple types of relationships with an organization in ensuring coordinated and continuous care. Increased funding for mental health also allowed CMHCs to collaborate with those beyond the health care delivery system, such as law enforcement/criminal justice partners, to implement innovative projects aimed at increasing access to mental health for those at risk for entering the criminal justice system.

Second, one challenge to achieving optimal health is that the systems tasked with the responsibility of providing care across this continuum often operate in silos, missing opportunities to provide quality, coordinated care. Many organizations in addition to hospitals, such as public health agencies and CMHCs, are central within the continuum of care. Unfortunately, public health services are historically and systematically 
underfunded and under-resourced. As resources become scarce, health service delivery organizations are being incentivized to pool resources in strategic ways so as to meet the demands of a complex and fragmented health care system. State level policy changes, like the Waiver can promote and incentivize meaningful opportunities for intersectoral collaboration, particularly around resource and data sharing for service integration efforts. This provides an opportunity for public health agencies and other organizations to leverage funding through multiple partners and potentially expand and integrate the services provided across other organizations. This is important because public health departments and CMHCs are acknowledged as important organizations that provide access to population-based and behavioral health services in ways that can contribute to the Triple Aim strategies for an improved health care system.

Finally, there is a need to integrate more forcefully the social determinants of health with health care, specifically as it relates to addressing the needs of low-income, underserved populations. Achieving optimal health requires fundamental needs, often in the form of social services, to be met. Promoting and incentivizing collaboration that values a health in all policies approach can help to advance health equity goals. Future waivers should consider the inclusion of social service and non-traditional partners in achieving the Triple Aim strategies, as they provide many of the services critical to improving population health outcomes and reducing health care costs (Heiman \& Artiga, 2015). Moreover, since Texas was the first state to implement DSRIP through the formation of RHPs, this collaborative provider network approach can be adapted in other states to address health service delivery concerns responsive to local needs. 


\section{Future Research}

The findings of this study also have a number of implications for future research. It would be beneficial to explore the ways in which collaboration as a result of the Waiver impacted health outcomes. Many organizations were incentivized to work in conjunction with one another to fulfill an identified health need within the region. As such, it would be worthwhile to assess the impact increased or decreased collaboration had on the health outcomes of various low-income, underserved populations in the state.

It would be worthwhile to examine the extent to which CMHCs sustain relationships with hospitals and other organizations after the completion of the Waiver. Since the Waiver significantly expanded behavioral health services, it would be useful to examine trends in collaboration before and after the Waiver period. This may allow for the evaluation of sustained partnerships and possibly the impact on access to behavioral health services and health outcomes more broadly. It might also be useful to explore the ways in which the Waiver impacted the perceptions of the Texas Medicaid system in recognizing the critical role of CMHCs in the state. Additional research is also needed to understand how service integration projects implemented using DSRIP funds are be sustained after the Waiver.

Given the benefits of intersectoral collaboration, future research should examine the impact such types of collaboration have on organizations. This could provide in-depth information that helps to contextualize the benefits of collaboration at the organizational level. Additionally, with the Waiver's focus on achieving the Triple Aim strategies, research examining the impact of DSRIP on these strategies is critical to addressing issues of fragmentation in the current health care system. Finally, DSRIP initiatives have 
brought renewed attention to social services. Understanding the outcomes linked to collaboration with social service partners and other non-traditional partners can help to make the case for designating such organizations as performing providers in future policies. 


\section{REFERENCES}

Adler, L. \& William Hoagland, G. (2012). What is Driving US Healthcare Spending? America's Unstainable Health Care Cost Growth. Retrieved February 3, 2017 from http://cdn.bipartisanpolicy.org/wpcontent/uploads/sites/default/files/BPC\%20Health\%20Care\%20Cost\%20Drivers $\% 20$ Brief\%20Sept\%202012.pdf.

Ahuja, G., Polidoro, F., \& Mitchell, W. (2009). Structural homophily or social asymmetry? The formation of alliances by poorly embedded firms. Strategic Management Journal, 30(9), 941-958.

American Public Health Association. (2012). The Prevention and Public Health Fund: A critical investment in our nation's physical and fiscal health. Retrieved March 4, 2017 from https://www.apha.org/ /media/files/pdf/factsheets/apha_prevfundbrief_june2012. ashx.

Artiga, S. (2011). Five key questions and answers about Section 1115 Medicaid Demonstration Waivers. Kaiser Family Foundation's Commission on Medicaid and the Uninsured.

Atouba, Y. C., \& Shumate, M. (2015). International nonprofit collaboration: Examining the role of homophily. Nonprofit and Voluntary Sector Quarterly, 44(3), 587-608.

Bevc, C. A., H. Retrum, J., \& M. Varda, D. (2015). New perspectives on the "silo effect": initial comparisons of network structures across public health collaboratives. American Journal of Public Health, 105(S2), S230-S235.

Bodin, Ö., Crona, B., \& Ernstson, H. (2006). Social networks in natural resource management: What is there to learn from a structural perspective? Ecology and Society, 11(2).

Bolland, J. M., \& Wilson, J. V. (1994). Three faces of integrative coordination: a model of interorganizational relations in community-based health and human services. Health Services Research, 29(3), 341-366.

Bonacich, P. (1987). Power and centrality: A family of measures. American Journal of Sociology, 92(5), 1170-1182. 
Borgatti, S. P., Everett, M. G., \& Freeman, L. C. (2002). Ucinet for Windows: Software for social network analysis. Harvard, MA: Analytic Technologies.

Borgatti, S. P., \& Foster, P. C. (2003). The network paradigm in organizational research: A review and typology. Journal of Management, 29(6), 991-1013.

Borgatti, S. P., Mehra, A., Brass, D. J., \& Labianca, G. (2009). Network analysis in the social sciences. Science, 323(5916), 892-895.

Borgatti, S. P., Everett, M. G., \& Johnson, J. C. (2013). Analyzing social networks. SAGE Publications Limited.

Brass, D. J., Galaskiewicz, J., Greve, H. R., \& Tsai, W. (2004). Taking stock of networks and organizations: A multilevel perspective. Academy of Management Journal, 47(6), 795-817.

Bray, J. H., Maxwell, S. E., \& Howard, G. S. (1984). Methods of analysis with responseshift bias. Educational and Psychological Measurement, 44(4), 781-804.

Bryson, J. M., Crosby, B. C., \& Stone, M. M. (2006). The design and implementation of cross-sector collaborations: Propositions from the literature. Public Administration Review, 66(S1), 44-55.

Burns, L. R., \& Pauly, M. V. (2002). Integrated delivery networks: a detour on the road to integrated health care? Health Affairs, 21(4), 128-143.

Burt, R. S. (2005). Brokerage and closure: An introduction to social capital. Oxford University Press.

Calanni, J. C., Siddiki, S. N., Weible, C. M., \& Leach, W. D. (2014). Explaining coordination in collaborative partnerships and clarifying the scope of the belief homophily hypothesis. Journal of Public Administration Research and Theory, 25(3): 1-27.

Carboni, J. L., \& Milward, H. B. (2012). Governance, privatization, and systemic risk in the disarticulated state. Public Administration Review, 72(S1), S36-S44.

Centers for Disease Control and Prevention [CDC]. (2007). Evaluation guide: fundamentals of evaluating partnerships. Atlanta (GA): US Department of Health and Human Services.

Centers for Medicare and Medicaid Services. (2013). Section 1115 Demonstrations. Retrieved January 4, 2017 from http://www.medicaid.gov/Medicaid-CHIPProgram-Information/By-Topics/Waivers/1115/Section-1115Demonstrations.html. 
Centers for Medicare and Medicaid Services. (2015). National Health Expenditures 2015

Highlights. Retrieved January 4, 2017 from https://www.cms.gov/researchstatistics-data-and-systems/statistics-trends-andreports/nationalhealthexpenddata/downloads/highlights.pdf.

Centers for Medicare and Medicaid Services. (2017). List of Medicaid Benefits. Retrieved February 15, 2017 from https://www.medicaid.gov/medicaid/benefits/list-ofbenefits/index.html.

Centers for Medicare and Medicaid Services. (n.d.). Medicaid. Retrieved February 16, 2017 from https://www.medicaid.gov/medicaid/.

Charmaz, K. (2014). Constructing Grounded Theory (2nd ed). London, UK: Sage Publications.

Cook, K. S., \& Emerson, R. M. (1978). Power, equity and commitment in exchange networks. American Sociological Review, 721-739.

Corbin, J. \& Strauss, A. (2008). Basics of qualitative research: Techniques to developing grounded theory (3rd ed.). Thousand Oaks, CA: Sage Publications.

Creel, L.M., \& Wendel, M.L. (2016). Changes in Regional Interorganizational Collaboration Related to the Texas 1115(a) Medicaid Waiver. Unpublished manuscript.

Creel, L.M., Wendel, M.L., \& Ali, N. (2016). Evaluation of the Texas Delivery System Reform Incentive Payment Demonstration Final Report-Appendix C: Changes in Collaboration Among Organizations. Section in Final Evaluation Report to the Texas Health and Human Services Commission.

Creswell, J. W. (2013). Qualitative inquiry and research design: Choosing among five approaches (3rd ed.). Thousand Oaks, CA: Sage Publications.

Currall, S. C., \& Judge, T. A. (1995). Measuring trust between organizational boundary role persons. Organizational Behavior and Human Decision Processes, 64(2), $151-170$.

Davis, K. (2015). To Lower the cost of health care, invest in social services. Retrieved on February 3, 2017 from http://healthaffairs.org/blog/2015/07/14/to-lower-the-costof-health-care-invest-in-social-services/.

Davis, K., Stremikis, K., Squires, D., \& Schoen, C. (2014). Mirror, mirror on the wall. How the performance of the US Health care system compares internationally. New York: CommonWealth Fund. 
Enthoven, A. C. (2009). Integrated delivery systems: the cure for fragmentation. American Journal of Managed Care, 15(12), S284-S290.

Essential Hospitals Institute. (2013). Integrated Health Care: Literature Review. Retrirved February 3, 2017 from http://essentialhospitals.org/wpcontent/uploads/2013/12/Integrated-Health-Care-Literature-Review-Webpost-822-13-CB.pdf.

Fattore, G., Frosini, F., Salvatore, D., \& Tozzi, V. (2009). Social network analysis in primary care: the impact of interactions on prescribing behaviour. Health Policy, 92(2), 141-148.

Foster-Fishman, P. G., Salem, D. A., Allen, N. A., \& Fahrbach, K. (2001). Facilitating interorganizational collaboration: The contributions of interorganizational alliances. American Journal of Community Psychology, 29(6), 875-905.

Freeman, L. C. (1979). Centrality in social networks conceptual clarification. Social Networks, 1(3), 215-239.

Friedkin, N. E. (1991). Theoretical foundations for centrality measures. American Journal of Sociology, 96(6), 1478-1504.

Fried, B. J., Johnsen, M. C., Starrett, B. E., Calloway, M. O., \& Morrissey, J. P. (1998). An empirical assessment of rural community support networks for individuals with severe mental disorders. Community Mental Health Journal, 34(1), 39-56.

Frey, B. B., Lohmeier, J. H., Lee, S. W., \& Tollefson, N. (2006). Measuring collaboration among grant partners. American Journal of Evaluation, 27(3), 383-392.

Gates, A., Rudowitz, R., \& Guyer, J. (2014). An Overview of Delivery System Reform Incentive Payment (DSRIP) Waivers. New York: Kaiser Family Foundation.

Gibbons, D. E. (2007). Interorganizational network structures and diffusion of information through a health system. American Journal of Public Health, 97(9), $1684-1692$.

Glisson, C., \& James, L. (1992). The interorganizational coordination of services to children in state custody. In D. Bargal, \& H. Schmid (Eds.), Organizational change and development in human service organizations (pp. 65-80). New York, NY: Haworth Press, Inc.

Greenhalgh, T., Robert, G., Macfarlane, F., Bate, P., \& Kyriakidou, O. (2004). Diffusion of innovations in service organizations: systematic review and recommendations. Milbank Quarterly, 82(4), 581-629. 
Gulati, R., Lavie, D., \& Madhavan, R. (2011). How do networks matter? The performance effects of interorganizational networks. Research in Organizational Behavior, 31, 207-224.

Hanneman, R. A., \& Riddle, M. (2005). Introduction to social network methods. Riverside, CA: University of California, Riverside.

Hastings, J., Taylor, S., \& Austin, M. J. (2006). The status of low-income families in the post-welfare reform environment: Mapping the relationships between poverty and family. Journal of Health \& Social Policy, 21(1), 33-63.

Heffren, W., McDonald, A., Casebeer, A., \& Wallsten, D. (2003). Mandated intersectoral, interdisciplinary collaboration: Opportunity or oxymoron. $\mathrm{Co}$ creating Emergent Insight, 221-227.

Heijmans, N., van Lieshout, J., \& Wensing, M. (2017). Information exchange networks of health care providers and evidence-based cardiovascular risk management: an observational study. Implementation Science, 12(1), 7.

Heiman, H. J., \& Artiga, S. (2015). Beyond health care: the role of social determinants in promoting health and health equity. Health, 20(10), 1-11.

Henderson, C. (2006). Why people with a mental illness are Over-represented in the Criminal Justice System. Mental Health Coordinating Council.

Hill, C. (2002). Network literature review: Conceptualizing and evaluating networks. Calgary Health Region.

Hogg Foundation for Mental Health [HFMH]. (2014). A Guide to Understanding Mental Health Systems and Services in Texas. Retrieved February 1, 2017 from https://hoggblogdotcom.files.wordpress.com/2014/12/mhguide_final-1.pdf.

Howard, G. S., \& Dailey, P. R. (1979). Response-shift bias: A source of contamination of self-report measures. Journal of Applied Psychology, 64(2), 144-150.

Huerta, T., Casebeer, A., \& VanderPlaat, M. (2006). Using networks to enhance health services delivery: Perspectives, paradoxes, propositions. Healthcare Papers, 7(2): $10-26$.

Institute for Healthcare Improvement. (2009). The Triple Aim. Retrieved on February 3, 2017 from

http://www.ihi.org/engage/initiatives/TripleAim/Documents/BeasleyTripleAim_A CHEJan09.pdf

Institute of Medicine. (2001). Crossing the quality chasm: A new health system for the 21st century. Washington, DC: National Academy Press. 
Isett, K. R., \& Provan, K. G. (2005). The evolution of dyadic interorganizational relationships in a network of publicly funded nonprofit agencies. Journal of Public Administration Research and Theory, 15(1), 149-165.

Isett, K. R., Mergel, I. A., LeRoux, K., Mischen, P. A., \& Rethemeyer, R. K. (2011). Networks in public administration scholarship: Understanding where we are and where we need to go. Journal of Public Administration Research and Theory, 21(suppl 1), i157-i173.

Johnsen, M. C., \& Morrissey, J. P. (1996). Structure and change in child mental health service delivery networks. Journal of Community Psychology,24(3), 275-289.

Kanter, R. M. (1994). Collaborative advantage. Harvard Business Review, 72(4), 96-108.

Kaiser Family Foundation [KFF]. (2017). State mental health agency per capita mental health services expenditures, FY2010. Retrieved February 1, 2017 from http://www.statehealthfacts.org/comparemaptable.jsp?cat=5\&ind=278.

Kaiser Family Foundation [KFF]. (2015). Health Insurance Coverage of the Total Population. Retrieved February 20, 2017 from http://kff.org/other/stateindicator/totalpopulation/?currentTimeframe=0\&sortModel $=\% 7 \mathrm{~B} \% 22 \mathrm{colId} \% 22: \% 22$ Uninsured $\% 22, \% 22$ sort $\% 22: \% 22$ desc $\% 22 \% 7 \mathrm{D}$.

Katz, N., Lazer, D., Arrow, H., \& Contractor, N. (2004). Network theory and small groups. Small Group Research, 35(3), 307-332.

Kwait, J., Valente, T. W., \& Celentano, D. D. (2001). Interorganizational relationships among HIV/AIDS service organizations in Baltimore: A network analysis. Journal of Urban Health, 78(3), 468-487.

Lee, S. K., Kim, H., \& Piercy, C. W. (2016). The Role of Status Differentials and Homophily in the Formation of Social Support Networks of a Voluntary Organization. Communication Research, 1, 1-28.

Leavitt, M., McClellan, M., DeVore, S.D., Fisher, E., Gilfillan, R.J., Lieber, H.S., Merkin, R., Rideout, J., Thiry, K.J. (2016). Competencies and Tools to Shift Payments from Volume to Value. Vital Directions for Health and Health Care Series. Discussion Paper. Retrieved January 29, 2017 from https://nam.edu/wpcontent/uploads/2016/09/Competencies-and-Tools-to-Shift-Payments-fromVolume-to-Value.pdf.

Luke, D. A., \& Harris, J. K. (2007). Network analysis in public health: history, methods, and applications. Annual Review of Public Health, 28, 69-93. 
Mack, M. (2016). What drives rising health-care costs? Retrieved January 5, 2017 from http://www.gfoa.org/sites/default/files/GFR081626.pdf.

Mascia, D., Di Vincenzo, F., Iacopino, V., Fantini, M. P., \& Cicchetti, A. (2015).

Unfolding similarity in interphysician networks: the impact of institutional and professional homophily. BMC Health Services Research, 15(1), 92.

Mattessich, Murray-Close, and Monsey. (2004). Collaboration: What makes it work (2nd Ed.). Saint Paul, MN: Wilder Publishing Center.

McPherson, J. M., \& Smith-Lovin, L. (1987). Homophily in voluntary organizations:

Status distance and the composition of face-to-face groups. American

Sociological Review, 52, 370-379.

McPherson, M., Smith-Lovin, L., \& Cook, J. M. (2001). Birds of a feather: Homophily in social networks. Annual Review of Sociology, 27(1), 415-444.

Mental Health America. (2015). Parity or Disparity: The State of Mental Health in America. Retrieved February 1, 2017 from https://www.mentalhealthamerica.net/sites/default/files/Parity\%20or\%20Disparity \%202015\%20Report.pdf.

Milward, H. B., \& Provan, K. G. (1998) Principles for controlling agents: The political economy of network structure. Journal of Public Administration Research and Theory, 8(2), 203-222.

Milward, H. B., \& Provan, K. G. (2006). A manager's guide to choosing and using collaborative networks (Vol. 8). Washington, DC: IBM Center for the Business of Government.

Mitchell, M. (2008). An overview of public private partnerships in health. International Health Systems Program Publication, Harvard School of Public Health.

Mizruchi, M. S., \& Marquis, C. (2006). Egocentric, sociocentric, or dyadic?: Identifying the appropriate level of analysis in the study of organizational networks. Social Networks, 28(3), 187-208.

Moore, S., Smith, C., Simpson, T., \& Minke, S. W. (2006). The influence of partnership centrality on organizational perceptions of support: a case study of the AHLN structure. BMC Health Services Research, 6(1), 141.

Morrissey, J. P., Tausig, M., \& Lindsey, M. L. (1985). Community mental health delivery systems: A network perspective. American Behavioral Scientist, 28, 704-720.

Morrissey, J. P. (1992). An interorganizational network approach to evaluating children's mental health service systems. In: L. Bickman \& D. J. Rog (Eds.), Evaluating mental health services for children. San Francisco, CA: Jossey-Bass. 
Nakonezny, P. A., \& Rodgers, J. L. (2005). An Empirical Evaluation Of The Retrospective Pretest: Are There Advantages To Looking Back? Journal of Modern Applied Statistical Methods, 4(1), 22.

National Association of County and City Health Officials [NACCHO]. (2017). Pulling Together, Section Two: Building Collaboration. Retrieved January 4, 2017 from http://archived.naccho.org/topics/environmental/pullingtogether/sectiontwo.cfm.

National Research Council, \& Committee on Population. (2013). US health in international perspective: Shorter lives, poorer health. National Academies Press.

Obama, B. (2016). United States health care reform: progress to date and next steps. Journal of the American Medical Association, 316(5), 525-532.

Obama, B. H. (2017). Repealing the ACA without a Replacement-The Risks to American Health Care. New England Journal of Medicine, 376, 297-299.

Olden, P. C. (2011). Management of Healthcare Organizations: An Introduction. Health Administration Press.

Oliver, A. L., \& Montgomery, K. (1996). A network approach to outpatient service delivery systems: resources flow and system influence. Health Services Research, 30(6), 771-789.

O'malley, A. J., \& Marsden, P. V. (2008). The analysis of social networks. Health Services and Outcomes Research Methodology, 8(4), 222-269.

Popp, J., MacKean, G. L., Casebeer, A., Milward, H. B., \& Lindstrom, R. R. (2014). Inter-organizational networks: A critical review of the literature to Inform practice. Retrieved on January 3, 2017 from http://www.businessofgovernment.org/sites/default/files/InterOrganizational\%20Networks_0.pdf.

Provan, K. G., \& Milward, H. B. (1995). A preliminary theory of interorganizational network effectiveness: A comparative study of four community mental health systems. Administrative Science Quarterly, 40, 1-33.

Provan, K. G., Nakama, L., Veazie, M. A., Teufel-Shone, N. I., \& Huddleston, C. (2003). Building community capacity around chronic disease services through a collaborative interorganizational network. Health Education \& Behavior, 30(6), 646-662.

Provan, K. G., Fish, A., \& Sydow, J. (2007). Interorganizational networks at the network level: A review of the empirical literature on whole networks. Journal of Management, 33(3), 479-516. 
Provan, K. G., \& Kenis, P. (2008). Modes of network governance: Structure, management, and effectiveness. Journal of Public Administration Research and Theory, 18(2), 229-252.

Provan, K. G., Huang, K., \& Milward, H. B. (2009). The evolution of structural embeddedness and organizational social outcomes in a centrally governed health and human services network. Journal of Public Administration Research and Theory, 19(4), 873-893.

Provan, K. G., \& Lemaire, R. H. (2012). Core concepts and key ideas for understanding public sector organizational networks: Using research to inform scholarship and practice. Public Administration Review, 72(5), 638-648.

Ramanadhan, S., Salhi, C., Achille, E., Baril, N., D'Entremont, K., Grullon, M., ... \& Viswanath, K. (2012). Addressing cancer disparities via community network mobilization and intersectoral partnerships: a social network analysis. PLoS One, 7(2), e32130.

Robert Wood Johnson Foundation. (2011). Health Care's Blind Side: The overlooked connection between social needs and good health. Retrieved February 20, 2017 from http://www.rwjf.org/content/dam/farm/reports/surveys_and_polls/2011/rwjf71795

Rosenbaum, S., Schmucker, S., Rothenberg, S., \& Gunsalus, R. (2016). How will section 1115 Medicaid expansion demonstrations inform federal policy? Issue Brief (Commonwealth Fund), 13, 1-10.

Schwartz, C. E., \& Sprangers, M. A. (1999). Methodological approaches for assessing response shift in longitudinal health-related quality-of-life research. Social Science \& Medicine, 48(11), 1531-1548.

Schwartz, C. E., \& Sprangers, M. A. (2010). Guidelines for improving the stringency of response shift research using the thentest. Quality of Life Research, 19(4), 455464.

Shi, L., \& Singh, D. A. (2014). Delivering health care in America. Jones \& Bartlett Learning.

Simatupang, T. M., \& Sridharan, R. (2005). The collaboration index: a measure for supply chain collaboration. International Journal of Physical Distribution \& Logistics Management, 35(1), 44-62. 
Texas Council of Community Centers. (2016). Role of Community Mental Health Centers in Texas Medicaid 1115 Demonstration Waiver. Retrieved March 23, 2017 from https://txcouncil.com/wp-content/uploads/2016/12/1115-Waiver-IssueBrief-3-1-16-Release-UPDATED-8.2016.pdf.

Texas Health and Human Services Commission [HSSC]. (2014). Presentation to the House Appropriations Subcommittee on Article II: Mental health coordination [PowerPoint slides]. Retrieved from http://www.hhsc. state.tx.us/news/presentations/2014/Mental-Health-Coordination.pdf.

Texas Health and Human Services [HHSC]. (n.d.). Waiver Overview and Background Resources. Retrieved December 7, 2016 from https://hhs.texas.gov/node/4917.

Texas Health and Human Services [HHSC]. (n.d.). Attachment I: Regional Healthcare Partnership (RHP) Planning Protocol. Retrieved February 13, 2017 from https://hhs.texas.gov/sites/hhs/files/documents/laws-regulations/policiesrules/1115-docs/RHP/Introduction-RHP.pdf.

Tichy, N. M., Tushman, M. L., \& Fombrun, C. (1979). Social network analysis for organizations. Academy of Management Review, 4(4), 507-519.

University of Michigan Health System. (2003). Business Associate Agreements for HIPAA Privacy Regulations Compliance [PowerPoint slides]. Retrieved from http://www.med.umich.edu/hipaa/ppt/ppt_files/BusinessAssociates.ppt.

Valente, T. W., Chou, C. P., \& Pentz, M. A. (2007). Community coalitions as a system: Effects of network change on adoption of evidence-based substance abuse prevention. American Journal of Public Health, 97(5), 880-886.

Valente, T. W., Coronges, K., Lakon, C., \& Costenbader, E. (2008). How correlated are network centrality measures? Connections (Toronto, Ont.), 28(1), 16.

Van Wijk, R., Jansen, J. J., \& Lyles, M. A. (2008). Inter-and intra-organizational knowledge transfer: a meta-analytic review and assessment of its antecedents and consequences. Journal of Management Studies, 45(4), 830-853.

Venkatraman, N., \& Lee, C. H. (2004). Preferential linkage and network evolution: A conceptual model and empirical test in the US video game sector. Academy of Management Journal, 47(6), 876-892.

Wasserman, S., \& Faust, K. (1994). Social network analysis: Methods and applications. New York, NY: Cambridge University Press.

World Health Organization. (2007). Retrieved January 14, 2017 from http://www.who.int/social_determinants/media/iah_tor_case_studies.pdf?ua=1. 
World Health Organization. (2008). Integrated Health Services-What and Why? Retrieved February 3, 2017 from

http://www.who.int/healthsystems/service_delivery_techbrief1.pdf

World Health Organization. (2012). 10 facts on universal health coverage. Retrieved January 27, 2017 from http://www.who.int/features/factfiles/universal_health_coverage/en/. 


\section{APPENDICES}

Appendix A - Interorganizational Network Survey, $\mathrm{T}_{0} / \mathrm{T}_{1}$ Instrument

[SCRIPT] Thank you for agreeing to participate in our Interorganizational Network Survey! The purpose of the survey is to understand how the development of the Regional Healthcare Partnerships for implementation of the 1115 Medicaid Waiver affects relationships among organizations within the region.

As a representative of your organization, you are being asked participate in this survey because your organization is participating in the 1115 Medicaid Waiver through your Regional Healthcare Partnership.

You received a copy of the Information Sheet in your original recruitment email. Would you like for me to review the information? Did you have any questions about the information provided?

Do you have any questions before we get started?

I am going to ask you a series of questions about your organization's interactions with a few other organizations within your region. When I mention collaboration, I am specifically interested in collaboration that focuses on serving the low-income or medically indigent population in your community.

If you are unsure about the answer to any question, you can tell me that you do not know the answer. At that point I will ask you for another individual at your organization that we can contact for more information.

I am going to read a list of $X$ organizations that are part of your Regional Healthcare Partnership. Please indicate your response to the question with a "yes" or a "no".

Does [Organization X] currently work with [LIST OF ORGS] on activities that target improved access or services for the underserved? Yes or No or I don't know

[For the "Yes" Organizations:]

[If "I don't know":] Can you give me the name of someone else at your organization that we may contact to learn about these relationships?

In the past 12 months, has [Organization $\mathrm{X}$ ] collaborated with [Organization $\mathrm{Y}$ ] to deliver programs or services? Yes or No or I don't know 
[If yes:] What programs or services?

[If "I don't know":] Can you give me the name of someone else at your organization that we may contact to learn about these relationships?

In the past 12 months, has [Organization $\mathrm{X}$ ] shared tangible resources with [Organization $\mathrm{Y}]$ for the purpose of increasing access to services? Yes or No or I don't know

[If yes:] What were those resources intended to support?

[If "I don't know":] Can you give me the name of someone else at your organization that we may contact to learn about these relationships?

Does [Organization $\mathrm{X}$ ] currently have a formal data sharing agreement with [Organization Y]? Yes or No or I don't know

[If yes:] What data is shared? Do they provide data to you, do you provide data to them, or both?

[If "I don't know":] Can you give me the name of someone else at your organization that we may contact to learn about these relationships?

[If no to all three:] You answered no to the last three questions but indicated that you do work with [Organization Y]. Can you tell me a little about what you do with them?

[REPEAT SET OF QUESTIONS FOR ALL “YES” ORGANIZATIONS.]

[SCRIPT] Now I am going to ask you some questions about the organizations you said [Organization X] does not currently collaborate with.

[For the "No" organizations:]

Is [Organization $\mathrm{Y}$ ] an organization [Organization $\mathrm{X}$ ] is likely to collaborate with in the future on activities that target improved access or services for the underserved? Yes or no or I don't know

[If yes:] What would you envision the collaboration involving?

[If no:] Can you tell me more about that?

[If "I don't know":] Can you give me the name of someone else at your organization that we may contact to learn about these relationships?

[Once through all:]

[SCRIPT] Now that we have discussed your current relationships with these organizations, I would like to ask you about these relationships before [Regional Healthcare Partnership \#] was established. 
I am going to read the same list of organizations from your RHP. Please indicate your response with a "yes" or a "no":

Prior to the establishment of [RHP \#], did [Organization X] work with [LIST OF ORGS] on activities that target improved access or services for the underserved? Yes or No or I don't know

[For the "Yes" Organizations]

[If "I don't know":] Can you give me the name of someone else at your organization that we may contact to learn about these relationships?

Prior to the establishment of RHP \#, did [Organization X] collaborate with [Organization Y] to deliver programs or services? Yes or No or I don't know

[If yes:] What programs or services?

[If "I don't know":] Can you give me the name of someone else at your organization that we may contact to learn about these relationships?

Prior to the establishment of RHP \#, has [Organization X] shared tangible resources with [Organization $\mathrm{Y}$ ] for the purpose of increasing access to services? Yes or No or I don't know

[If yes:] What were those resources intended to support?

[If "I don't know":] Can you give me the name of someone else at your organization that we may contact to learn about these relationships?

Prior to the establishment of RHP \#, did [Organization X] have a data sharing agreement with [Organization Y]? Yes or No or I don't know

[If yes:] What data is shared? Do they provide data to you, do you provide data to them, or both?

[If "I don't know":] Can you give me the name of someone else at your organization that we may contact to learn about these relationships?

[If no to all three previous questions:] Can you tell me how [Organization X] worked with [Organization Y] prior to the establishment of RHP \#?

[REPEAT SET OF QUESTIONS FOR ALL “YES” ORGANIZATIONS.]

[SCRIPT] Thank you for participating in this survey 
Appendix B - Interorganizational Network Survey, $\mathrm{T}_{2}$ Instrument

\section{INTRODUCTION}

[SCRIPT] Thank you for agreeing to participate in our Interorganizational Network Survey! The purpose of the survey is to understand how the development of the Regional Healthcare Partnerships for implementation of the 1115 Medicaid Waiver affects relationships among organizations within the region.

As a representative of your organization, you are being asked participate in this survey because your organization is participating in the 1115 Medicaid Waiver through your Regional Healthcare Partnership.

You received a copy of the Information Sheet in your original recruitment email. Would you like for me to review the information? Did you have any questions about the information provided?

Do you have any questions before we get started?

I am going to ask you a series of questions about your organization's interactions with a few other organizations within your region. When I mention collaboration, I am specifically interested in collaboration that focuses on serving the low-income or medically indigent population in your community.

If you are unsure about the answer to any question, you can tell me that you do not know the answer. At that point I will ask you for another individual at your organization that we can contact for more information.

\section{SECTION I - T2 Collaboration Network Survey}

[SCRIPT] I am going to read a list of [X] organizations that are part of your Regional Healthcare Partnership. Please indicate your response to the question with a "yes" or a "no".

Does [Organization X] currently work with [LIST OF ORGS] on activities that target improved access or services for the underserved? Yes or No or I don't know

[SCRIPT] Some of the feedback we received when we conducted this survey previously was that by only including RHP member organizations participating in DSRIP, we were missing information about collaboration with other important partners.

Other than the organizations I've asked you about, can you tell me the names of up to 3 other organizations with which you work the most on activities that target improved access or services for the underserved? [Open-ended with three boxes - these will pre-populate follow-up questions so we are asking the same questions about these new orgs as we are those orgs already in our list]. 
[Follow-up question for each organization] Can you tell me what kind of organization that is?

[For the "Yes" Organizations and for each of the other organizations listed by respondent:]

[If "I don't know":] Can you give me the name of someone else at your organization that we may contact to learn about these relationships?

In the past 12 months, has [Organization $\mathrm{X}$ ] collaborated with [Organization $\mathrm{Y}$ ] to deliver programs or services? Yes or No or I don't know

[If yes:] What programs or services?

[If "I don't know":] Can you give me the name of someone else at your organization that we may contact to learn about these relationships?

In the past 12 months, has [Organization $\mathrm{X}$ ] shared tangible resources with [Organization Y] for the purpose of increasing access to services? Yes or No or I don't know

[If yes:] What were those resources intended to support?

[If "I don't know":] Can you give me the name of someone else at your organization that we may contact to learn about these relationships?

Does [Organization $\mathrm{X}$ ] currently have a formal data sharing agreement with [Organization Y]? Yes or No or I don't know

[If yes:] What data is shared? Do they provide data to you, do you provide data to them, or both?

[If "I don't know":] Can you give me the name of someone else at your organization that we may contact to learn about these relationships?

[If no to all three:] You answered no to the last three questions but indicated that you do work with [Organization Y]. Can you tell me a little about what you do with them?

[REPEAT SET OF QUESTIONS FOR ALL “YES” ORGANIZATIONS.]

[SCRIPT] Now I am going to ask you some questions about the organizations you said [Organization X] does not currently collaborate with.

[For the "No" organizations:] 
Is [Organization $\mathrm{Y}$ ] an organization [Organization $\mathrm{X}$ ] is likely to collaborate with in the future on activities that target improved access or services for the underserved? Yes or no or I don't know

[If yes:] What would you envision the collaboration involving?

[If no:] Can you tell me more about that?

[If "I don't know":] Can you give me the name of someone else at your organization that we may contact to learn about these relationships?

[REPEAT SET OF QUESTIONS FOR ALL “NO” ORGANIZATIONS. Once through all move to Section II]

\section{SECTION II: Uncompensated Care and Changes in Access}

[SCRIPT] We've been talking about your organization's collaborative activities related to DSRIP but I'd like to shift the focus slightly and discuss changes in access to care brought about by the change in the Uncompensated Care program.

Are you familiar with the changes to Uncompensated Care as part of the Waiver Program? Yes or No

[If "No," move to the end of the survey]

[For those responding "Yes"]

[SCRIPT] Ok, now I'd like to ask you a question about the effect of changes in the Uncompensated Care program associated with the 1115 Waiver Program on access to care in your community.

[If "Yes":] To the extent that you can, think about the uncompensated care program as distinct from ACA or other changes affecting health insurance coverage in general. Overall, would you say that the changes in uncompensated care payment associated with the 1115 Waiver Program Improved access to care for the underserved within your organization's service area, Reduced access, or Had no meaningful impact on access to care?

[Follow-up:] Can you tell me more about that? (Interviewer can provide clarifying questions such as: how do you think the changes in UC led to improved/reduced access, why do you think there was no impact) [OPEN ENDED]

[SCRIPT] This concludes the survey, thank you for your participation! 


\section{CURRICULUM VITAE}

NIDA ALI

485 East Gray Street

Louisville, KY 40202

nida.ali@louisville.edu

Phone: 502-852-1119

\section{EDUCATION}

University of Louisville, School of Public Health, Louisville, KY

- $\quad$ Doctor of Philosophy (PhD), May 2017

- Health Promotion and Behavioral Sciences

- Dissertation: Evaluating the impact of statewide policy implementation on interorganizational collaboration at the regional level: An application of network analysis

- GPA: 4.00

Texas A\&M University, School of Public Health, College Station, TX

- Master of Public Health (MPH), May 2014

- Health Policy and Management

- Graduated with honors

University of Michigan, Ann Arbor, MI

- Bachelor of Science (BS), April 2012

- Major: Brain Behavior Cognitive Science (Psychology)| Minor: Gender \& Health

- University Honors

\section{RESEARCH/WORK EXPERIENCE}

Office of Public Health Practice \& Community Outreach, University of Louisville, Louisville, KY

Doctoral Research Fellow

Jul. 2014-Present

- Assisting with activities related to the development and implementation of a social norming campaign through the Youth Violence Prevention Research Center

- Developing and disseminating surveys for assessment of community readiness and quality of leadership to address violence among youth within West Louisville 
- Using interorganizational network analysis to assess changes in relationships over time among community organizations addressing youth violence and assessing the extent to which resources have been shared, increased collaboration, network expansion, formalization of relationships, sharing of resources, and strengthening of network ties has occurred

- Assisting with facilitation and preparation for pre-campaign focus groups with youth and other community residents

- Examining the development, use, applicability, and design of health insurance, health systems, and health behavior literacy materials to residents of West Louisville

- Utilizing innovative CBPR methods like Boot Camp Translation to understand how to improve health literacy on depression, asthma, and HIV among West Louisville residents via tailored health communication campaigning

- Conducting and assisting with a series of focus groups with community members from across West Louisville to solicit input in directing community related efforts

- Engaging with key community stakeholders to establish a comprehensive city plan targeting social determinants of health in West Louisville

- Assisting with facilitation and evaluation of youth-violence prevention initiative (e.g. Zones of Hope)

- Assisting with federal, state, and local grant writing initiatives focused on health disparities and community-based issues

The Commonwealth Institute of Kentucky, University of Louisville, Louisville, KY Project Consultant for the Evaluation of the Texas 1115 Medicaid Transformation Waiver Jul. 2015-Present

- Perform social network analysis for an evaluation goal related to collaboration under the Texas 1115 Medicaid Waiver Evaluation Project

- Develop some and refine other aspects of the original data collection tool to assess collaboration between and among organizations within each Regional Healthcare Partnership (RHP) under the waiver project

- Conducted telephone-based surveys and quantitative data analysis for the social network study under waiver project

- Evaluated RHP governance structure and process for stakeholder input for the waiver evaluation

- Analyzed intergovernmental transfer (IGT) financial data as it pertains to collaboration among organizations

USA Center for Rural Public Health Preparedness, Texas A\&M Health Science Center, College Station, TX

\section{Graduate Research Assistant}

Aug. 2012-Jun. 2014

- Assisted with development and application of an evidence-based Texas Public Health Risk Assessment Tool (TPHRAT) intended to measure and rank hazards and response capabilities useful for public health preparedness planning

- Involved in creating a strategic plan to systematically integrate the TPHRAT mitigation planning process into public health emergency preparedness in Texas 
- Conducted a public health preparedness assessment with licensed hospitals, End Stage Renal Disease (ESRD) facilities, nursing homes and assisted living centers, and residential child care facilities throughout Texas

- Programmed surveys in Qualtrics for organizations to complete for one component of the preparedness assessment

- Analyzed qualitative data collected via telephone-based interviews for the other component of the preparedness assessment

- Developed user guides detailing instructions on navigating outputs of data analysis for the preparedness assessment

HealthPOiNT Community Health Center, Bryan, TX Compliance Program Specialist

Jun. 2013-Aug. 2013

- Prepared for the Health Resources and Services Administration (HRSA) site visit

- Assessed compliance with key program requirements based on HRSA guidelines

- Established an organizational site visit binder to consolidate resources for the visit

- Identified gaps in fulfilling program requirements for performance improvement

Department of Social Psychology, University of Michigan, Ann Arbor, MI Research Assistant

Sept. 2010-Jul. 2012

- Acquired a number of methods-based skills involving exposure to conducting literature reviews, subject recruitment, experiment implementation, data entry, data processing, and disseminating findings through poster presentations

- Tested whether various theories from social and cognitive psychology can be combined within a waiting scenario to compare the subjective experience of both duration and frequency judgments for a time perception study

- Developed a study on the psychology of competitive advantage which combines social psychology and decision-making literatures to explore factors that influence motivation to compete and, consequently, willingness to enter joint ventures, form strategic alliances, share scarce resources, and collaborate with competitors

Institute for Social Research, University of Michigan, Ann Arbor, MI

Research Assistant Nov. 2011-Apr. 2012

- Assisted in the development of data and documentation files for the American National Election Studies (ANES) project studies aimed to provide high quality data from its own surveys on voting, public opinion, and political participation

- Provided support in the form of data processing, proofing, verifying and researching methodological practices in survey design and distribution, and conducting confidentiality reviews

Undergraduate Research Opportunity Program (UROP), University of Michigan, Ann Arbor, MI

Research Assistant

Sept. 2008-Apr. 2010

- Managed several research projects with minimal supervision acquiring skills, such as managing participants, running experiment sessions, collecting data, and preliminary data analysis (for which I received independent research credit) 
- Conducted research experiments focused on human aggression and catharsis to determine whether catharsis is a motivator to play violent video games, and tested the effect of various genres of video games on helping behavior

\section{PUBLICATIONS AND TECHNICAL REPORTS}

\section{Publications}

Quiram, B., Ali, N., \& Babicz, K. (2015). Rural Public Health Infrastructure. In Bolin, J.N., Bellamy, G., Ferdinand, A.O., Kash, B.A., Helduser, J.W., (Eds.), Rural healthy people 2020 (Vol. 2, pp. 67-74) College Station, TX: Texas A\&M Health Science Center School of Public Health, Southwest Rural Health Research Center.

Wendel, M.L., Jackson, T., Golden, T., Castle, B., Ali, N., Ingram, M., \& Combs, R. Yet We Live, Strive, and Succeed: Using Photovoice to Understand West Louisville Residents' Experience of Justice, Safety, Hope, and Racial Equity. (Under Review).

Muvuka, B., Combs, R.M., Ayangeakaa, S.D., Ali, N., Wendel, M.L., \& Jackson, T. Barriers to Health Literacy among African Americans. (Submitted to Journal of Health Care for the Poor and Underserved).

Ali, N., Wendel, M.L., \& Jackson, T. Public Outcry $\neq$ Readiness for Action: Results from an Assessment of Community Readiness to Address Youth Violence in Louisville, Kentucky. (In preparation for submission).

Ali, N., Combs, R.M., \& Muvuka, B. Addressing Health Insurance Literacy Gaps in an Urban African American Population: A Qualitative Study. (In preparation for submission).

\section{Technical Reports}

Creel, L., Wendel, M.L., \& Ali, N. (2017). Final RHP Reports for the Network Study and Stakeholders Survey-- Evaluation Goals 9, 10, and 11, Texas 1115 Medicaid Transformation Waiver. Final Reports to the Texas Health and Human Services Commission.

Creel, L., Wendel, M.L., \& Ali, N. (2016). Evaluation of the Texas Delivery System Reform Incentive Payment Demonstration Final Report-Appendix C: Changes in Collaboration Among Organizations. Section in Final Evaluation Report to the Texas Health and Human Services Commission.

Pool, S., Cizmas, L., Ali, N., Mahmoud, N., Beaugh, K., Mueller, B., Geray, J., Hachimi, H., Reddy, H., Stewart, C., Jadhav, V., Poland, B., Mullins, E., Achgill, D., Gray, C., Darkhalil, A., Caldwell, M., Sparks, T., Walker, E., Valdez-Vivas, N., \& Hirase, T. (2014). Improving Health Interventions in Conflict-Affected Liberia: A CommunityBased Approach. Final Report to the United States Agency for International 
Development (USAID) Center of Excellence on Democracy, Human Rights, and Governance (DRG Center) Cross Sector Program Team.

Griffith, J., Carpender K., Ali, N., \& Babicz, K. (2014). Integration Plan for the Texas Public Health Risk Assessment Tool Mitigation Planning Process. Final Report to the Texas Department of State Health Services, Community Preparedness Section.

Pennel C., Carpender K., Griffith, J., Gaukler, C., Ali, N, Babicz, K., Yang, S., \& Beaugh, K. (2013). Hospital and Health Care Facilitates Preparedness Project. Final

Project Report to the Texas Department of State Health Services-Regulatory Division.

\section{SCIENTIFIC PRESENTATIONS}

\section{7}

Addressing Homophobic and Transphobic Stigma in Predominantly Heterosexual African American HIV Initiatives. Combs, R.M., Brown, K.T., Muvuka, B., Ali, N., \& Mitchell, C. Poster presentation at the National LGBTQ Health Conference, April 28April 30, 2017, Chicago, IL.

Addressing Health Literacy in an African American Population. Combs, R.M., Ali, N., Muvuka, B., Brown, K.T., \& Mitchell, C. Oral presentation at the Kentucky Public Health Association Conference, April 10-April 13, 2017, Owensboro, KY.

\section{6}

What makes a tweet in healthcare successful? Yuen, M. \& Ali, N. Roundtable presentation at the $144^{\text {th }}$ Annual Meeting of the American Public Health Association, October 29-November 2, 2016, Denver, CO.

Promoting Health Through the Utilization of Novel Community-Based Participatory Research Methods: Using Boot Camp Translation to Improve Depression Literacy in West Louisville. Ali, N., Combs, R.M., Muvuka, B., Ayangeakaa, S.D., \& Wendel, M.L. Poster presentation at Research!Louisville, October 11-October 14, 2016, Louisville, KY.

Health Literacy in West Louisville: examining the development, use, applicability, and design of health insurance, health systems, and health behavior literacy materials to West Louisville residents. Ayangeakaa, S.D., Combs, R.M., Muvuka, B., \& Ali, N. Poster presentation at Research!Louisville, October 11-October 14, 2016, Louisville, KY.

Factors Contributing to Low Health Literacy among African Americans. Muvuka, B., Combs, R.M., Ayangeakaa, S.D., Ali, N., Wendel, M.L., \& Jackson, T. Poster presentation at Research!Louisville, October 11-October 14, 2016, Louisville, KY. 
West Louisville photovoice project: Local perspectives on justice, safety, hope, and racial equity. Wendel, M.L., Jackson, T., Ingram, M., Ali, N., Castle, B., Combs, R., Jones, G., Rogers, W., Carthan, Q., \& Smith, A.D. Panel presentation at the Community-Campus Partnerships for Health $14^{\text {th }}$ International Conference, May 11-14, 2016, New Orleans, LA.

Louisville listens to Ferguson in order to sow justice, safety, hope, and racial equity. Jackson, T., Wendel, M.L., Ingram, M., Carthan, Q., Castle, B., Jones, G., Ali, N. \& Combs, R. Poster presented at the Community-Campus Partnerships for Health 14th International Conference, May 11-14, 2016, New Orleans, LA.

\section{5}

United we stand: The role of an urban university in strengthening community capacity. Ali, N., Wendel, M.L., Ingram, M., Castle, B., Jackson, T., \& Combs, R. Oral presentation at the 143rd Annual Meeting of the American Public Health Association, October 31-November 4, 2015, Chicago, IL.

Toward a new framework for FQHCs: Promoting and facilitating a culture of compliance through public health. Ali, N. Poster presentation at the 143rd Annual Meeting of the American Public Health Association, October 31-November 4, 2015, Chicago, IL.

Addressing social determinants of health through photovoice. Ingram, M., Jackson, T., Wendel, M.L., Ali, N., Castle, B., \& Combs, R. Roundtable presentation at the 143rd Annual Meeting of the American Public Health Association, October 31-November 4, 2015, Chicago, IL.

Transgender messaging gap: Including trans and gender nonconforming people in public health campaigns. Combs, R., Gonzales, T., Wendel, M.L., Ali, N., \& Jackson, T. Poster presentation at the 143rd Annual Meeting of the American Public Health Association, October 31-November 4, 2015, Chicago, IL.

A partnership approach to addressing violence in West Louisville, Kentucky. Castle, B., Wendel, M.L., Ingram, M., Ali, N., Jackson, T., \& Combs, R. Poster presentation at the 143rd Annual Meeting of the American Public Health Association, October 31November 4, 2015, Chicago, IL.

\section{FUNDED RESEARCH, GRANTS, AND CONTRACTS}

Project Title: Changing the Narrative: Using Media to Shift Norms of Violence among Youth in West Louisville Funding Period: 2015-2020 Funded by the Centers for Disease Control and Prevention Total Funding: \$5.7 million

Role: Key Staff Personnel 
Project Title: West Louisville Health Literacy Project

Funding Period: 2015-2018

Funded by KentuckyOne Health through the Commonwealth Institute of Kentucky (Total Funding: $\$ 300,000$

Role: Sub-Investigator

Project Title: Increasing Health Literacy on Chronic Conditions in an Underserved Population

Funding Period: 2015-2017

Funded by the Jewish Heritage Fund for Excellence

Total Funding: $\$ 105,000$

Role: Sub-Investigator

Project Title: Statewide Evaluation of the Texas 1115 Medicaid Transformation Waiver Funding Period: 2013-2017

Funded by the Texas Health and Human Services Commission

Total Funding: \$2.4 million

Role: Key Staff Personnel

\section{TEACHING}

\section{Graduate Courses}

Graduate Teaching Assistant, University of Louisville School of Public Health \& Information Sciences

Community Organization \& Assessment (PHPB 611), Fall 2015

\section{Undergraduate Courses}

Teaching Assistant, University of Louisville School of Public Health \& Information Sciences

Global Health (PHUN 410), Fall 2016

\section{PROFESSIONAL ASSOCIATIONS}

American Public Health Association, member

Kentucky Public Health Association, member

\section{SELECTED ACTIVTIES}

Community Engagement Academy, University of Louisville, Louisville, KY

\section{Graduate Fellow}

Sept. 2016-Present

- Participate in monthly seminars and workshops with faculty and graduate students from across the university to gain a broad perspective of the foundations of community engaged research and disciplinary variations and methodologies of such research 


\section{Community Health Planning and Policy Development Committee (CHPPD),}

American Public Health Association

Student Committee Secretary \& Member Mar. 2015-Present

- Act as a volunteer abstract reviewer for the Committee's APHA section

- Ensure accurate and sufficient documentation exists to determine when, how, and by whom section business was conducted

- Manage general correspondence to the CHPPD Section and stimulate member discussions about public health on social media

Student Government Association/Public Health Association, Louisville, KY Treasurer, Academic Grievance Committee Member Sept. 2014-Present

- Assume responsibility for general financial oversight including financial planning, budgeting and reporting, collection, management, and disbursement of funds, and book and record keeping

- Identify local public health related organizations and speakers to share experiences and insight with students

Community Youth Volunteers, San Antonio, TX, Southfield, MI, College Station, TX, \& Louisville, $\mathrm{KY}$

\section{Academic Counselor \& Team Leader}

Jul. 2004-Present

- Provide guidance to middle and high school students in preparation for college as an Academic counselor

- Managed and coordinated service events for youth volunteers to get involved within the community

- Taught an early childhood development course and summer reading courses as a teacher and assistant

- Led the logistics and management team and served as counselor for a summer camp, Camp Mosaic for two years

Alumni-Student Mentorship Program, University of Louisville School of Public Health, Louisville, KY

\section{Program Planner \& Evaluator}

Sept. 2014- Sept. 2015

- Designed a new mentor-mentee program focused on connecting current public health students with alumni

- Established metrics for surveys aimed at continuously monitoring and evaluating efficacy of the program

Graduate Teaching Academy, University of Louisville, Louisville, KY

Graduate Fellow Sept. 2014-Mar. 2015

- Participated in monthly professional development seminars and workshops that facilitate professional development in teaching, specifically highlighting innovative pedagogical knowledge, strategies, and skills

- Developed innovative teaching and learning strategies to engage students in public health coursework 
Public Health Student Association, Texas A\&M, College Station, TX

Public Health Practice Chair \& First Year Social Chair Sept. 2012-May 2014

- Coordinated guest speaker presentations and community service activities with federal, state, and local agencies

- Organized social events for students to network and promoted opportunities that fostered learning and collaboration

- Volunteered and participated in National Public Health Week 2013 eventssoliciting a \$1000 donation from Wal-Mart for two consecutive years to help offset costs, serving on the Fun Run Committee, and helping out at the Golf Tournament Fundraiser

Department of Psychology, University of Michigan, Ann Arbor, MI

Peer Advisor

Sept. 2011-Apr. 2012

- Supported new students with schedule planning, course registration, and preparation in psychology concentrations

- Discussed long-term graduate school/career goal plans with students and acted as a referral source

- Collaborated with a group of peer advisors in leading the management of online concentration orientations for students

Aga Khan University Hospital, Karachi, Pakistan

Volunteer

May 2009-Aug. 2009

- Translated health literacy materials in English to Urdu in an attempt to bridge a communication gap for some patients

- Involved in hands-on training on ways to approach the dissemination of proper hygiene techniques with community members

\section{RECOGNITIONS AND SKILLS}

\section{Recognitions}

Delta Omega Honorary Society in Public Health, Beta Pi Chapter Graduate Dean's Citation for Excellence Award

Excellence in Health Disparities Research Award, Research!Louisville

Delta Omega Honorary Society in Public Health, Alpha Tau Chapter

Texas A\&M University, Faculty Scholarship Award

University of Michigan Ann Arbor, University Honors

The President's Volunteer Service Award-Gold
May 2017

April 2017

October 2016

May 2014

July 2013

April 2012

June 2005-11 


\section{Skills}

- Proficient in Microsoft Office including Word, PowerPoint, Outlook, Publisher, Excel, and Access

- Proficiency with and knowledge of Social Network Analysis (Attended LINKS workshop in summer 2015)

- Proficiency with and knowledge of Qualtrics (Survey Development and Distribution Software)

- Proficiency with and knowledge of NVivo, ATLAS.ti, and Dedoose (Qualitative Software)

- Proficiency with and knowledge of SPSS (Quantitative Software)

- Experience with Stata and R (Quantitative Software)

- Experience with grant writing, institutional review board (IRB) protocol and submission, survey design, focus group facilitation, Blackboard navigation and management, quantitative and qualitative data collection and analysis, and program planning, implementation, and evaluation

- Project Management: Critical decision-making, negotiating, conflict resolution, and delegating abilities

- Multilingual: Urdu, Hindi, Gujarati, and Spanish 